
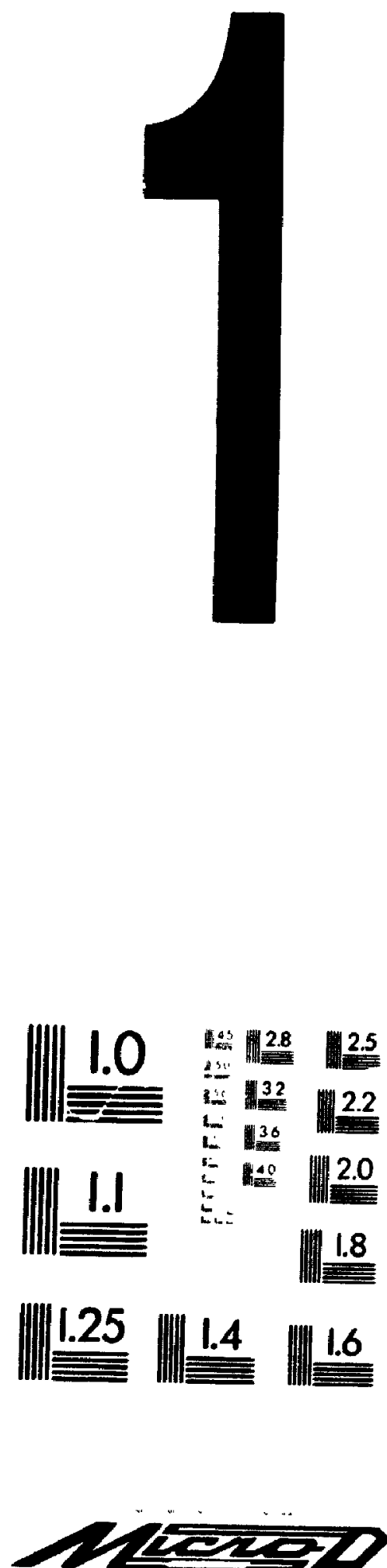
Otawa, Canada

KIA ON4

\section{NOTICE}

The quality of this microform is heavily dependent upon the quality of the original thesis submitted for microfilming. Every effort has been made to ensure the highest quality of reproduction possible.

If pages are missing, contact the university which granted the degree.

Some pages may have indistinct print esperially if the original pages were typed with a poor typewriter ribbon or if the university sent us an inferior photocopy.

Reproduction in full or in part of this microlorm is governed by the Canadian Copyright ACt, R.S.C. 1970, C. C-30, and subsequent amendments.

\section{AVIS}

La qualité de celte microforme dépend grandement de la qualité de la these soumise au microfilmage. Nous avons tout tait pour assurer une qualité supérieure de reproduc tion.

S'it manque des pages, veuillez communiquer avec Puniversité qui a contéré le grade

La qualité d'impression de centaines pages peut laisser a désirer, surtoul si les pages originales ont été dactylogra phiées a l'aide d'un nuban usé ou si l'université nous a fatt parvenir une photocopie de qualité intérieure.

La reproduction, méme partielle, de cefte microforme est soumise a la Loi canadienne sur le droil d'auteur, SHC 1970 , c. C-30, el ses amendements subséquents. 


\title{
ESSAYS CONCERNING THE IMPACT OF MEASUREMENT COSTS UPON COMMODITY FUTURES MARKETS,
}

by

\section{Michael A. Bowe}

B. A. (llons.) Oxford., M. A. (Econ) Manchester

A THESIS SUBMITTED TO THE FACULTY OF GRADUATE STUDIES AND RESEARCH IN PARTIAL FULFILMENT OF THE REQUIREMENTS FOR THE DEGREE OF DOCTOR OF PHILOSOPHY

in the Department

of

Economics

\author{
CARLETON UNIVERSITY \\ Ottawa, Ontario \\ November 1988
}

(a) 1988, Michael A. Bowe

Al1 rights reserved. This work may not be reproduced in whole or in part, by photocopying or other means, without permission of the author 
Canadian Theses Service Service des thèses canadiennes

The author has granted an irrevocable nonexclusive licence allowing the National Library of Canada to reproduce, loan, distributc or sell copies of his/her thesis by any means and in any form or format, making this thesis available to interested persons.

The author retains ownership of the copyright in his/her thesis. Neither the thesis nor substantial extracts from it may be printed or otherwise reproduced without his/her permission.
L'auteur a accordé une licence irrévocable et non exclusive permettant à la Bibliothèque nationale du Canada de reproduire, preter. distribuer ou vendre des copies de sa these de quelque manière et sous quelque forme que ce soit pour mettre des exemplaires de cette thèse à la disposition des personnes intéressées.

L'auteur conserve la propriété du droit d'auteur qui protège sa thèse. Ni la thèse ni cies extraits substantiels de celle-ci ne doivent etre imprimés ou autrement reproduits sans son autorisation. 


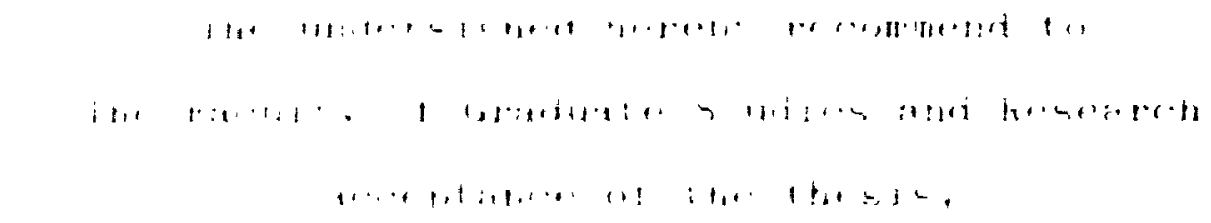

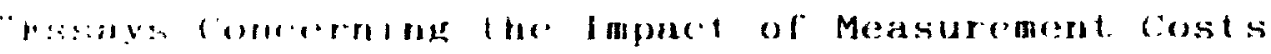
upun rommonith Futuress Markets".

$.11111+1+11+1$

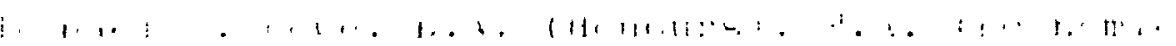

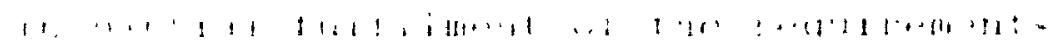

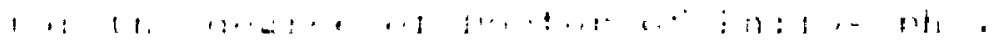
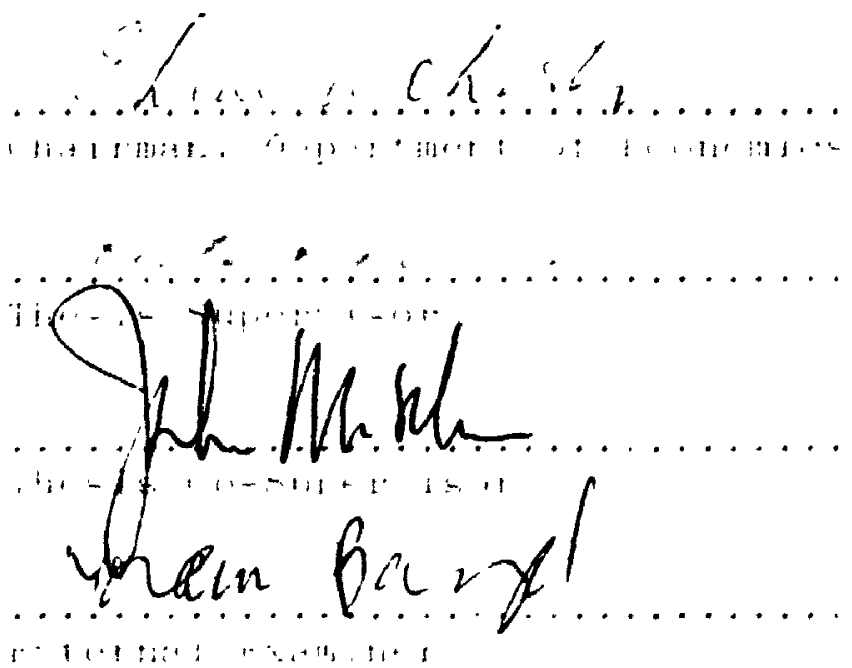

$11 \ldots 1+11+11, i, i=1 ;:$

Feb ruary 22, 1989 


\section{ABSIRACT}

Commodity futures markets are instiutions designed lo manimisc a lladers expected net gain from ownership of the right 10 transler exclusivity. McM.unus and Acheson (1979, 1983) and Telser (1981, 1986) arguc that to minimise the cont of transfe-, trading in futures is confincd to adopting only impersmal and objective specifications of contractual performance. Futures contract specilications will. therefore. be incomplete when traders in the cash market to which the futures contricl pelluius adopt additional idiosyncratic measures of contractual enforcement. The cons of lhis incompleteness imply a range of indeterminacy in the lutures price withun which setulement price changes cannot be constrained by arbitrage in the delivery market for contract goods. This creates an opportunity for manipulation of the fittures price by traders with lower cost access to the market Such a possibility comld restrict postential order flow and may lead to the market's demise. This hypothe',is, relatmg minkel failure and contractual incompleteness is designated the measurentent cost hypothests.

The threc essays in this thesis attempt to identify empirical dimensions in whols the measurement cost hypothesis can be adapted to make it aminable (1I) (mu!nulk.1) corroboration. Chapter II argues incompletely specilied futures contracts may be opportunistically exploited in their delivery period by the delivery of contlat pends. Exchange regulatory constraints on redelivery are interpreted as attempts 10 multgalte the effects of such informed trader opportunism. Their prescnec cotdd, thereforc, te interpreted as evidence of an inherent exploitable contractual weisiliess. Ille measurement cost hypothesis would predict regulations goveming tedelivery will be musc restrictive in failed or dormant contracts than in mort active markcts. Thus conjeclunte is tested using qualitative response models, and results obtaincd which alc comsstent with the hypothesis. 
Chapter III clarifies the consequences of the range of arbitrage indeterminacy in certain future:, prices for the conventional theory of intertemporal price relauonships for storable commodities. Specifically, the model develops testable propositions relating to the relative price variability of open and spread contract portfolios. By relating contract price variability to the initial speculative margin requirements established by commodity exchanges, results of tests of the measurement cost hypothesis using contract market data on margin requirements for one hundred and eleven commodities for the period 1970-1984 are presented. Once more strong support for the hypothesis is evidenced.

The limal exsay in chapter IV extends the model of chapter III to analyse its implications for the behaviour of the price volatility of spread positions in futures as the spread's constitucnt contracts approach maturity. After a comparison of the models predictions with those of currently existing alternatives, tests are conducted in an altenipt to distinguish competing theories. The test results are inconclusive, appearing sensitive to test specilication, in particular the measure of price volatility adopted. 


\section{DEDICATION}

To William P. McGough and Fithel A. Mtciongh 


\section{ACKNOWI.EDGHMENIS}

My grcatest debts, are to my thesis supervisors, Keith Acheson and John McManus. Not only did they nurse this $\cdot$ :at along from its conception, but their sustaincd cnthusiasm during its cvolution, grcaly facilitated its completion. Whilc they are to be absolved of responsibility for any llaws in the final product. their advice. capertisc. and meticulous sitcnion to detail, has contributed greatly to whatever merits this study may posscss. Randy Gechan read various drafts of the manuscript and provided valuable comments.

Among those individuals at Conmodity Futures Fxchanges throughout the United States whose help was solicited in acquiring and interpreting data, the following mern yecial mention: Farlene Baptist (New York Mercantile Exchange); Christine thrke. Suan Saluman. Carol Piergis, Paul Burreck and William Coccanıs (Chicago Mercantile Fxchange): Gilbert Heath and Donald Cheval (Chicago Board of Trade); Ann Rous (MidAmerna Commodily Exchange): Jon Hansen (Kansas City Board of Trade): Deborah Ilogan (Coffec, Sigar and Cocoa tixchange); and Andrea Corcoran (Commorlity futures Trading (ommission).

Debra I co and Pepi Andolfatto are to be thanked for their fast and expert word processng. and paticnic through numerous revisions. Ther ingenuity in deciphering the unintelligible and in constructing order out of chaos is greatly appreciatcd.

The gencrous linancial support receiped in a grant from the Centre for the Stud! of Fillures Markets, Columbia University Graduate School of Business. New York. is glatciully acknowlidgced. 
Finally, I must express gratitude and admiration to my nilis, Julic. Ind ammpl for tolerating a disconsolate husband for much longer than 11 should lathe lo wrile . thesis, but for her qualities as a human being. 
Approval ii

Abstract iii

Ixdication v

Acknowledgements $\mathrm{vi}$

I ist of Tables $\mathbf{x}$

I. Introdiction 1 HOOTNOTHS

II. Measurement Costs and Requlation: Delivery Provisions in Futures Contracts ................ 10 INTROISUCTION

I: MIASIIRI-MIENT COSTS ANI) ALTERNATIVE CONTRACTUAL SPPCIHICATIONS

II: THF CHOICF OF PHRIORMANCE MFCHANISMS IN CONTRACT MARKLTS

III: THE I HIIVIRY PHRIOI OF A FUTURES CONTRACT 20

IV: I-MPIRICAI. PROCFDURIS 37

V: CONCIUIDING RFMARKS 44 1.OOTNOTHS

III. Medsurement Coss. Margin Kequirements and Market Failure in Futures Markets ..... 56 INTKOISUCIION 56

I: IHI: THIOKY OF STORAGE AND CONTRACT PRICE RELATIONSHIPS ....... 50

II: MIASUIRMMIFT COSTS ANI) FUTURES PRICE BEHAVIOUR ............................ 60

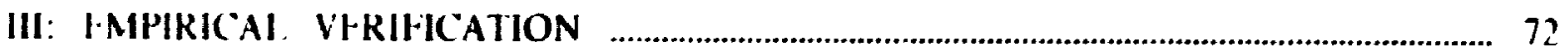

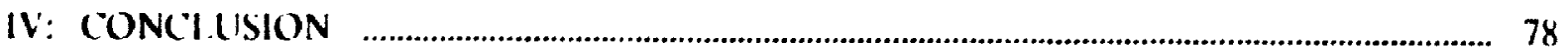

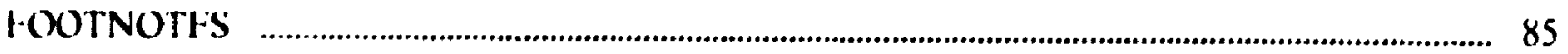

IV. Measurement Cons and Price Volatility: Evidence from Futures Markets ....................... 88 INTRODUKTION 88 
I: THE DYNAMICS OF SPRFAD HEHAVIOUK

II: ALTHRNATIVE: HYPOTHESIS RIGARIDING SPRIAM) MIIIAIU)(R

III: EMPIRICAL VERIFICATION

FOOTNOTES

REFERENCES 


\section{IISI OF TABLES}

Tix ile

Page

2.1 The Fiffects of Independent Variables on Commodity Exchange Policy Choicc 46

2.2 The Ffrects of Independent Variables on Commodity Exchange Policy Choice 48

3.1 Commodiay Futures Contracts and Exchanges 80

3.2 Results of Wikcoxon-Mann-Whitney U-Test: Full Sample 82

3.3 Kesults of Wilcoxon-Mann-Whitney U-Test: Commodily Sub-Samples 83

4.1 Kurtosis and Ratio of Kange to the Standard Deviation Tests 112

4.2 I.inear Model Results: Cocoa Spreads 113

4.3 I.inear Model Results: Cotton Spreads 114

4.4 I.incar Model Kesults: Silver Spreads 115

4.5 I.incar Morlel Results: Copper Spreads 116 


\section{CIIAPTEK I}

\section{INIRODUCHION}

One of the prevalent themes in recent microeconomic literature is that the gains from trade may be limited by the extent of asymmetric information across transacting palltes. Differences in trader's costs of quantifying information relevant lo contratclual performante imply that the costs of enforcing exclusive rights will differ across Iransicting individiuls. Ille potential then exists for better informed traders, acting opportunistically. to transler wealth to themselves at the expense of less well-informed parties. A conclusion of this litcialure is lh.tI the revealed reluctance of the latter to sufter the consequent losses may ultimalch la sufficient to lead to the failure of the market.

However. despite the threat of market breakdown. differences in Iracler kmowledge ant characteristic of most market enviroments. This specialisation (and thus asymmetric infiormiltimin) has been revealed profitable upon a close examination of the details of governance struclintes which have emerged in an attempt to reduce its associated costs. Specific investments ly transacting parties, brand names (personal specification of contractual perfoumantec) .ust monitoring and bonding constraints, ate conmonly cited examples of mechanisnis whicls preserve infornational asymmetries across traders, yet provide sulficient incentuves to cllalle markets to operate effectively.'

The following essays are concerned with the effects of asymmetric mformation upon the operation of futures markets. Both McManus and Acheson (197\%. 1983) and lelser (19\%1. 1986), have examined the costs associated with the transfer of ownership of fulutes comitack The former argue that to enhance traisferability, trading in futures is confince is adepunus only impersonal and objective specifications of contractual performance. These conforccuncm measures effectively reduce differences in the costs to traders of enforcing comiracts, therclty making a contract more uniformly enforceable over a wider range of prolenual holdcrs 
Viewed from Iciser's perspective, this has the important effect of increasing the liquidity of the market.

Unfortunately, these restrictions imposed upon the measurement technology by Iranslerability considerations are not without their cost, as they may deliberately suppress information which is of value to cash market traders when evaluating the objects of trade. 'hus, liutures contract markets adopt a transactional mode unable to offer traders the same contracilual inforcement options they would possess when transacting in the regular cash market. Here, governance structures may supplement impersonal and objective specifications with additional. more idiosyncratic measures of contractual enforcement. Those considered carlicr are primary examples. When this suppression of information occurs, the specifications used 10 govern futures trading are termed contractually incomplete. Contractual incompleteness places the futures contract at a comparative disadvantage. relative to the cash market, as a method of Iransacting in the commodity.

How does this comparative disadvantage manifest itself? McManus and Acheson (1979, 198.3) demonstrate that the net gains from trade foregone by using the relauvely inferior mode of transacting, the futures market. will: (i) be directly reflected in the difference between the but-sell spreads in the futures and cash markets, and (ii) imply a range of Indelerminaty in the futures price within which price movements cannot be constrained by polentlal arbitrage transactions in the delivery market for contract goods. For contracts containing a delivery option. the delivery market is established by the measures specified in the futures contrat determining satisfaction of contractual obligations at delivery. This range of arbitrags indeterminacy cteates an opportunity for manipulation of the value of the contract by individuals with lower cost access to the contract market, specifically, exchange member brokers:

Although commodity ecchanges regulation of trading activity will altempt to restrict the potentul for exploitation of the incompleteness of certain futures contracts, an inability to 
perfectly constrain such activities implies non-exchange nembers are inherently at a disadvantage when assuming a position in the contract market. As the cupected losics to such traders from their futures transactions are directly related to the inability of arbitrage (1) constrain futures settlement price changes, the more contractually incomplete the contrat, the less likely it will be to aturact non-member order flow. This reduction in the potential number of traders will diminish transferability of the contract. curtail trading interest in lite market, and may be severe enough to lead to its failure. This hypothesis, relating contractual incompleteness to futures market 'thinness' and potential lailurc. lirst proposed in McManus and Acheson (1979), is henceforth designated the measurement cost hypothesis.

To place this hypothesis in context. one major deficiency in the theory of futures trading is the lack of a systematic analytical framework from which the necessary conditions for the feasibility and success of trading in a futures contract can be derived. A comsistent theme emerging from an examination of the typical life cycle of a fulures market is thal the rate of contractual failure is significant. Carlton (1984) studies 184 contracts listed in the Wall St Journal between 1921 and 1983, and his findings will be used as illustrative." Ihe majority (over 57 per cent) of new futures contracts become dormant within 11) years of their introduction on a commodity exchange, with over 40 per cent of all contracts lalling dormant by the end of their sixth year. If a contract survives its sixth year, it then has a better than even chance of surviving for 20 years, by which lime 70 percent of all fulures contract innovations have become dormant or have been delisted. For those contracls in existence in 1921, and those introduced in the years through 1983. the averagc lifitime is less than 12 years and the median approximately seven years. Fxcluding futures contrats already in existence in 1921. which are above average in terms of their success rate. the average contract lifetime falls to nine years and the median to five.

Moreover, with the exception of financial contracts, whose introduction is $(1 x)$ recent to enable current data to accurately reflect their life patterns, the similaritics across commosdity 
groups are mote evident than the differences." A cross-section examination of commodity classifications reveals that excepting the metals, 55 per cent of contracts possess life cycles under nine ycars. Of all commodity groupings, indusual materials have the longest average life (14.7 years), while metals have the smallest (9.1 years). Industrial materials also have the longest median life (13 years), while livestock have the shortest (5 years).

What theorics have been advanced to explain the patterns of futures market 'thinness' and failure across different contracts? Working (1953. 1954) hypothesises the major reason for contractual failure is the lack of hedging interest in the contract market. Working argues that futures trading emerges only when there is a need for hedging facilities by those producing. handling. merchandising or processing the commodity. In turn, a hedging need arises when there are. or are expected to be, material fluctuations in the price of the commodity. for it is then that any price discovery function of the futures contract is enhanced.

The identification of this critical role played by commercial hedging interest stimulated the formation of several other theories in the literature, which although differing in their cmphasis. have interconnecting themes. Carlton (1983) maintains that if, as evidence suggests (lincher (1981)). periods of price inflation coincide with periods of increased relative price dispersion. one may expect inflation and futures trading volume to be positively correlated. This he altributes to the use of futures positions to mitigate the effects of real price uncertainty: Carlton finds that, all things equal, each one per cent increase in the rate of intlation is associated with a nine per cent increase in trading volume in oats futures, and a sic per cent volume increase in both wheat and corn futures. It is suggested that trading volume would fall if the real price uncertainty associated with inflation diminished.

Given the importance of price fluctuations in creating hedging interest, there is likely to be a conspicuous lack of futures trading in commodities subject to certain specific government policics. such as rrice controls or price stabilisation schemes. Government price support programs in peanuts and tobacto appear to be a major factor in stifling trading interest in 
these commodities. Trading in colton was virtually eliminated at a time when government stocks were large and increasing. and did not revive until aficr the disappearance of the government inventory. During the World War II period, one would conjecture that governmemt controls played a major role in the reduction of the number of fulures markets from a pre-war level of over 50 to 17 in 1945. By 1946. when a number of restrictions had been relaxed. the number of active markets had grewn to 36 . More recently, acting through the Commodity Credit Corporation (CCC). the US government had been gradually decumulitung grain stocks since 1973. This development was paralleled by a trading volume increase on grain futures contract markets. In the early 1980's CCC influence on grain prices began II reappear. For example, in 1981-1982 the CCC accumulated its largest slocks since 1473. Perhaps it is no coincidence that trading volume in grains in 1982 was signilicantly below that in 1981. Further evidence on the effect of government regulation on futures market trading activity is discussed in Telser and Higinbotham (1977). and Telse: (1981).

It is also maintained that to be viable, a futures contract must stucced in attracling a sufficient body of non-hedging traders (scalpers and other speculators). 10 maintain sufficient market liquidity and trading continuity (Gray (1967) and Working (1967)). The activitics ol these traders facilitate the placing and lifting of hedge positions, and in their absence the execution costs of hedging could be driven high enough to reduce hedgers' interest in the contrach

Thus, viable futures trading is also seen to be dependent upon those factors likely 10 influence the level of speculative activity in the contract market. On the supply wds. speculative interest is likely to be heavily influenced by the processes detcrmining cqualibrium contract market prices. Market structure considerations now become paramount. (ienctally, onle would expect a conspicuous absence of futures trading in contracts were the cash markct supply is concentrated in a small number of sources. Here, concern would relate to the: possibility that individuals possessing market power could manipulate cash prices, or through 
their control of deliverable supply. increase the risk of 'corners' and 'squeezes', in the contract market as delivery approaches. This activity would occur to the detriment of other market participants. However, despite the threat of such practices, it appears market structure considerations, even in such heavily concentrated industries as aluminium and chemicals (petroleum), are themselves not sufficient to suppress the credibility of a futures market when either the existing pricing structure is perceived to be unstable (owing for instance to large excess capacity in the industry (Carlton (1984)). or when increased supply sources become tcmporarily available.

On the demand side. market structure will impact upon hedging use of the market through its effect upon the nature and availability of adequate substitutes for futures trading. The benefits accruing from the establishment of a futures market to allocate price risk and provide a price discovery mechanism for commodity traders, depend upon the existence of feasible alternative governance structures serving the same function. Consider the position of a risk aversc grain elevator operator. storing wheat for future delivery via the cash market to a thour producer. The elevator operator may desire to hedge against the revenue loss which would result from a fall in the price of wheat while it is in storage. Several distinct options suggest themselves as a possibilitiies. The elevator operator could:

(1) Asume a position in the appropriate futures contract

(2) Store a diversilied portlolio of grains.

(3) Sill shares in the equity market, and let the shareholders diversify away the risk.

(4) Inter into a long-term forward contract with the flour producer.

(5) Vertically integrate with the llour producer.

The general point is that traders with an interest in the cash market may be accustomed to, or prefer. other hedging arrangements which dispense with the need to engage in futures trating: This points 10 a fundamental weakness in the price insurance theory of futures Ir.ating. This theor: does not explain why an organised futures market is necessary to dccommotate the hedging needs of cash market participants (Telser (1981)). Indeed. casual 
empiricism would suggest that hedging by forwart contracts is by lar the mont previlcm arrangement.

Nowhere in the essays to follow is it claimed that the measurement cont hypothess provides the grand unification theory by which these diverse strands of thought on contracl market 'thinness' and failure can be effectively synthesised. However, the choice of riscarch strategy does reflect the belief that the analysis of one component of transaction covis. namely measurement costs, and their relationship to the struciure of contracts and propirts rights, may provoke the insights, and eventuaily produce the research necessary to resolve the deficiencies in current approaches.

The central purpose of the essays which follow is to viggest ways in which the measurement cost hypothesis can be made amenable to empirical verification. In the proxiss. several directions in which the existing analysis can usefully be generalised are also promucel. A direct test of the hypothesis is precluded as estimates of the potential gain to individatial traders utilisation of idiosyncratic measurement devices across different cash markets cannot ' $x$ ascertained directly. Although no claim is made that the lests proposed are delinitive (given) certain of the evidence alluded to may be explained using other existing theorses). the consistency of test results across alternative independent specifications of the model atlest in its robustness and potential generality.

The content of the essays to follow can be briefly summariscd. (hapter II delath the incentives for one class of informed traders, trading specialisls in the relevant cash wiakils. to engage in the exploitation of incompletely specified contracts by the delivery of comllitu goods during the contracts delivery period. These incentives are argued to be dusculy relifued to the comparative disadvantage of transacting va futures. Given commodity exchanges have an interest in restraining such activity, it is argued that the regulatory conslatants on redelivery procedures may be interpreted as attempts to prevent opportunistuc behaviout by these more informed (i.e. lower measurement cost) traders. As such they are manifestaturis ": 
an inherent contractual weakness. The costs of attenuating the potential for such opportunism will, however, vary across contract markets, and in some will prove prohibitive. The hypothesis that failed and dormant contract markets are those which have exhibited the greatest difficulty in reducing the resource losses and wealth transfers from informed trader's exploitation of incompletcly specified contracts, is then formalised and tested using qualitative response models. The results obtained are broadly consistent with the theory.

Chapter III clarifies the consequences of the range of arbitrage indeterminacy in certain futures prices for the conventional theory of intertemporal price relationships for storable commodities. Specifically, the model develops testable propositions relating to the relative price variability of open and spread contract portfolios. By relating this relative price variability to the initial speculative margin requirements established by commodity exchanges, results of tests of the measurement cost hypothesis using contract market data on margin requirements for one hundred and eleven commodities for the period 1970-1984 are presented. Again corroboration of the hypothesis is evidenced.

The linal essay in chapter IV extends the model of chapter 111 to analyse its implications for the behaviour of the price volatility of spread positions in futures as the upreads constituent conuracts approach maturity. After a comparison of the model's predictions with those of currentl! existing alternatives. tests are conducted in an attempt to distinguish between the empirical predictions of the various analyses. The results of the tests are inconclusice. and appear sensitive to their specification. in particular the measure of price Wlatilits adopted. A future research agenda would be to attempt to refine the model further. chabling a more discriminating analysis of its implications to be conducted. 


\section{FOOTNOTES}

1. For examples and further discussion see Klein and I effler (1981). Har/el (198?). and Williamson (1983).

2. By assumption. the measures adopted in the cash market produce the mavimum giails from trade. net of the costs of measurement.

3. Joseph Mehl ((1937), p. 314) as cited in McManus and Acheson (1479). commonling on regulation under the Grain Futures $A c t$ is instructive:

"An earlier case involved certain floor brokers who systematically injected themselves between the trades of customers for price cllts from $1 / 8$ to 2 cents per bushel. depending upon the movement in the market while the orders were in their possession."

4. The markets listed in the Wall Street Journal account for the vast majority of all (IS futures trading. measured by the total volume of contracts traded. In 1983, the littil year of the Carlton study. they accounted for 98 per cont of lotal trading.

5. Three contracts are listed continuously over the entire 1921-198.3 period: wheal on ille Minneapolis Grain Exchange. Oats on the Chicago Board of Trade, and collon onl the New York Cotton Exchange.

6. Carlton adopts the following commodity classifications: foodstufts, grains, metuls. industrial materials, livestock, oilseed products, and linancial instruments

7. For an explicit model. see Kyle (1984).

8. It is not suggested that a desire to hedge their cash markel exponure would be the onlv; or even a major reason for grain elevator operators, or cash market particupinils in any commodity. to engage in trading futures. For alternative explanations. includung the hypothesis that these traders take futures positions to speculate on the cish filluter price differential (the basis), sce Working (1953). 


\section{CIIAPIRK II \\ MHASUREMENI COSIS ANI RRCOULATION: DELIVERY PROVISIONS IN FUTURES CONIRACIS}

\section{INTROIDUCTION}

This cssay is an investigation of the importance of mcasurencent costs in the design of futures contracts. Mcasurement costs are defined as the costs of quantifying the information necessary to verify fullillment of a contractual obligation in the absence of trust.' Adopting Williamson's (1979) perspective that the assessment of transaction (measurement) costs is a comparative institutional undertaking, an analysis of contractual arrangements existing during the delivery period of a futures contract provides an ideal opportunity to identify actual dimensions with respect to which measurement costs differ across transacting modes. For litures contracts posessing a delivery option. the delivery period encompasses two coincident spot markets dealing in the same commodity, the regular cash market and the delivery matket for contract gouds. However, as both McManus and Acheson (1979. 1983) and Telser (1981. 1986) argue. the former is an institutional mode designed to maximize the net gains to exclusivity. while the latter attempts to maxinize the expected net gains from ownership of the right to transfer.' Perhaps Telser puts the argument most tersely in his conviction that futures markets exist to "facilitate trade among strangers."

Section I of lle essay demonstrates that the difference in ownership rights being transicted is not vactlous. indicating why transferability considerations may preclude the ddoption of the most efficient measurement technology in futures contracts. When this occurs a market is designaled contractually incomplete. The discussion is illustrated with cvidence drawn from seconlary sources describing market institutions in the cotton market. The impottance measurement considerations play in a contract market's choice of delivery mechanisms. cither cash setlement or a dedivery option. is the subject of section 11 . A delivery option is shown to be necessary in certain markets to prevent manipulation of the setlement price of the contract. The manipulative activity considered differs from that aimost 
universally discussed in the literature. in that it docs not emanate from monopoly pumcr. III the sense of 'comers' or 'squeeres' resulting from concentration of deliverable supplies in the hands of a few traders. but from contractual constaints upon the measurement lichmology. Section III details the measurement procedures adopted by contract markets in the delivery period, and indicates the resulting incentives which may occur for traders to engage in the unhedged production of contract goods. These incentives are demonstrated to be direcily related to the comparative disadvantage of transacting via fulures. It is argued the self-regulatory constraints imposed by commodity exchanges in the delivery month. cinl he interpreted as attempts to ninimize the losses resulting from contractual terms which thly lead to incentives for the production of contract goods. The cost of altenuating the dissipallum will, however. vary across contract markets, and be greatest in those futures which are conuactually incomplete. These are also the markets argued to be most open to manipulattont by traders with lower costs of measurement. This manipulative activity exploits other poltential contract holders. reducing the transferability of contracts and possibly culminates in the lisilure of the contract market The hypothesis that thin or dormant contract markets are thisc which have exhibited the greatest costs in reducing the resource lonses resulting from wh manipulative activity is formalised, and tested usirg qualitative response moxlels in wctuon IV. The results provide tentative support for the postulated relationship. Some concluding femalks follow.

\section{I: MEASURFMENT COSTS AND AITHRNATIVF CONTRACTUAL SPHCIFICAIIONS}

In order to examine the nature and incidence of measurement costs, this essidy addepts a framework of analysis which provides an exhauslive classilication of measurement proxcelures. The framework is first proposed in Acheson and McManus (1979), and certain of lis relevilll components are now outlined. The results of a measurement technology that the respective contracting parties agree may be verified by an independent ihird party replualung the 
measurement procedure, is sild to consist of objective measures. Although these measures may be explkilly incorporated into an! contractual agreement. such an objective description of the rights to be transferred will often be incomplete. Trading parties will supplement them by subjcctivcly (or idiosyncratically) monitoring certain elements of contractual performarice. The characteristic leature of these measures is the inability of transacting parties to agree on their verification in a joinuly atisfactory manner."

Both methods of contractual enforcement indicated above may be supplemented by a further measure if the identity of one or both of the contracting parties is of importance in specifying the value of the contractual obligation. The monitoring technology then incorporates a perunal measure. for example. when the seller or buyer is named in a contract. The distinguishing leature of such a contract is the inability of the designated principal(s) to unilaterally transfer their obligations to another individual. In contrast, when the bundles of rights owned by different individuals trade at the same price per unit as objectively described in the contract regardless of the principal's identity, the contract is said to be specified imperwonally. An impersonal specification is. therefore, a necessary condition for contracting prencupats to ponsess the right to unilaterally transfer their contractual obligations.

Av all measurement procedures involve costs. the gains from transacting will be a fiunction of the procedures adop:ed by the contract governing the exchange process. By swomplion. contracting partics select those measures. thus the form of contract maximising the g.ums from transating in the relevant exclusive rights associated with ownership. net of the cont of yecifying and enforcing performance.

following Willamson (1976. 1979). Goldberg (1976) and Barzel (1982) it is clear that for mun! Iranxactions, the entorcement of only impersonal and objective measures for those markets normally termed price taking) are often revealed uneconomical compared to the more personduced. didom!niratic alternatives adopted in price searching cash markets. However. in an iffort to inhance Iransferability of the asset in question. governance structures sometimes 
suppress these latter methods of trading. The associalcd costs are perhaps best illustrulced by consideration of the relative costs of transacting in lorward and futures markets. The definition of 'futures' and 'forward' this essay adopts, again proposcel in McManus ant Acheson (1979), and consistent with Telset's (1981. 1986) analysis. is particularly well suitcil II) present purposes, as it incorporates eiplicit consideration of the measurement costs asuxiulted with the right to transfer an exclusive asset.

A contract is simply a promise or set of promises, the performance of which is recognized as a legal duty of the contracting parties. A futures contract is written $x$ ) that it may be performed by unidentified third partics. This right to transler contractual obligatıms accorded to both principals, is a feature which emerges as a produced altributc of the contract governing the exchange process. Specifically, to ensure bi-lateral Iransferability. littures contract specifications must be objective and impersonal.' In contrast, in a forward contract. .1 least one of the contracting parties will agree to assume personal responsibility firr performance of the promised obligation. and for that individual the contract is not uansferable. A forward contract incorporates identity as a valued specilication of performar: c. therefore embodying an explicit denial of the right to transfer. The parties to a lorward contract may also agree to the use of subjective measures of contlactual enforcement.

For our purposes, it is sufficient to note two characteristics of the allernatlve contractual forms governing exchange which are distinguished by the respective measurcement devices employed. First, the contractual rights established by the futures contrat will in general not correspond to those which would be adopted in a governance structure destented to maximize the net benefit from transferring exclusivity. A sinple objective descriptuon of a commodity as transacted in the cash (spot and forward) market is usually incompletc. as "I does not constrain all the characteristics of goods entering into wellets costs and bulptes evaluations. Because of measurement costs. commodiues destgnated to be of the same zratle when classified accurately on the basis of the discretc objective measurement standards, mas 
vary comsudersbly in quality and valuc. 1..1). Howell's dexcription of the imprecision of (1.S.I).A. grading standards in collon is illusurative:"

"If the differences in value of cotton of different qualities within grade and vaple Iength designations are proportionately about as great as the differences in value from onc grade and staple length designation to another - and this aprean to be a reasonable assumption - the differences between the market value of the highest quality of low Middling 15/16-inch cotton and that of the lowest quality of Jow Middling 15/16-inch cotton in Houston during the year cnded July 1954 averaged more than 3 cents a pound." (emphasis added)

Io circumvent such difficulties, trading in cash markets regularly supplements the use of .hicctive and impersonal specifications with personal. subjective measures and relies upon subjective monitoring for contractual enforcement. The institutional features of cash markets (brand names, reciprocal dealing. the use of warranties. etc..) simply offer traders more measurement alternatives than a futures contract, and as such will usually possess a comparative advantage over the latter in organising the specified transaction. The ability of subjective monitoring techniques to more easily detect variations in quality within the range of yuallics defined by the official standards in cotton, can again be clarified by reference to Howcll:

"...unpublished data relating to prices of colton sold on ex-warehouse terms in Niw Orlcans during the seasons $1929-30$ and 1930-31 ... show that cotton designaled as "full" in grade or staple length sold at a premium over the price of colton equal in quality to the average for the standard. These premiums amounted. on the average, to about one-half of the difference between the price of colton of the nevt higher grade and longer staple... Cotton sold on "watchousc terms in New Orleans and described as "shy" in grade or staple length wold at a discount from the price of cotion equal in quality to the acrage for the standard. The discount amounted. on the average, to approvimately 30 per cent of the difference between the price of cotton of the pecilied grade and staple length and that of the next lower grade and shorter tuple."

Sicond. measurement is not performed in an! market with perfect precision. As Barzel (1482) Indicates. If the cost of measurement rises with accuracy. there will exist some errors in miasurement traders will not find it worthwhile to eliminate. A certain degree of imprcicisun will be tolcrated by Iraders, who transact with the knowledge that the behaviour 
of sellers will not perfecty conform to the prefiences of busers. These diflerences in the value of the commodity as a result of random variations in quality would cist cren if classification, based on the discrete measurement s:andards, were absolutely accurate. All! constraints imposed upon the trading parties' choice of measurement techniques compounds the problem, in the present example serving to increase the range in the value of ciolton included within a specified grade and staple length designation. The buyer and/or the seller may have an incentive to exploit this imprecision arising from inclficient measurement, by engaging in costly alterations of the traded commodity to their own advantage. withoul foregoing a loss in expected revenue equal to the market price per the units in which the commodity is being measured (McManus (1975)). Such wealth maximiring activity on the part of individuals, resulting from costy measurement and random errors thercin. takes place at the expense of joint maximization. The following discussion demonstrales why transfirability considerations imply the existence of such opportunities in futures markets, indicalles the effects upon trader behaviour. and attempts to identiiy the governance structures which emerge to minimize the losses from the dissipating exploitation of mexisurement crrors.

\section{II: THE CHOICE OF PERFORMANCE MECHANISMS IN CONTRACT MARKETS}

\section{a. Cash Settlement and Price Taking Markets}

The delivery month of a futures conuract is that specified period of time within which parties to outstanding contracts must fulfill their contractual obligations. All futures contrac/s specify one of two forms of contractual performance. Trading principals are either requircd "1) make and take delivery of the asset designated in the contract. subject in enforcement of the contractual specifications indicated therein, or the certract will specify performance through cash settement. 
McManus and Acheson (1979, 1983) and Garbade and Silber (1983a,b), while differing signilicanily in their emphasis, both argue that the mechanism underlying the contractual choice between cash settlement and physical delivery as the method of performance, can be clarified by consideration of the ability of the futures contract to incorporate the measurement devices adopted in cash market trading. A stylized synthesis of their insights follows. In essence, when the futures contract enters the delivery month it becomes a spot contract. Hfectively, there are then two coincident spot markets in operation. the contract goods market and the regular cash market. If the relevant cash market is price taking, futures contract upcutications can perfectly duplicate, at the same measurement cost, those used in the cash market." Fxcept for the timing of the transaction. which shall be ignored, the two markets are obstensibly equivalent and the seller (buyer) will be indifferent between making (taking) (clivery and a cash sale (purchase). Arbitrage by risk neutral traders ensures that prior to the delivery month. the futures price will be an unbiased estimate of the spot price expected on the lirst delivery day. and during the delivery snonth the price to buyers will be identical in the cash and futures markets." Clearly, once a procedure for drawing and utilising cash market price observations has been stipulated, outstanding futures contracts written on commoxities trading in price laking cash markets, are amenable to performance by a transfer of cash payments. These payments are calculated as the difference between the value of a Iraders contractual obligation and the linal setuement price when the contract matures. ${ }^{10}$

\section{b: The Deluery Optın and Price Searching Markets}

The problems encountered by cash settlement are revealed upon consideration of futures contracts which relate to price searching cash markets. A characteristic feature of such markets is that buy cell spreads tiffer :cross trading principals." One result of these differences in medsurement costs is that price searching markets do not provide a price that traders would all agrec on is the market price at any moment of time. Once more. Howell's analysis of certuin of the evisting cash market trading procedures operative in the cotton market is 
enlightening:

"Much of the colton in designated markets is sold in mixed lots of tarious sizes composed of two or more grades and staple longths at an average price for all cotton included in the lot. Differences in terms and conditions of sale. in size and composition of the lots sold, in bargaining power of traders in the market, in quality and value of cotton of the same grade and staple designation, and in other factors affect the markets. Therefore, prices of cotton of the same grade and staple designation, sold in the sane market on the same day vary widely.... Under such conditions, it is obviously difficult to arrive at quotations that accurately reflect actual commercial values or price differences for colton of the various grades and staple lengths." 1 :

A cash setulement procedure is unfavourable to the fair determination of a price al which contractual obligations can be seiiled in such futures markets. Transficrability and enforcement considerations require the exclusion of subjective measurement procedures from the terms of the tutures contract. The problem with cash settlement arises in attempling 10 establish an acceptable rule for drawing upon and utilising cash prices at contract maturity in the construction of a cash setulement index. The relative incompleteness of the measures incorporated in the futures contract may create an incentive for the production of commodities with attributes chosen 10 deliberately affect the final settement price. Market participants when observing cash market prices at contract expiry, will encounter difficulties in distinguishing between:

(i) prices relating to trading in commodities which have been produced incorporaling only those attributes objectively specified in the futures contract, and

(ii) prices relating to trading in goods which is designed to generate revenue from the subjective and personal monitoring of cash market traders.

A trader in possession of this information, could take a position in futures which wonld generate a sufficient (risk-adjusted) return to more than offset its cost. As lutures lrading is a cero-sum game. this return is made at the expense of other futures market participants.

The function of the delivery option now becomes clearer. ${ }^{\prime}$ This provision cstablishces it delivery market where transactions are negociated and cnforced subject to the moasures 
adopled in the futures contract. The settement price of the contract is then revealed, through arbitragc, by potential transactions in the delivery market, and not from transactions on the pertinent cash market.

Traders in futures will take into account the cost and value of contract goods, defined as thosc commodities incorporating the minimum attributes necessary to meet futures contract specifications. Production of contract goods would generate commodities with different attributes, and/or levels of attributes, than would be planned for cash market deliverv. Attributes left unspecified in the futures contract or measured with less precision than in the spot market will be less intensively produced in contract goods. ${ }^{14}$ If the market price does not appear a true reflection of the market value of these contract goods, ci.her shorts can plan 10 acquire or produce the commodity below the futures price and deliver on their obligations for a clear gain, or longs may take delivery of commodities they expect to be worth more than the price they will pay.

The delivery option, therefore, attempts to enforce against informed traders manipulation of tis: value of the futures contract. This enforcement is attained at a cost, as trading in contract goods is confined to a transactional mode which is relatively inefficient, being unable to ofler traders the same enforcement options they possess in the regular cash market Over the range of reduction in quality attributes, the fall in the cost of production and measurement for delivery to sellers, must be less than the corresponding reduction in value to buyers. Oiherwise futures contract specifications would be utilised in cash markets.

In equilibrium the losses associated with competition in the planned delivery of contract goods cannot persist. As it involves an ex ante loss to one class of trading principal (either longs unaware of the quality of eligible deliveries, or shorts mistakenly planning deliveries in the belict longs are uninformed), the misinformation upon which such production is based will be self-correctung." As such, the final settement price of the contract with a delivery option. will reflect the value of the lowest quality goods sold in regular cash markets which 
meet the delivery specifications stipulated in the fitures contract."

The net gains from trade foregone by using this rclativily inferior mole, will be directly reflected in the difference in the buy-sell spreads between the lutures and cilsh markets. This difference creates a range of indeterminacy in the lutures price. within which price movements cannot be constrained by potential arbitrage via delivery. An opportunity then exists for manipulation of the value of the contract by traders with lower cost access (1) the contract market. The greater the contractual incompleteness of the lutures contract, and the less sensitive the futures price to arbitrage. the greater the copected loss to wher potential traders of taking a position in the contract. These individuals will avoid the markst. inhibiting transferability of the contract. Consequenty. one may expect the contract market to become thin or even dormant.

As estimates of the potential gains 10 traders' use of subjective measures in different cash markets cannot be ascertained, a direct test of this measurement cost hypothesis relating contractual failure to informed traders' exploitation of measurement errors is prohibited. Ihe next two sections argue that, as an alternative, the severity of futures exchange restrictions in the redelivery of contract goods may be used as a proxy measure for the degree to which the futures contract is incomplete. Hmpirical evidence, linking the severity of redelively restrictions to contract failure is then examined. and argued to lend tentative corroboration (a) the hypothesis.

The emphasis of this analysis is to be contrasted with that of Fdwards and F.dwath (1984) who write:

"Neither contracts with a cash delivery feature or those written on stock indices are intrinsically more susceptible to manipulation than are other, more traditional. types of futures contracts. Indeed, such contracts are likely to be less prone is manipulation." ${ }^{*}$ 
The authors contend that the cash settement feature of such contracts reduces the transaction costs associated with specifying a broader deliverable supply, thereby permitting the contracts to be written on a 'large enough' cash market to sufficiently discourage manipulative activity. From the context of their argument (p.345), it is clear that by manipulative activity. the authors are referring to the potential for the exercise of temporary monopoly power as manifest in "corners" or "squeczes" near or in the delivery period of the contract. Although the occurence of such activity appears to be a non-trivial problem. ${ }^{18}$ it is not of direct relevance to the present analysis. Here the concern is upon informational asymmetries resulting from differential costs of measurement, rather than monopoly power as the source of any manipulation." These effects can be isolated through consideration of futures contracts pertaining to commodities which trade in open, competitive cash maikets, ie., those with no crclusive right to trade. Such markets are not necessarily price taking. ${ }^{20}$

\section{III: THE DHIIVFRY PFRIOD OF A FUTURES CONTRACT}

To csamine the incidence and specific nature of the measurement difficulties cncountered in transacting via the futures market, attention is confined to a consideration of the relevant institutional procedures governing trading in the delivery period of futures contracts containing a delivery option. Once trading enters the delivery (or maturity) period, each contract holder with a short position has the contractual right to sell (deliver) the yuantity and quality of the specified commodity at the location(s) stipulated in the futures contract. To implement delivery. the short issues a formal delivery notice, or notice of intent to duver to the exchange clearing house on the position day of his choice. This can be at any tine from the first notice day to the last day of trading in the delivery month. It is understood that when tendering the delivery notice, the seller has complied with all the obligations imposed by the delivery procedures of the exchange clearing house. Foremost among these. is having the grade and quality of the commodity certified by officially 
approved exchange inspectors.

Tr.e measures utilised in certifying contract goxds are, of course. those objuctive measures snecified in the futures contract. The procedures adopted by the Chicago Mercantils Exchange are typical and will be used for illustration. All agricultural commodities delivered through the exchange carry an Exchange Inspection Certilicatc bearing the signature of the President or Executive Vice-President and the seal of the Fxchange. If the contract grater are based on USDA standards, the commodity is inspected by government inspectors. and the government inspection certificate is attached to that of the exchange." In the calse of non-agricultural commodities. certification is undertaken by an exchange approved relinter. assayer or other authority."2 The exchange itself is not liable for any error or negligence of any inspector, and all claims for liability relating to inspections are waived by the application for an Fxchange Inspection. Weighing or Testing certilicate." Moreover, the exchange assumes no responsibility and disclaims all liability on account of the grade. quantity or specifications of any commodity delivered on the basis of an U.S.D.A. or other required inspection certificate. $^{24}$ In addition, the delivery notice will generally stipulate the name and business address of the issuer (clearing member). the date of issuc. the date of delivery, a dexriplum of the negotiable instrument by which lite to the commodity will be transferred, and any other information exchange regulations and contractual specifications require in regard (1) anly particular commodity. It is important to note. that all deliveries on maturing contracts are made through the exchange clearing housc:"s

On receipt of the delivery notice, the clearing house promply (the same business (day) informs a designated long (clearing member) that they are obligated to take delivery of the contract goods from the short issuing the notice. The procedure for apportioning notices varics from exchange to exchange. On some exchanges the clearing member with the oldest opurt long position receives the notice: on others, it is assigned to the member with the oldert itc1 long position. Finally, some clearing houses allocate notices according to the percentage of the 
groms long position in the delivery month held by their clearing firms. In turn. the clearing lirm informs the long trading principal with the oldest open position (as of close of trading the previous day). that they are bound to accept delivery.

Once in receipt of the names of the buyers (clearing member(s)) obligated to receive delivery, the seller prepares invoices containing the net invoicing price, which is the last sctllement price plus or minus allowances and adjustments, provisions for which are made in the fulures contract. Ownership of the commodity is transferred on the delivery day, at which lime the buyer is entitled to all documents required by the delivery notice, with such endorscments as may be necessary to convey title and possession. One may note at this juncture that unlike trading on the regular cash market. the buyer is not free to inspect the commodity prior to delivery and refuse any tendered unit which they do not perceive to be of contract quality.

(i) Production of Contract Goods: Incentives and Fffects

The next lask is to develop a model to analyse under what circumstances traders' participating in the exchange of goods during the delivery period of a futures contract, obtain net gams from engaging in the unhedged production of contract goods. This will facilitate the derivation of the equilibrium cash-futures price relationships existing during the delivery period of the lutures contract. It is also central in explaining this essay's rationale as to the nature and purpose of the regulations imposed by commodity exchanges on the redelivery of goods during the futures delivery period.

\section{a: The Cash Markel}

Production and sale in the cash market is assumed to be undertaken by risk neutral individuals and ocurs in unit si/e bundles, at a constant cost of $c_{c}$ per bundle. Each unit produced for cash market delivery contains two quality categories of goods, high quality with 
an expected value $q_{\mathrm{h}}$, and low quality (contract goods). with an expected value $q_{\mathrm{l}}$. High ind low quality goods differ only in the amount of subjectively valled altribules they contain. In general. the quantity of $\mathrm{q}_{h}$ and $\mathrm{q}_{1}$ goods varies across bundles. This variation in quality is . result of evogenous factors effecting the production function of cash market gexkls. For simplicity. it is assumed that the values of bundles of cash market goods atre Innilormly distributed over the interval $\left(q_{h}-q_{l}\right)$. Thus, if the average proportion of $q_{h}$ and $q_{l}$ finkts in each bundle is $p$ and $(1-p)$. respectively. then $p=0.5$. The expected value of the average quality bundle produced for sale in the cash market is $q_{a}=p q_{h}+(1-p) q_{1}=0.5 u_{h}$ $+0.5 q_{1}$

To motivate the requirement of a variety of qualities being eschanged in a single carli market transaction. it is assumed that on a stand-alone basis, a cash market in contract goods would not be viable. If low quality goods could be produced at a cinit of hily. if pis bundle, where $c_{c}>c_{1}$. tnis requires that the production and delivery costs of a tImI of contract goods exceeds their value. $q_{1}+x>q_{l}$. which in turn implies $c_{c}+1>q_{1}$. Jhe difference $c_{c}-c_{1}$ will be directy related to the contractual incompleteness of the liutures contract.

Individuals trading in the cash market all possess the same cost of objeclive measurement, \$x. In addition, idiosyncratic measurement may be undertaken by Iraders to form an estimate of the proportion of high and low quality goods in tach bundle. I his subjective measurement cost is fixed at $\$ f$ per unit. where $f<q_{a}-\left(c_{c}+x\right)$. Io molivalle buyers spending $\mathrm{Sf}$ to subjectively evaluate cash market purchases, they arc assumcd 10 be risk averse with respect to variations in wealth.

Individual buyers are assumed to differ in their ability to measure quality proportums in cash market bundles. They fall into two catcgories, designated informed (or I type). and uninformed (or U-type). At any given cost of idiosyncratic measurcment, a represcntallve I-type trader is assumed to assess the value of a given bundle more accuratcly. and with 
lower variabitity. than a U-type trader. Specilically. at a measurement cost of $\$ \mathbf{S r}$, an i-type Irader $(i=I, U)$. accurately estimates the quality of a bundle with probability $z_{i}$. They believe a bundle to be above (below) average quality in proportion to the average amount of $q_{h}$ $(4)$ goods in each bundle. As bundles are drawn from a uniform distribution over the interval $\left(q_{h}-q_{1}\right)$. the probabilities of over- and undervaluation are equal, at the level $0.5(1$ - ${ }_{i}$ ). To reflect the assumption that informed traders perform measurement with greater accuracy and precision, $I_{I}>\prime_{U}$, which in turn, implies $0.5\left(1-I_{1}\right)<0.5\left(1-z_{U}\right)$.

Cash market trading procedures are designed to capture competition for tendered bundles between $1-$ and U-type traders, and are represented as follows. Once a buyer has subjectively estimated the quality of a bundle. they submit a bid price, $b_{i j}, \quad(i=I . U: j=$ h.a.l). to the seller. The bid price may be thought of as derived from a marginal willingness 10 pay whedule (inverse demand schedule) $b_{i}$. which is dependent upon a certainty equivalent measure $q_{c}$, reflecting the buyer's subjective assessment of a given bundle's quality, $b_{i}=$ $b\left(q_{c}\right) \cdot d b / d q_{c}>0$. Thus, the bid price represents the maximum price that an i-type trader will pay for the bundle. and is made privately and independently by buyer to seller. This is the simplest way to explicitly rule out the possibility of informational free-riding across different buser-lypes. Bids may be considered as average bids within their class. and are assumed to fall into three catcgories: high $b_{h}$. low $b_{1}$, and accurate $b_{a}$. The bid levels are defired in relation to the (unknown) actual quality level of the bundle, with $b_{h}>b_{a}>b_{1}$. The carlier assumption that the quality of goods within each quality category is stochastic. is suflicient to ruke out the possibility that buyers find it profitable to submit low bids, $b_{1}$. without incurring the fixed measurement cost, \$r. In addition, bids satisfy the following resirictions:

(i) the accurate bid price is a weighted average of the high and low bids, with weights corresponding to the average proportion of high and low quality goods in each bundle. This implies $b_{a}=0.5 b_{h}+0.5 b_{1}$. More will be said regarding the specific level of bids later in the chapler. Clearly. given positive costs of subjective assessment. $b_{a}<q_{a}-f$. 
(ii) the difference between high and low quality bids is positively related to the difference in traders' valuation of high and low quality goods:

(2.1) $b_{h}-b_{1}=r\left(q_{h}-q_{l}\right), r()>$.0 .

Once bids have been received. the bundle is sold to the highest bidder. In the cvent Iwo individuals submit identical bids. the bundle is assigned randomly.

in general. goods delivered on the cash market will be measured to the extent that an additional unit of expenditure devoted to meastirement yiclds a unit increment in enpected value to the seller and buyer jointly (Barzel 1982). The commodity will then have been sorted optimally in that by assertion. any further expenditure on measurement will increasc the expected value of the commodity by less than that unit. In the above model, absent a mechanism whereby sellers can credibly signal to buyers the precise quality of any delivered bundle, competition ensures that in equilibrium, sellers will refrain from assessing the yutality of their goods prior to sale. Bundles of goods of mixed quality will be sold in the cilsh markeL

\section{b: The futures Market}

Concurrent with the operation of the cash market, at time $\Gamma$, individuals may als) make and accept delivery of the commodity in the delivery market created by a luidies contract. The objective specifications governing quality standards for delivery in the lutures market, are identical to those used in cash trading, and contract sise is one unit. Ihus. traders may deliver both high and low quality goods, or a mixture thereof. to saltsfy any futures delivery obligations at a cos. of $\$ x$ above the per unit production Lost. II III production of contract goods $q_{l}$ occurs, production and delivery via futures will cost it minimum of $c_{c}+x$ per unit delivered, and in the absence of quality sorting. goods tendered in satisfaction of futures obligations will have an expected value of $\mathrm{a}_{\mathrm{a}}$. 
(ii) Tyuilibrium in the Cash Market

Consider a representative informed and uninformed buyer engaged in a bidding competition to secure a bundle of cash market goods. The task is to determine which trader will secure the bundle, and to calculate the average bid price they will pay.

\section{a: Informed Traders}

Informed buyers obtain the bundle if $b_{1}>b_{U}$. or $b_{l}=b_{U}$ and they are awarded the bundle via the random allocation procedure. The possible bid prices of informed buyer's, logether with the associated probability of obtaining the bundle at each price. $\left.y_{\mathrm{Ij}}, \mathrm{j}=\mathrm{h}, \mathrm{a} . \mathrm{l}\right)$. are given by:

(i) price $b_{h}$ : probability $y_{\mathrm{Ih}}=0.125\left(1-{ }_{1}\right)\left(1-{ }{ }_{U}\right)+0.5\left(1-4_{1}\right)\left(1-0.5\left(1-{ }{ }_{U}\right)\right)$

(ii) price $b_{a}$ : probability $y_{l a}=0.5\left(/ I^{\prime} U\right)+0.5 l_{l}\left(1-\iota_{U}\right)$

(iii) price $b_{1}$ : probability $y_{I l}=0.125\left(1-{ }_{1}\right)\left(1-{ }_{U}\right)$

\section{b: Uninformed Traders}

Ininformed buyers obtain the bundle if $b_{U}>b_{I}$, or $b_{U}=b_{I}$ and they are awarded the bundle via the random allocation procedure. The possible bid prices of uninformed buyer's. logether with the associated probability of ob:aining the bundle at each price. $y_{\mathrm{Uj}}$ (j $=$ h.a.l). are given by:

(i) price $b_{h}$ : probability $y_{U h}=0.125\left(1-\prime_{U}\right)\left(1-t_{1}\right)+0.5\left(1-t_{U}\right)\left(1-0.5\left(1-z_{1}\right)\right)$

(ii) price $b_{a}$ : probability $y_{U_{a}}=0.5\left(t_{U^{\prime}}\right)+0.5 / U^{\left(1-\iota_{1}\right)}$

(iii) price $b_{1}$ : prooabilit! $!_{U 1}=0.125\left(1-{ }^{\prime} \mathrm{U} \times\left(1-1_{\mathrm{I}}\right)\right.$

Soveral 'calures of this allocation mechanism are worth comment. First, for any given ${ }^{\prime}$. ' $\mathrm{l} f$. the probabilities of informed and uninformed traders obtaining the bundle are equal. In this model. this is a conscyetence of the assumption that the average bundle contains $\mathrm{q}_{\mathrm{h}}$. 
and $q_{1}$ goods in equal proportions. In general, if $y_{i}$ is the probability an $i$-lype trater $(i=$ I.U) obtains the bundle. then $y_{I}-y_{U}=(1-2 p)\left(t_{1}-l_{(1}\right)$. Restricting $p$ to to 11.5 in the present model, simplifies the analysis without effecting the qualitative conclusions.

Second, as $y_{I}=y_{U}=0.5$. the average price paid per bundle is. for i-type buters: $2\left(y_{\mathrm{ih}}\left(b_{h}\right)+y_{i a}\left(b_{a}\right)+y_{i l}\left(b_{l}\right)\right\}$

Substituting for $y_{\mathrm{in}} y_{\mathrm{ia}}$ and $y_{\mathrm{il}}$. the average bid prices paid by informed and uninliomed traders which secure a cash market bundle are, respectively:

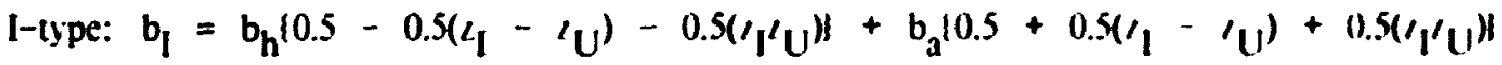
U-type: $b_{U}=b_{h} 10.5-0.5\left(l_{U}-l_{1}\right)-0.5\left(z_{U} l_{1}\right) !+b_{a}\left(0.5+0.5\left(t_{U}-l_{l}\right)+0.5\left(t_{(I} f_{1}\right) 1\right.$

The difference in average winning bids is. therefore:

(2.2) $\left.b_{U}-b_{I}=\left(b_{h}-b_{a}\right) z_{I}-t_{U}\right)>0$.

The average winning bid of the uninformed buyer exceds that of the informed buycr. alud the latter gain more surplus than the uninformed buyers from their cash markel Irading activities. The reason is that the uninformed buyers are more likely than the informed (1) win the bidding when their subjective estimate of the quality of the bundle is loo high. and lose when it is too low. Moreover. $d\left(b_{U}-b_{1}\right) / d\left(/_{1}-(U)>0\right.$ : for any given distribulion of quality levels in a cash market bundle. the difference in average winning bids of uninformed and informed traders, $\left(b_{U}-b_{p}\right)$. is positively related to the difference in accuracy of traders' subjective measurement capabilities. 'I - 'U.

Third, it was earlier assumed that the difference between average high and fow bids is positively related to the difference in the expected quality valuation of high and low yualitv goods, $b_{h}-b_{1}=f\left(a_{h}-q_{l}\right)$. $\Gamma()>$.0 . Substituting for $b_{a}$ in cquation (2.2) fiom (?.1) implies:

(2.3) $d\left(b_{U}-b_{1}\right) / d\left(a_{h}-q_{l}\right)=0.5\left(l_{1}-t_{U}\right) f^{*}()>$.0 .

The natural way to depict an increase in contractual incompleteness in the prescont model. is by way of a mean-preserving spread increase in the range of qualitics comprisng the $\varphi_{a}$ 
bundle. Thus, cyuation (2.3) indicates that the difference between the average cash market prices paid by informed and uninformed traders increases, the greater the comparative disadvantagc of engaging in transactions governed simply by the objective specifications of the littures contuact relative to those governed by cash market trading procedures.

If the cash market continues to attract participants:

(i) buyers' gross purchase price (winning bids plus costs of idiosyncratic measurement) must not exced the expected value of the average quality bundle. $b_{i}+f \leq q_{a}$, and (ii) sellers' net revenue must cover their cost of production plus objective measurement, $c_{c}$ $1<b_{i}$

Consider one possible senario:

$c_{c}+1<b_{l}+r<b_{u}+r \leq a_{a}$

As dexribed. informed buyers obtain a surplus from their cash market transactions of magnitude $\left(a_{a}-b_{1}-f\right)$. while, in the limit, uninformed traders pay a price for the average quality bundle equal to its cxpected value $\left(b_{U}+f=q_{a}\right)$. Rather than continue to trade at a disadvantage to informed individuals, uninformed traders may prefer to trade in the delivery market established by the futures contract for goods of the same objective description as those trading in the cash market. By trading in the futures market, uninformed traders save \$1, and will obtain. on average, a better price for each bundle purchased (it is later demonstrated that in equilibrium the maximum futures price, $f(T, T)=q_{a}$ ). However, given the quality of a bundle delivered in the futures market can vary between $q_{l}$ and $q_{h}$, by foregoing the opportunity to idiosyncratically (albeit imperfectly) ascertain the quality of delivered goods. uninformed traders have increased their wealth variability in relation to quality for the bundles they actually purchase.

The revealid outcome is that two governance structures for delivery of the same objectively defined commodity may be in operation simultaneously. Informed buyers do not find it profitable to migrate to the delivery market established by the futures contract, and 
would trade with each othcr. adopting conventional practices, in the regular cash marhet. Uninformed buyers would be active in the delivery market established by the funures contract.

The reader may inquire why. given the potential benefits to uninformed individuals. an equivalent governance structure to the delivery market in contract goods is not cstablished in conjunction with the existing cash market. This would preclude the necessity of aiting delivery via futures. The revealed absence of stuch a market implics that the covis of establishing this governance structure exceed the discounted benclits uninformed traders derive from its existence. The futures exchange may, however, be prepared to subsidise the "vistenct of the delivery market with the returns generated from futures trading activity. The reasurt is that earlier indicated. The presence of a delivery market is, for some contracts, nectisary in prevent manipulation of the futures settlement price. thereby promoting trading activity in the contract market. The circumstances under which a commodity can sustain deliveries in imsh cash and futures markets are analysed in the next section.

(iii) Equilibrium in the Futures Market

Farlier discussion, following Acheson and McManus (1979. 1983). related the comsuramts on the bounds of the futures setuement price of a futures contract possessing a deliverv option to potential arbitrage transactions in the delivery market for contract goxds. (Furly. therefore, such bounds will be sensitive to variations in the unit cost and delivery of contrat goods. While the dynamics of setulement price behaviour are considered morc lully in Chapter IV, an appreciation of its central features is crucial to the prescnt analysis, and alt brieny summarised.

Specifically. assume a cost function for contract goods. $c_{1}+x$, with the pruperlles discussed in Alchian (1953). namely; (i) for a given total volume of production. the munmusu per unit cost of production increases with the rate of production at an increasing late: (ii) for a given rate of production, over some range of culput, minimum pur unil c(1ms 
decline with planned volume of output; (iii) minimum per unit costs of production with respect to increased rates of production decrease as the total contemplated volume of output increases. Under these conditions. nıovements in the futures settlement price will be sufficient (o) detcr the competitive hedged production of contract goods. As no contract goods are expected to be available, the higher costs of producing and sorting goods closer to the delivery period. implies a tendency for the futures price to rise as the maturity period of the contract approaches. This increase in the futures price will continue until $c_{1}+x=c_{c}+$ 1. i.c. the cost of production and delivery of contract goods, equals that of the lowest quality goods meeting contractual specifications which are produced for delivery on the regular cash market. If no contract good, are produced for delivery, this synthesis of pricing relations in cash and litures will occur at/by contract maturity. Under this scenario, in the present model. goods of quality $q_{a}$ are traded in the futures market, where they are purchased by uninformed individuals. They sell for a maximum price, f(T.T). equal to their expected value. $\mathbf{q}_{\mathrm{a}}$, while their minimum sale price $b_{1} \leq q_{a}-f$, cannot fall below the average price received by sellers for goods of the same average quality trading in the regular cash market. (A) unin'ormed individuals trade in the delivery market for contract goods, this will be the werage cash market price paid by informed traders.) If the futures settement price fell any further, the delivery market could not induce any cash market goods to be presented for delivery. The equalibrium cash futures price relationship during the delivery period is dictated b! the value of the average quality of the most profitable grades of the commodity available for delwert under the respective governance structures: ${ }^{\circ}$ Notice that as goods are not sorted by chlers prior to futures delivery. unless $f(T, T)=q_{a}$, uninformed traders generate surplus from thing deliver! ria the futures market.

(iv) Market Fuilure in the Futures Market

Clarly, as sarlier dixilssed. if the production of contract goods is expected, the Mislshe of a price taking lutures market equilibrium is precluded. However, consider another 
case where potential producers of contract goods are small cnough to be trealed is a monopolist. Additionally, assume the cost function for contract goots is such that their supply is perfectly inelastic during the delivery period.

Now the concern is that the dynamics of the futures settement price may be unable to deter unhedged production of contract goods, prior to the delivery period, at the lowest cost volume and rate of production, $\min c_{1}+x$, with the intention of selling them during the maturity period, by which time the futures price will have risen sufficiently to make the activity profitable on average. The presence of two conditions is necessary for this unhedged production of contract goods to occur. First, as indicated above, the delivery of contrat goods must be unexpected. Any transactions in goods produced as a result of the cvistcmc: of an incomplete futures contract generate ex post losses to traders. Under full information, the associated trading losses cannot persist in equilibrium, as they may be avoided by dealing in the regular cash market. Second, the level of open intercst in the contract market musl be sufficient to sustain the level of planned deliveries. Given the assumed properties of the cost function, any constrained volume effects may serve to raise production costs sufficientiy to make planned production of contract goods unprofitable (even for risk neutral traders).

In the presence of these two conditions, a producer of contraci goods could poltentialls benefit by assuming a short position in the futures market in excess of their planneal deliveries in the contact market. Their resulting gain derives from two sources. First they obtain the difference between the futures setulement price at the lime delivery is imlialcel. and the per unit cost of production and delivery of contract goods, $\left(c_{1}+x\right)$. Second. is the production of contract goods is unexpected, their presence will only be revealed after deliver: has occured. After this information becomes available. under circumstances to be demonstraterl later, the futures price will have a tendency to fall to the maximum busers will be prepafel to pay for low quality goods, $f(T, T)=q_{p}$. This generates a further positive relurn (1) an: residual short position (i.e. that in excess of deliveries) held by traders deliverung contrat 
goods. This short position may be closed-out by assuming an equal and opposite long position in the contract market at the favourable lower futures price. Traders must offset against these gains, any losses arising from increases in the futures price, at a time prior to the delivery period. during which they held a net short position.

From the perspective of uninformed traders accepting delivery via futures, the unhedged production of contract goods creates an adverse selection problem, which acts to severely mitigatc their incentives to participate in the futures delivery market As discussed earlier, although a trader would not willingly take delivery of contract goods at a price above $q_{l}$, longs accepting delivery via futures are unable to inspect goods prior to receipt. Consequenty, when a commodity bundle is tendered for futures delivery. they possess no mechanism by which they can distinguish between: (i) a randomly selected commodity oundle, with an average quality equivalent to that exchanged in the cash market, and (ii) contract goods. (laarly. the potential unhedged production of contract goods, will have far reaching implications for the nature of the equilibrium in the futures contract delivery market.

Once the existence of contract goods is revealed after delivery, there may be no sustainable cquilibrium cash-lutures price relationship during the remainder of the delivery period which involves continuous delivery under both governance structures. Note, that once a delivery of contract goods has been effected. their producer has an incentive to reveal their evistence (if not their origin) to market participants. This publicity given to the presence of contract goods. will induce buyers to revise downwards their expectations concerning the acrage quality of goods they expect to be delivered via the futures market, in the process causing a decline in the equilibrium futures settement price. This fall in price would lead to a positite relurn to the monopoly producer's residual short position.

(1) Redeliver! Regulations and Futures Market Fquilibrium 
This essay argues that the degree to which information on the vislence of contrat goods can impact upon the futures settement price, is direcily related to the evtent contractual provisions place restrictions on the redelivery of goods that have already been tendered during the delivery period. Redelivery on futures markets is undertaken when a long who has previously accepted delivery assumes a short position in the contract and reissues a notice of intent to the clearing house in the same delivery period. Provided contract goxls have not been removed from their initial delivery location. and their exchange inspection certificate has not been invalidated." redelivered commodities are assured of lulfilling contractual specifications.

\section{a: Redelivery Permitted}

If unconstrained redelivery is allowed, once information attesting to the unexpected presence of contract goods is received in the market, the futures price which formerly reflected the average quality of the most profitable grade of the commodity available lior delivery. will exhibit a tendency to fall towards $q_{l}$. The magnitude of this fall rellects the extent to which traders continuing to participate in the contract markel. expect further fittures deliveries within the delivery period, to consist of contract goods. A critical point in the decline of $f(T, T)$ is reached at $f(T, T)=b_{l}$, after which the futures settlement price falls below the average price received by sellers for goods trading in the regular cash markel. Once the price declines below this tevel, sellers no longer have an incentive to deliver any goods produced for the cash market via futures, as they can obtain a higher expected relum in the regular cash market. Any further deliveries in the futures market will be comprisced entirely of redelivered bundles of contract goods. Buyers will not be preparced (o) rewaret the delivery of such goods. and the futures price will fall to $y_{1}$. Concern regarding potential redelivery of contract goods has effectively eliminated the futures contratt delivery markct. This eliminates the benefits accruing to both the uninformed traders, who customatily tike delivery via futures, and to the exchanges own members, who suffer from the reducuon in 
contract market trading volume.

\section{b: Redelivery Constrained}

Trading in all existing futures contracts is governed by the rules of formally organised commodity exchanges, established explicitly for the purpose of earning revenue for their membership from the trading of contracts. Ideally, the commodity exchange would like to mitigate the incentives for unhedged production of contract goods, while preserving the delivery market in lutures. This they can do to some degree, through the self-regulatory constraints they impose on trading activity, specifically redelivery, during the delivery period of a contract. Consider an exchange invoking the ultimate sanction, outright prohibition of redelivery. Market participants have then received a credible commitment that in the event of any unanticipated deliverics of contract goods, such commodities could not be recirculated to satisly further contractual obligations later in the delivery period.

The advantages to market participants are easily enumerated. First, as further deliveries of contract goouts will be unexpected. the probability that average quality bundles will be delivered via futures over the remaining duration of the delivery period is increased relative (1) a situation in which redelivery is unconstrained. Second, the equilibrium futures price will no longer be sensitive to the delivery of contract goods. The failure of the futures price to fall consicuuent to the delivery of contract goods. eliminates the returns to holders of any residual short positions (i.e. producers of contract goods) from wagering on the futures price. Although this will reduce the incentives for traders to engage in the unhedged production of contract goods. such activity is unlikely to be totally precluded. A monopoly producer may still lind it profitable to produce and deliver just enough contract goods to reduce the value of the average quality bundle delivered via futures by an amount sufficient to dissipate some. or all. of the surplus which is otherwise obtained by uninformed buyers taking delivery in the contract market. 
Against these benefits must be offset the costs associated with overly comstraming trading activity in the delivery market for contract goods. As the lime during which delivery can be undertaken is reduced, shorts desiring to make delivery run an increased risk thill cash market supplies in the delivery locations specified in the contract. will become concentrated in the hands of traders holding long positions. This monopolisation of the ciash market allows the longs to 'squeeze' the shorts, by temporarily withholding supplies of gorols from the cash market. Shorts, anxious to purchase goods to fulfil delivery oblizations. will increase their bid prices for goods, thercby driving up both cash and futures market prices. realising immediate gains to the longs. As a result of these trade-olls, laced with the possibility of a squeeze. one would conjecture that redelivery constraints would only be imposed by the exchange, to the minimum degree necessary to miligate the effects of the unhedged production of contract goods. A total ban on all redelivery activity would nol generally be predicted.

In the context of the present model, the maximum magnilude of the redelivery constraints required to preclude contract goods production is equal to $q_{a}-m i n i c t+v$, the difference between the average value of cash commodities, and the cost of prodicuon ol contract goods. This difference will be larger, the less completely the measures governing fuifillment of the futures contract constrain the range of qualities which may be offered in satisfaction of futures delivery obligations. In other words, the greater the contractual incompleteness of the futures contract, the greater the severity of the delivery restrictions thit have to be imposed to vitiate the incentives for unhedged production of contract gexds.

The redelivery constraints also serve as a signal 10 uninformed buyers that they are entering a fair game when transacting for delivery in the contract markct. In particular, they ensure that any sorting errors on redelivered goods are random not biased. Absent such: constraints on behaviour, the transferability of contractual obligations will be impeded. and the volume of futures trading diminished:" Thus. this analyss is conssitent with the vICN 
expressed by Cirossman:

"it is in the interest of an exchange to self-regulate some types of informed trading...the negative consequence of informed trading is that it can decrease the participation of traders. That is, there are some types of informed trading that increase the risk of participation and hence will lead to a decrease in the volume of trade that takes place on the floor of the exchange." 29

It should be stressed that unlike previous studies addressing the issue of incomplete contractual specifications, the use of implicit governance structures such as warranties, brand names, various forms of long term contracts, or vertical restraints are not advocated as a response to the dilemma." The distinguishing feature of these contractual forms is their reliance upon personal attributes of at least one of the trading parties. As transferability considerations require futures contracts are specified impersonally, their use in this transactional modc is effectively precluded. Reliance must instead be placed upon the explicit xll-regulatory constraints exchanges impose upon the trading activities of individuals wishing to take a position in the contract market. These regulations are considered to be amung the most restrictive of those applying to any class of commodity transactions. ${ }^{31}$ With respect to the reduction of the losses deriving from the unhedged production of contract goods. the regulatory constraints will be confined to the maturity period of the contract, when traders attempt to exploit the gains from such activities.

(aution must be exercised not to interpret the preceeding analysis too narrowly. Recall that incentives for production of contract goods have been argued to be directly related to the comparative disadvantage of trading via the futures contract. As a consequence, the werity of the regulations at delivery are simply a maturity pericd manisestation of, thus may be uliliscd as a proy for, a fundamental contractual weakness, namely its inability to cost affecticely replicate cash market measurement procedures. More importantiy, in this capacity the' reflect opportunities for informed traders manipulation of the value of futures obligations which hase instict throughoul the life of the contract. The implication of the latter consideration is that for some commodities. trading in the contract market will not be a fair 
game at any stage in the life of the contract. Despite the best elforts of the enchange to constrain such trader behaviour, the most obvious being the arbitrage opportunity present in the delivery option. the reluctance of other trading parties to risk their wealth by participation in the market may ultimately be revealed directly by its lailure.

\section{IV: EMPIRICAL PROCEDURES}

The following empirical work is intended to analyse the natire of the nevus betwe'll the commodity futures market's choice of contractual constraints governing trading in the delivery period of a contrach, and the perceived success or failure of the contract market. The :ariety of contractual restrictions governing redelivery procedures, both intracxchange and interexchange on U.S. contract markets is striking. ranging from attempts at dixcouragemcol bu making redelivery more costly. to outright prohibition. A study of lifty-threc contracts. representative of those possessing a delivery option': and which traded on a U.S. commoxlit! exchange during the 1970-84 period, revealed the most common delivery restrictions in be is follows:

\section{R1: Nontransferability of Delivery Notices:}

Certain contracts totally preclude the possibility of redelivery, by postulating that delivery be undertaken by means of a non-transferable delivery notice. The provisions of such contrack stipulate only one day on which notices of intent can be issued, almost universally the last trading day in the expiring contract month. These notices are then assigned to buyers in the manner indicated earlier, without any opportunity for retendering of delivered goxds in the same delivery period. A sample contract is as follows:"

(a) Initiation of Deliveries: Deliveries shall be initiated by the presentation is, the Clearing House by the seller by $5 \mathrm{p.m}$. On the last day of trading in the delivery month of a signed delivery notice.

(b) Notice Day: The Clearing House shall pass the delivery notice to the oldest buyer on the morning of the next fxchange business day. The day the buyer receives the delivery notice shall be referred to as the Notice 1)ay. 
(c) Delivery Notices are Non-Transferable: The buyer who thus receives a Delivery Notice from the Clearing House shall accept delivery. Delivery Notices are not transferable.

\section{R2: Redelivery tec:}

This catcgorisation covers two contingencies. Certain contracts allow redelivery concomitant with payment of a fee by the retendering short. This fee is attached to the delivery notice and is payable to the long who accepts or is designated redelivery. Other contracts permit redelivery only after the retendering short has assumed legal ownership of the goods for a Iwenty-four hour period, implying they are responsible for all holding costs associated with the commodity for that period of time. The fees will deter the redelivery of contract goods if they esceed the potential gain the retenderiag short expects to extract from engaging in it. There lollows a representative contractual stipulation of the redelivery fee:"4

(a) A clearing member representing a long that is assigned a Certificate of Delivery may retender that Certificate.

(b) A Certificate may not be retendered after the last trading day of the contract month. In order to retender. a long assigned a Certificate must establish a short position in the delivery month.

(c) The retendering short will be assessed a retender charge of $\$ \mathrm{x}$ per contract. The retender charges accrue to the Certificate and are payable to the long assigned the Certificate.

\section{R3: Iime Limils on Redeliverv:}

For these contracts, provision is allowed for redelivery only within a certain period following the lime the notce of intent to deliver was first issued. A technical reason for setting a lime limit on the validity of certificates is that the commodity is perishable in the sense that in qualit! and grade deteriorate with time. The Fresh Eggs and Live Cattle contracts Irading at the Chicago Mercantile Fichange would be examples of such goods. Generally. these stipulations will curtail the redelivery of contract goods if the time during which the rekondering short can prolitably conduct the activity exceeds that available under the contract. A typcal prowsions states:"

(a) A Certulicate of Delivery that has been assigned to a clearing member may be relendiced only up to the Nth business day after assignment. In order to relender the assignee must establish a short position in the contract month by 
10:30 a.m. on the day of retender. Retender is made at the scttement price on the day of retendering less accrued carrying charges.

(b) A clearing member who is assigned a Certificate that is cligible for retender must inform the Clearing House by 10:40 a.m. on the day of retender whether it is: (1) exercising the Certificate: (2) retendering the Certificatc; (3) pwiponing the retender. To be eligible for postponing retender one day, the clearing member must have entered a market order between 9:30 a.m. and 10:30 a.m. and have not received a fill, and by 10:10 a.m. submit to the Clearing Housc a copy of this unfilled market order.

(c) A clearing member who has delayed retender as a result of being unable 10 establish a short position cannot subsequently crercise the Certilicate. elcept that if retender cannot be made on the last day of trading. the certiticate must in exercised.

\section{a. Data and Test Procedure}

The hypothesis under consideration maintains that the degree of contractllal incompleteness of the futures contract, as rellected in the soverity if exchanke impurcl delivery/redelivery restrictions. is inversely related to the trading success of the contract. Ihe fifty-three contracts alluded to earlier are utilised as the data sample. The contracts are listerl in Appendix 2.1.

Probability models of qualitative choice are estimated for the following binary dependent variable: whether the commodity exchange has chosen to delist the commodity contracl over the 1970-84 period, or has allowed it to continue trading. A value of one indicaltes thal the contract was delisted during the $1970-84$ period: the variable cyuals 2 ero otherwise.

The explanatory variables consist of commodity cuchanges restrucusm on delivery/redelivery which are serving as proxy measures for the evtent of contratlual incompleteness. Also included as an explanatory variable is the smallest ratio of open in spread initial margin requirements operative at delivery over the 1970 ) $\$ 4$ period, the ratuonils for the inclusion of which is discussed in Chapter III." Specifically, the vecter ol independent variables utilised in the study is defined as follows:

REDEL = one, indicates that the contract goods delivered by the short first effecting deliver. can be utilssed for subsequent delivery within the same maturity period: the variable equish 
/ oro otherwise.

HF.F.F: = minimum accrued fecs and allowances attached to retendering of ccrtificates of delivery, and redelivery of contract goods in the same delivery period, payable by the retendering short. The fees are initially classified in terms of a dummy variable assigned a valuc of one for fees greater than one days storage charges, and zero otherwise. However. as these fies are conditional upon goods being redeliverable. in the estimation equation they are represented by an interactive dummy variable. obtained by multiplying the current dummy variable with the value for the dummy variable representing REDEL. This procedure follows a suggestion in Johnston (1972).

RFIIV = maximum operative time limit within which goods initially tendered in satisfaction of a delivery obligation may be redelivered. The time is defined both as a percentage of cligible delivery days within the delivery period. RETIM(1). and as the absolute time. in days, within which redelivery can be made. RETIM(2).

MAKGiN = ratio of open to spread initial speculative margin requirements on the last day of trading in the contract.

PrkISII = one. indicates that either the quality or the grade of the commodity initially delivered is time dependent. in the sense such commodities are effectively prohibited from being vibsequent! redelivered within the same delivery period: the variable equals tero otherwis:

A minimum degree of perishability has been enumerated as a prerequisite characteristic fior a commodity to be successfully traded on a futures market (Baer and Saxon (1948)). As recent expericnces with such commodities as live catte, fresh eggs, and live hogs indicates. the reasoning behind such arguments has been revealed to be flawed. Perishability per se. appears to have no role as a necessaly condition for the tsading success of an efficiently designed fiutures contract. 
From previous discussion the expected signs of the estimated corflicients are as lisllows: RFDEL < 0: REFEE > 0: RETIM < 0; MARGIN < 0: PFRISH < 0.

\section{b: Test Specification}

The data on futures contracts are examined using two alternative but closely related techniques, employed when the dependent variable of interest is dichotomous rather than continuous. The first procedure adopted is a simple linear probability specification. . methodology related to linear regression. The dependent variable, whether the contract is dormant/delisted or still urading. is observable only in a 0 or 1 state. The moxtel crealts predicted values for each sample point $\left(y_{i}\right)$ equating the predicted probabilitics of group membership. where the estimated model is $F\left(y_{j}\right)=f\left(x_{i}\right)+1$. . and $F\left(11_{i}\right)=11$. 11 , distinguishing feature in relation to other binary choice models lies in the specilication of the $f\left(x_{i}\right)$ function. Under a linear probability specification, one performs ordinary least syllares inI the dichotomous dependent variable and interprets the estimated coeflicients as measuring the effect on the probability of the dependent variable equalling one, of a unit change in the explanatory variable. That is, the model assumes the true functional form of $1\left(t_{1}\right)$ it) ixe $a+$ $\beta \mathbf{x}_{\mathbf{i}}$

The advantage of the linear probability model is the straightlorward interpretation of the coefficients. However. the methodology has several major shortcomings. First, and mint serious, is that the predicted probabilities need not necessarily fall between 1$)$ and 1 . Secund. the Bernoulli character of $y_{i}$ implies a variance for $u_{i}$ of $\left(\alpha+\beta x_{j} \times l\right.$ a $\left.\beta y_{i}\right)$. Sillc the variance of $u_{i}$ depends on $i$, the $u_{i}$ are heteroscedastic, implying ordinary least syasales will result in inefficient estimates, and although the estimated cocficients are unbiasced. lhe estimated standard errors are not consistent. and the usual tests of siznificance for the coefficients (t-tests) do not apply. Correction for heteroxcedasticity is undertaken, howeves. following a procedure outlined by White (1980) which provides a consisten! estimatc of the variance-covariance matrix that is positive definte. Therd. the filled relationship is acty 
sensitive to the values taken by the explanatory variables, expecially when they are bunched. Finally, since the $y_{i}$ 's are not normally distributed. no method of estimation that is linear in the $y_{i}{ }^{\prime}$ is enerally efliciene. That is an estimator that is linear in the $y_{i}$ 's such as ordinary or generalized least squares can be improved upon.

Although Amemiya (1981) suggests using a linear probability specification to obtain estimate: in the preliminary stages of econometric estimation, the difficulties associated with its uxe point to the need for alternative model specifications." Since the most serious set of difficultes arise from the fact that predictions be outside the $\{0.1$ interval, searching for distributional assumptions confining the predictions to within the appropriate interval wouid appear the natural alternative. The contract data are. therefore. also analysed utilising a logit model. which differs from the linear probability model in its specification of the $f\left(x_{i}\right)$ fienction. sclling $f\left(s_{i}\right)=1 /\left(1+e^{-\left(\alpha+\beta x_{i}\right)}\right.$, with $c$ iepresenung the base of natural logarithms. A simple transformation of this model yields a functional relationship which is lincar in its parameters, and a maximum likelihood estimation process may then be employed which yiclds consistent and asymptotically efficient estimations. (Amemiya (1931). Madda!a (1983)).

(: Eimpirical Results

The results of the full sample estimations appear in Table 2.1. With the exception of the Ialues of the RFTIM(.) coefficients in the logit specification, all of the agns in equations

(t) confirm the expectations of the measurement cost hypothesis outlined earlier. Furthermore, again cucmpting the RHTIM (.) variables, in all four equations the estimated coclificients arc significanty different from tero at commonly accepted levels of significance. Houcter. a potentially serious problem arises with the current specification and should be noled. Giicen toth the RPTIM(.) variabies are positive (/ero) when REDEL is one (zero). these threc coplanatory variables are likely to be highly positively multicollinear. The resulting incfikiencies of the estimation procedure are well documented (e.g. Judges et al. (1032)). This 
conjecture was confirmed on examination of /ero-order and partial correlation cocmicicuts. As neither the acquisition of new data or new information was considered likely or resilve the multicollinearity problem, a solution was sought in re estimating the cquations. onitting the RETIM(.) variables from one set of estimates, and the RFIPII and RFFFF variables from the other.

The results of the procedure adopted are presented in Table 2.2. In these estimills. all coefficients are significant and confirm prior cxpectations with respect to sign. This suggews the lack of explanatory power in the RHTIM(.) variables in the lull sample estimation in.s be a result of a multicollinearity problem.

Owing to the nature of the logit and linear probability models, as they sand the regression coefficients are not directly comparable. although a varicty of options still evist for relating the different models. Comparing models in terms of goodncss of lit. one may usc the maximum likelihood results to obtain statistics analagous to $R^{2}$. The results of ihc procedures sug̨ested by McFadden (1974) and Cragg and Uhler (1970) are reported, losth giving $\mathbf{R}^{2}$ measure; for the logit model in geniral slighuly higher than the adjusted $\mathbf{R}^{2}$ from the linear probability model. suggesting the former specification may to prefierable. The significance levels for the logit model reported in the linal row of Tables 2.1 and 2.2. arc based upon likelihood ratio tests. Statistical significance is determined by comparing the log of the likelihood function of the models as estimated. with that generated by regressing the dependent variable only on a constant term. Using this criterta all logit model. . significam at the $1 \%$ level. Row (12) presents an alternative measure of goodness of : for the loyil estimate. the in-sample predictive success of the model, which varies from 81.1 10 92.5 per cenL":

In the light of these linding. and the theoretical objections to the lincar probability specification alluded to earlier, one is smpted to conclude that logit is the preferred specification. Independent of this consideration, whatever model onc adopts, the measurcment 
cost hypothess appears to perform tolerably well in explaining cross-sectional variation in the chrice of contractual constraints in the delivery period of commodity futures contracts.

\section{V: CONCI.UII)ING RFMARKS}

One of the lessons which emerges from the recent literatu.e examining efficiency properties of alte, lative contractual forms under conditions of imperfect information. is that attuntion to transactional detail is required in order to reveal the issues of interest. In gencral, this approach pionecred by Williamson (1976, 1979) and Goldberg (1976), emphasises identifying mechanisms for monitoring. adapting and terminating long-term relationships between trading principals, and in the process has criticised economic theory for excessive Iutisation of the discrete-transaction paradigm in discussing exchanges of property rights.

While agreeing in substance with the aforementioned authors, the orientation of this isty is somewhat different. Interesting questions involving contracting modes, in particular the notion of transferability as a produced aturibute of contracts. may be analysed absenting from the presence of long-term relationshups between trading principals. As Cheung (1974) and McMantss and Acheson (1979. 1983) indicate, the right to exclude and the right to transfer ciclusvity to others should be considered as separate elements in the generation of tents oblaimable from ownership. The present study of futures and forward contracis reveals this dwanction also has comparative institutional significance. An analysis of commodity futuies contracts iolated cerain difficulties inherent in the adoption by futures contracts of mcasurement and contractual enforcement procedures designed to maximise the net gains to Iransterablit!. Thex problems arise expliculy from the inability of the contracts to adopt idhonglustic and subjective measurement procedures. One avenue through which the! are itlumic. is the resulung incentises that certain trading principals possess to engage in the

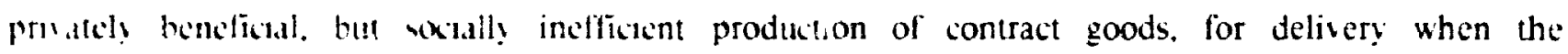


futures coniract matures. These activities terd to disspate the net gams from the right 11 transfer. Competition among contract markets will secure the evolution of contractual forms serving to minimise these losses, including where appropriate the imposition of regulations (11) trading activity which appear difficult to comprehend otherwise. Despite the best efforts of futures exchanges, the costs of attenuating this behaviour will vary across commodity contracls and the evidence presented in the analysis seems to indicaic that in some cases. these costs are high enongh to lerd to the markets eventual failure. The results of this csisay are preliminary. but suggest further empirical work assessing the importance of measurement costs in the organisation of markets, will yield important insights into issites of comparalive institutional choice. 
Table 2.1

I he Fffects of Independent Variables on Commodity Exchange Policy Choice

ESTIMATION METHOD

\begin{tabular}{|c|c|c|c|c|}
\hline $\begin{array}{l}\text { Independent } \\
\text { Variable }\end{array}$ & $1^{\text {line }}$ & bility & 3 & 4 \\
\hline RFIOHI. & $\begin{array}{c}-0.6971^{* \bullet} \\
(-3.05)\end{array}$ & $\begin{array}{c}-0.6058^{* *} \\
(-2.16)\end{array}$ & $\begin{array}{c}-5.0681^{* *} \\
(-2.43)\end{array}$ & $\begin{array}{c}-4.4453^{* *} \\
(-1.99)\end{array}$ \\
\hline $\mathrm{KH}+\mathrm{H}$ & $\begin{array}{l}0.4770^{* 1 *} \\
(2.87)\end{array}$ & $\begin{array}{c}0.4427^{\circ *} \\
(2.37)\end{array}$ & $\begin{array}{c}3.0905^{* *} \\
(2.13)\end{array}$ & $\begin{array}{l}2.9274^{*} \\
(1.94)\end{array}$ \\
\hline RHTIM(1) & -- & $\begin{array}{l}-0.0393 \\
(-0.18)\end{array}$ & -- & $\begin{array}{l}0.2276 \\
(0.12)\end{array}$ \\
\hline RF1IM(2) & $\begin{array}{l}-0.0048 \\
(-0.42)\end{array}$ & -- & $\begin{array}{l}0.0739 \\
(0.61)\end{array}$ & - \\
\hline PHRISH & $\begin{array}{c}-0.452 .4 * * \\
(-3.31)\end{array}$ & $\begin{array}{c}-0.4582^{* *} \\
(-3.36)\end{array}$ & $\begin{array}{c}-3.2157^{* *} \\
(-2.71)\end{array}$ & $\begin{array}{c}-3.2171 * * \\
(-2.72)\end{array}$ \\
\hline MARGIN & $\begin{array}{c}-0.0226 * * \\
(-2.52)\end{array}$ & $\begin{array}{c}-0.0217^{* *} \\
(-2.44)\end{array}$ & $\begin{array}{c}-0.8055^{* *} \\
(-2.04)\end{array}$ & $\begin{array}{c}-0.7684^{*} \\
(-1.95)\end{array}$ \\
\hline ('ONSTANT & $\begin{array}{l}1.0223^{* *} \\
(8.25)\end{array}$ & $\begin{array}{l}1.0221^{* *} \\
(8.22)\end{array}$ & $\begin{array}{l}5.6715^{* *} \\
(2.91)\end{array}$ & $\begin{array}{l}5.5522 * * \\
(2.86)\end{array}$ \\
\hline $\mathrm{R}^{?}$ & 0.55 & 0.55 & -- & - \\
\hline $\mathrm{SH}$ & 0.349 & 0.349 & -- & -- \\
\hline Mctadden $\mathrm{R}^{?}$ & & & 0.57 & 0.54 \\
\hline (inge l'hlor $\mathrm{K}^{2}$ & & & 0.73 & 0.72 \\
\hline $\begin{array}{l}\text { Percem of a } \\
\text { Correal Predituons }\end{array}$ & & & 90.5 & 92.5 \\
\hline $\begin{array}{l}\text { likelithond b } \\
\text { Ratwo-len }\end{array}$ & & & $41.28 * *$ & $40.92 * *$ \\
\hline
\end{tabular}


Note: Student t-values appear in parentheses under respective coefficients: 1- tests for significance are two tailed tests. Population si/e cquals 53 contracts.

a: Percentage of correct classifications using the following rule: classify in dormant grotup $(P=1)$ if $P>.5$; classify to active group $(P=0)$ if $P<.5$ where $P$ is predicted probability above and $P$ is observed value.

$\mathrm{b}$ : $\mathrm{x}^{2}$ statisitics with $\nu$ degrees of freedom, where $\nu$ is the number of constraints emboticit in the hypothesis being tested minus the number of constraints in the alternative hypothesis.

** 5\% level of significance

- $10 \%$ level of significance 
Table 2.2

The Fffects of Independent Variables on Commodity Exchange Policy Choice ESTIMATION METHOD

\begin{tabular}{|c|c|c|c|c|c|c|}
\hline $\begin{array}{l}\text { Independent } \\
\text { Variable }\end{array}$ & 1 & $\begin{array}{c}\text { ear Probab } \\
2\end{array}$ & 3 & \multicolumn{3}{|c|}{$\begin{array}{l}\text { L.ogit } \\
5\end{array}$} \\
\hline RFIDHI. & $\begin{array}{c}-\left(1.6402^{* 4}\right. \\
(-3.77)\end{array}$ & -- & - & $\begin{array}{c}-4.2457^{* *} \\
(-2.82)\end{array}$ & - & -- \\
\hline KFFrF & $\begin{array}{c}0.4568^{* * *} \\
(2.97)\end{array}$ & -- & -- & $\begin{array}{c}2.8513^{* *} \\
(2.08)\end{array}$ & -- & - \\
\hline RFTIM(I) & - & -- & $\begin{array}{c}-0.4816^{* *} \\
(-3.38)\end{array}$ & - & -- & $\begin{array}{c}-2.667 * 4 \\
(-2.33)\end{array}$ \\
\hline RH-TIM(2) & -- & $\begin{array}{c}-0.0265^{* *} \\
(-2.87)\end{array}$ & -- & - & $\begin{array}{c}-0.1325^{*} \\
(-1.91)\end{array}$ & -- \\
\hline PI.RISH & $\begin{array}{c}-0.4563^{* *} \\
(-3.36)\end{array}$ & $\begin{array}{c}-0.4012 * 0 \\
(-2.83)\end{array}$ & $\begin{array}{c}-0.4220^{* *} \\
(-3.13)\end{array}$ & $\begin{array}{c}-3.2208 * * \\
(-2.72)\end{array}$ & $\begin{array}{c}-2.229 * * \\
(-2.47)\end{array}$ & $\begin{array}{c}-2.6127^{* *} \\
(-2.54)\end{array}$ \\
\hline MAKCiIN & $\begin{array}{c}-0.2180^{* *} \\
(\cdots 2 .+())\end{array}$ & $\begin{array}{c}-0.0323^{* *} \\
(-2.86)\end{array}$ & $\begin{array}{c}-0.0312 * * \\
(-4.32)\end{array}$ & $\begin{array}{c}-0.7584^{* *} \\
(-1.97)\end{array}$ & $\begin{array}{c}-0.5318 * * \\
(-1.94)\end{array}$ & $\begin{array}{c}-0.5712^{* *} \\
(-1.97)\end{array}$ \\
\hline CONSTANT & $\begin{array}{c}1.0216^{* *} \\
(8.23)\end{array}$ & $\begin{array}{c}0.96+0 * * \\
(8.93)\end{array}$ & $\begin{array}{c}1.0078^{* 0} \\
(9.62)\end{array}$ & $\begin{array}{c}5.5228 * * \\
(2.88)\end{array}$ & $\begin{array}{c}3.6604 * * \\
(2.99)\end{array}$ & $\begin{array}{c}4.2170^{* *} \\
(3.07)\end{array}$ \\
\hline $\mathrm{R}^{2}$ & 0.55 & 0.45 & 0.49 & - & - & -- \\
\hline $\mathrm{SHF}$ & 0.340 & 0.378 & 0.365 & - & - & -- \\
\hline Matadien $\mathrm{R}$ & & & & 0.56 & 0.45 & 0.49 \\
\hline ('rayg (thier & & & & 0.72 & 0.61 & 0.65 \\
\hline $\begin{array}{l}\text { Percent of a } \\
\text { Correct Predi }\end{array}$ & & & & 92.5 & 81.1 & 84.9 \\
\hline 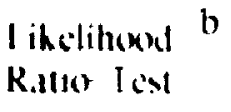 & & & & $40.90^{* *}$ & $32.69 * *$ & $35.96 * *$ \\
\hline
\end{tabular}


Note: Student t-values appear in parentheses under respective coeflicients: 1-tests for significance are two tailed tests. Population sire equals 53 contracts.

a: Percentage of correct classifications using the following rule: classify in tormant group $(P=1)$ if $P>.5$; classify to active group $(P=0)$ if $P<.5$ where $P$ is predicted probability above and $P$ is observed value.

b: $x^{2}$ statisitics with $\nu$ degrees of freedom, where $\nu$ is the number of constraints cmbolical in the hypothesis being tested minus the number of constraints in the alternative hypoihesis.

** $5 \%$ level of significance

- $10 \%$ level of significance 
IPPF.YIIX 2.1

The 53 contracts included in the sample. listed following the Commodity Exchange on which they trade(d) are:

New York Mercantile Fxchange: Gold, Aluminium, Butter, Idaho Potatoes, Apples, Plywood, Nickel. Imported Boncless Beef;

New York Cotton Fxchange: Cotton \#2;

(olfece Sugar and Cocoa Fxchange: Sugar \#12. Colfee 'C":

Commodily Fxchange Incorporated: Silver:

Chicago Board of Trade: Wheat. Corn. Oats, Soybeans, Soybean Oil. Soybean Meal, Gold. Silver:

(hicago Mercantilc Fichange (incl. IMM): Russets. Stud Lumber, Skinned Hams, Turkeys. Milo. Plywood. U.S. Silver Coins, U.S. T-Notes. Copper, Platinum, Frozen Eggs, Eggs, Frocen Pork Bellies. leaded Regular Gas. No 2. Fuel Oil, Broiler Chickens, Feeder Catte. Live (alle. Y)-dat T-Bills, Domestic C.I).'s, Gold;

Mid-America Commodilv Fachange: I.ive Catule, I.ive Hogs, Refined Sugar. Oats, Silver (Chicatgo). Silver (New York). Gold, Rough Rice. Wheat, Soybeans, Corn;

Kamsas (ilt Board of Trade: Sorghum.

IPPEXDIX 2.2

A Definition of lariables

\begin{tabular}{|c|c|c|c|c|c|c|}
\hline $\begin{array}{l}\text { Dependent } \\
\text { Vitiable }\end{array}$ & Redel & Margin & Relice & Retim(1) & Retim(2) & Perish \\
\hline 1 & 1 & 2 & 1 & 0.64 & $1 \mathrm{i}$ & 0 \\
\hline 1 & 1 & 2.5 & 1 & 0.011 & 0.125 & 0 \\
\hline 1 & (1) & 1.67 & 0 & 0 & 0 & 1 \\
\hline 1 & 0 & ; & () & 0 & 0 & 1 \\
\hline 1 & 0 & ? & 0 & 0 & 0 & 1 \\
\hline 1 & (1) & $\therefore 5$ & 0 & 0 & 0 & 0 \\
\hline 1 & 1 & $\vdots$ & 1 & 0.011 & 0.125 & 0 \\
\hline 1 & (1) & 2 & 0 & 0 & 0 & 0 \\
\hline 1 & () & 1.3 & 0 & 0 & 0 & 0 \\
\hline 1 & 11 & $1.0^{\circ}$ & 0 & 0 & 0 & 1 \\
\hline 1 & 1 & 1.14 & () & 0.64 & 9 & 0 \\
\hline 1 & 1 & $\vdots$ & 1 & 0.875 & 13 & 0 \\
\hline$i$ & $i$ & 4 & () & 0.875 & 13 & 0 \\
\hline
\end{tabular}




\begin{tabular}{|c|c|c|c|c|c|c|}
\hline 1 & 0 & 3 & 0 & 0 & 1) & 1 \\
\hline 1 & 0 & 5 & () & () & 0 & 11 \\
\hline 1 & 0 & 3.25 & 0 & 0 & 11 & 11 \\
\hline 1 & 1 & 1.67 & 1 & U.8 & 1? & 11 \\
\hline 1 & 1 & 6 & 1 & 0.8 & 12 & 11 \\
\hline 1 & 1 & 2.2 & 0 & 0.8 & $1 ?$ & 11 \\
\hline 0 & 1 & 3.1 & 0 & 0.98 & 9 & 11 \\
\hline 0 & 1 & 1.75 & 1 & 0.98 & 13 & 1 \\
\hline 0 & 1 & 2.18 & 0 & 0.92 & 14 & 11 \\
\hline 1 & 0 & 3.67 & 0 & 0 & 0 & 0 \\
\hline 1 & 0 & 3.67 & 0 & 0 & 0 & 0 \\
\hline 0 & 0 & 5 & 0 & 0 & 0 & 1 \\
\hline 0 & 1 & 2.1 & 0 & 0.92 & 13 & 1 \\
\hline 0 & 1 & 2.1 & 1 & $0.15 ?$ & 2 & 1 \\
\hline 0 & 1 & 2.1 & 1 & 0) & 11 & 1 \\
\hline 0 & 1 & 20 & 0 & 0.94 & 16 & 0 \\
\hline 0 & 1 & 20 & 0 & 0.94 & 16 & (1) \\
\hline 0 & 1 & 20 & 0 & 11.94 & 16 & 0 \\
\hline 0 & 1 & 20 & 0 & 0.91 & $1 ?$ & 0 \\
\hline 0 & 1 & 20 & 0 & 0.91 & 12 & 11 \\
\hline 0 & 1 & 20 & 0 & 0.91 & 12 & 0 \\
\hline 0 & 1 & 20 & 0 & 0.94 & 16 & 11 \\
\hline 0 & 1 & 20 & 0 & 0.94 & 16 & 11 \\
\hline 0 & 1 & 3.3 & 0 & 0.97 & 5 & 11 \\
\hline 0 & 0 & 2.6 & 0 & 0 & 0 & 11 \\
\hline 0 & 0 & 4.37 & 0 & 0 & 0 & 1 \\
\hline 0 & 1 & 20 & 0 & 0.92 & 13 & 11 \\
\hline 0 & 1 & 4.5 & 1 & 0.153 & 2 & 1 \\
\hline 0 & 1 & 3 & 1 & 0.86 & 13 & 1 \\
\hline 0 & 0 & 4 & 0 & () & 0 & 1) \\
\hline 0 & 1 & 6 & () & 0.94 & 16 & (1) \\
\hline 0 & 1 & 0.67 & 0 & 10.94 & 16 & 1) \\
\hline 0 & 1 & 7 & 0 & 0.94 & 16 & 11 \\
\hline 0 & 1 & 20 & 0 & 0.94 & 16 & 11 \\
\hline 0 & 1 & 15 & () & 11.94 & 16 & 11 \\
\hline 0 & 1 & 15 & 0 & 0.9 & 111 & 11 \\
\hline 0 & 1 & 15 & f) & 11.94 & 16 & 11 \\
\hline 0 & 1 & 18 & () & 0.91 & $1 ?$ & (1) \\
\hline 0 & 1 & 10 & () & 0.94 & 16 & 11 \\
\hline 1 & 0 & 5 & U) & 0 & 0 & 11 \\
\hline
\end{tabular}




\section{HOOTNOTHS}

1. Measurement (Transaction) costs can tentatively be divided into the costs of enforcing exclusive rights to valued attributes, and the cost of enforcing agreements made to transfer rights from one owner to another. Any voluntary exchange relationship between two individuals requires that the partners exclude others from the use of the attributes being exchanged, and that both parties are sufficienty certain of what they are buying and selling to expect that the trade will generate mutual gains.

2. The distinction between the right to exclude and the right to transfer exclusivity to others, is meaningful "only if rights are costly to enforce and only if enforcement costs vary for different individuals." McManus and Acheson (1983 p.1). For purposes of the present study, the issue is that the gains to exclusivity and transferability are not, in gencral. joint products.

1. Telser $(1981$ p.1). Telser develops his theme by drawing an analogy between the theory of futures markets and the theory of money. A measurement costs explanation of the emergence of money as a medium of exchange may be found in Alchian (1977).

4. Specilic evamples of such arrangements are described in Klein and Lefner (1981), and Harsel (1982).

5. Thus, although the emphasis in this essay is upon measurement costs, the importance of translerability serves to highlight certain common ground with the approaches taken by Telser (1981. 1986) and Carlion (1984). The former's discussion of the liquidity and fungibility of futures contracts $(1986 \mathrm{p} .524)$ is illustrative of the similarities.

(.) 1.1). Howell (1956, p. 18:.

7. 1.1). Howell, op. cil. p. 14 .

8. (iarbade and Silber (1983b. p. 252) make a parallel argument in their discussion of the uructure of premiums and discounts for nonpar delivery. The use of equivalence Whems to determine nonpar pricing rules is used when the underlying attribute of a commoxhty on which the differential is based "can be isolated through a technological "Wraction process." In the present terminology. this corresponds to traders' ability to measure the valued attribute objectively.

4. This analysis ignofes the possibility broached by McManus and Acheson that as the asistence of a futures contract raises the gain to manipulation of the setulement price br Inding at false prices: an otherwise price laking equilibrium nay not survive the presence of a futures market near the expiry time of the contract. See also Newberry $(198+1)$.

11. I nccensty condition for the viability of a futures contract market. is the abilit! of contracllal yecitications to reduce basis risk. measured by the coefficient of stochastic bartation of the difference between the current spot and futures price. to a level kcteplable to commercial hedging interests. See Working (1954). Gra! (1961). Powers (146-). (rou. Rile! and Purcell (1972). and Sandor (1973). For contracts pertaining to price tuking cash markets. hedgers bear no basis risk altributable to the futures contrat per $x$, allhough some resdual basis risk ma! be incurred if any of the cosls 
of having the commodity available at the delivers date and lexation are unhedfecd. For a discussion of the relationship of basis risk to cash settlement sec Ciarbade and Silber (1983a).

11. See Alchian (1977). for an analysis of buy-sell spread differences revulting from the distribution of measurement costs across traders in a personal market.

12. Howell, op. cil. p. 22-23. The conclusions of the analysis parallel ciarbade and Siller (1983a) when they state (p. 456) that "the desirability of mandaton cash vellement depends upon the accuracy with which the setulement inder measures the commercial value of the commodity." Their reasoning differs stubstantially from that given here.

13. It is noted in passing that a delivery option was once believed to have be'll necessary in U.S. futures conuacts to avoid them being interpreted legally as u.ipernitg agreements.

14. For further clarification see Bar/el (1976). This problem. of course. arises wilh .III! method of allocation.

15. Moreover. the majority of traders can avoid the associaled lonses by transacting in the cash market.

16. One qualification should be made at this point. Although the futures price durme the life of the contract will be below the cost of producing for delivery to elimumatc the incentive for the hedged production of contract goods. the ponsihility vill rematms th.st risk neutral individuals will produce contract goods unhedged. intending (1) Neliver .11 maturity when the futures price increases to reflect the value of the lowerl yetialits cash goods, as it would if(f) traders mistakenly believe no contract goxhls atre avialiatlis for delivery. This issue is diccussed later in the eusay.

17. Fdwards and Fdwards (1984 p. 349).

18. See the cases discussed in Fdwards and Fdwards. on. cil. and lasterbrexsk (19k6).

19. In this respect the model in this section is closer to Kyle (1984). who alx) pusits informational asymmetries as the source of manipulative actuvily.

20. Contrast this result with Telser (1986. p. S15) who concludes "provided there is it competitive spot market, cash settement works at least as well as detlivery." (n) demcl examination it appears Telser is equating competitive and price laking, in which cisc. the inconsistency between the present analyss and his disappears. However. 11 comll! then be argued his analysis is left incomplete.

21. Chicago Mercantile Fichange. (1985). Kulc $7(1) 7$.

22. Chicago Mercantile Fxhange, op. cit. Kule 34155 provides an example.

23. Chicago Mercantile Fichange. op. cit. Kule 710.

24. Chicago Mercantile txchange. op. cit. Rule 711.

25. There is a practice involving a parual cash settlement known as a translef of cash! for futures in which a slock of the commodity which is not deliverable under the terms of the contract is used to liquidate a short prosilion. The long mast aprese 
voluntarily 10 accept delivery, including if necessary a privately negotiated cash adjustment to reflect the difference between the price of the standardized commodity and whatcver grade is delivered. These transactions are permitted only after termination of trading in the contract. and are cleared through the clearing house in accordance with normal procedures. For example, see Chicago Mercantile Fxchange. op. cit. Rule 718.

26. Iongs may reasonably expect that in gencral, the shorts will select for delivery the lowest quality of goods available which satisfy contractual stipulations. As the delivery of such goods will be expected. the difference in value between the average and prorest grade of the most profitable grade of the commodity to deliver. will be rellected in the relationship between cash and futures prices in the delivery month. ihis. costs of measurement serve to rationalice the randomness of the basis during the maturity period, assumed to evist by Anderson and Danthine (1981, 1983b) in their analysis of hedging strategies in contract markets.

?7. ('hicago Mercantile Fxchange. op. cil. Rule 708.

?x. Ihis is of concern 10 exchange members as both commission revenue and the appreciation in value of a commodity exchange seat have been demonstrated to be pritively related to the volume of trade on the contract market. See Rystrom (1982).

39. (ironsman (1986 p.S143-SL44)

31. See Williamson (1979). Bar/el (1982), Kenney and Klein (1983), Goldberg and Frickson (1987). and the references cited therein.

i1. In essence this is an elficiency argument for self-regulation. As persuasively argued b! Fdwards (1983). Fasterbrook (1986) and Grossman (1986) there is no reason to believe that under the forces of competition, commodity exchanges will systematically adopt utwoptimal precautions azainst practices which impose real losses upon their members. Sice alwo Working (1953).

3. Fuch contract in the sample. therefore. represents the potential for excess measurement.

33. For example, se the provisions of the Apple Futures Contract on New York Mcrantile Fichange. (1971). Chap. 20. Rule 200.10.

i4. s.z. ('hicago Mercantile Fichange, op.cit. Rule 2505.

is. c.... ("hicago Mctcantile Fichange, op. cit. Rule 1503.

i1. Brictl!. the argument is that contractual incompleteness reduces the correlation between price movements of different delivery months in the same commodity contract. This micreases the price volatility of a spread position relative 10 an open position in that contrat market. Assuming initial speculative margin levels are directy related to contraclual price volatility. the more incomplete the measures utilized in the futures contract the luiver the ratio of open to spread initial speculative margin requirements.

:7. A lurther consideration in favuw: of preliminary estimation by a simple linear probability specilication. is that unbiased estimates may be derived even for small s.mples (Kendall and Siluart (1979. p. 83). Certain maximum likelihood logit estimators hase been examined in Monte Carlo studies. and discovered to be satisfactorily "cll behased onl! with ample sizes of aboul fifty. (1). McFadden (1974 p. 123)). 
38. An alternative method of comparing specilications, is to re-cstimate cich mentel alter normalizing each variable to have tero mean and unit sariance. The revillung: standardized coefficients are comparable. A second, slggested by Amemisa (148) p. 1488) is to evamine the derivatives of the probabilities with respert to the independent variables. The relative significance of the cipianatory variables can then be compared across specifications. However. it is not clear what the relevance of this procedure is when some of the independent variables are dummics, as thes are in this case. 


\section{CIIAPIKR III \\ MRASURFMENT COSTS, MARCIN RFQUIREMENTS AND MAKKET lAILURE: IN lUTURHS MAKKEIS}

\section{INTKOIDUCTION}

The analysis of this chapter investigates the relationship between the costs of quantifying information, or measurement costs, the behaviour of commodity futures prices and the trading success of lutures contract markets. The framework adopted builds naturally upon the theoretical outline propused in chapter II. and its development can be briefly summarised.

In section I the effects of introducing a range of arbitrage indeterminacy in the setllement price of a futures contract are clarified in the context of the conventional theory of intertemporal pricing relationships for sturable comnodities. Scction II develops a more formal framework in which the consequences of the contractual incompleteness of futures lor the behaviour of commodity futures prices is cxamined. Specifically, the analysis derives Iestable propositions relating to the relative price variability of portfolios comprising open and spread futures positions. These propositions are utilised as the basis for an indirect test of the measurement cost hypothesis. Recall that a direct test is precluded owing to the difficulty of estimating the potential gains to traders use of subjective measures across different cash markets. Finally. by relating contractual price variability to the initial speculative margin reyuirements established by commodity exchanges. results of tests of the hypottiesis conducted using contracl market data from the period 1970 - 1984 are presented. Some concluding remarhs follow.

\section{1: THI: THFOKY OF: STORAGI: ANI) CONTRACT PRICF RFIATIONSHIYS}

Since Kaldor (1939) and Working (1948. 1949) first developed the theory of the price of stordge. It has bccome acepted in the literature that the relationship between intertemporal fulures price spreds for storable commodities is determined by the marginal (net) carrying 
cost associated with the holding of physical stots over the interial betueen delitery ditts $T_{1}$ and $T_{2}$. of the two futures contracts comprising the spread.' This relationship call be represented in two ways, which are distinguished by the definition of the maryinal (nel) carrying cost they adopt. It is emphasised that tie implications of the analysis which follows are invariant to whichever of the two interpretations is adopted. Formally, invoke the following asssumptions: (i) no transaction (measurement) costs: (ii) no brokerage cinss of trading: (iii) no taxes: (iv) no limitations on borrowing. (v) risk neutrality. Dreline:

i) $f\left(t, T_{i}\right)$ as the futures price at ume $t$ for a contraci maturing at lime $T_{i}$; and

ii) $c\left(t, T_{i}\right)$ as the marginal net cost of carrying the commodity from lime 1 to $r_{i}$.

One class of models (see fama and french (1987)) delines this cost as identically equal to the marginal expenditure out rent for storage space. handling charges, intercst. insurance and allowances tor depreciation. less an! benefits from having the commelits available in inventory. customarily termed the convenience yield. The implication which follows is that the futures market is in equilibrium when:

$$
f\left(L_{2} T_{2}\right)-f\left(L_{0} T_{1}\right)=c\left(t, T_{2}\right)-c\left(t, T_{1}\right)
$$

The advantage of the parameter definitions incorporated in cquation (3.1a) is that 11 now becomes an identity. defined to hold for any intertemporal futures price difference. Ihis facilitates theoretical discussion of arbitrage activity. The disadvantages derive from the tat that the convenience yield is unobservable. and is usually considered as the residual when the relationship between the observable parameters in equation (3.1a) has been eslablinhed. Ihe influen:e of any other unobservable variables which may affect the futures pricte spread is. therefore, suppressed. The present analysis argues this perspective generally leads to incorrece conclusions.

There is, following Working 1949). a second class of models with a mote applact focus that have omitted the convenience yield from the detinition of $\left(\right.$ t. $\left._{1}\right)$. Ihe arialyss 
Ihen Implics that the left hand side of equation (3.1a) represents a full carrying charge' (Working 1944). or an upper limı to the intertemporal futures price spread. This is a value which can be reported given values for the parameters which now comprise net carrying costs. It is aiso the preferred interpretation in the context of the present analysis. This implics:

(3.lb) $\max \| f\left(t, T_{2}\right)-f\left(t, T_{1}\right)=c\left(t, T_{2}\right)-c\left(t, T_{1}\right)$

1 protrated violation of either equation $(3.1 \mathrm{a})$ or $(3.1 \mathrm{~b})$ is conventionally precluded by discusumg the impact of such a bicach upon the activities of the class of speculative intramarkel arbitrageurs commonly termed spread iraders. A spread position is defined as the vimulaneous holding of equal numbers of long and short positions in different maturity dates of a ungle commodity contract: Given the earlier assumptinns these potential transactions werve 10 tadintain the cquality in cquations (3.1a) or (3.1b) through the following simple arbitrage machanism.

Cimsider the senario which vioiates both (3.1a) and (3.1b). namely:

$f\left(1, T_{2}\right) \quad i\left(1, T_{1}\right)>c\left(t, T_{2}\right)-c\left(1, T_{1}\right)$. B! going long $T_{1}$ contracts at lime $t$, and simultaneous! clling an cyual number of $T_{2}$ contracts. a spread position carns a riskless return of $f\left(t, T_{2}\right)$ $\|\left(1, \Gamma_{1} \quad\left(1, T_{2}\right)-c\left(t, T_{1}\right) \|\right.$ per spraad. A trader long in $T_{1}$ contracts has the right to take delivel $\|$ llme $T_{1}$. contract for torage, and redeliver in satisfaction of their delivery whlgguton at lime $T_{2}$. The pressure eserted by such trading aclivity upon the respective contrat prices. will excontually restore the equality in equations (3.1a) and (3.1b). The point 1. Thut the assumplicins underlying equations (3.1a) and (3.1b) guarantee they cannot be violdad in the manner indicated, because the dictate an infinitely elastic supply of spread wises wheneter the relatonships are not satislied.

the arsuments of this esuly are predicated upon desiations from the equilibrium divnbit in squatuons (B.1a) and (3.1b) ocasioned by the contractual incompleteness of certain future comtrats. The nature of this contractual uncompleteness is first idenified in MoManus 
and tcheson (1979. 1983). An analyss of its affects on intertemporal lintutes prici relationships is one major contribution of this sisa!. Beforte procecting, the reamms lorr, and effects of, such deviations are briefly outlined.

Consider as a benchmark the situation if the impersonal and objective mledsures adoptcel in the futures contract can duplicate at the sane cost of Iransicting those l.allised in thh trading, in other words, a futures contract relating to a price taking cauh murket. Arbutt.tét ensures the two markets will be analytically indistinguishable with respect 10 price moscments:" necessitating equality of their buy-sell spreads.

Relaving the price taking assumption introduces interesting compleviltes Into the athslus. As McManus and Acheson (1979, 1983) dernonstrate, for fitures reldting to proce remb!hme

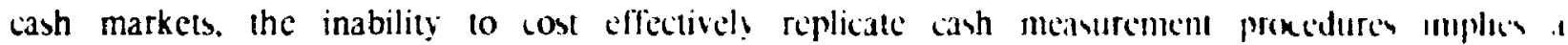
mutual loss to any transactions adhering stricll! to futures contract vipulatums. Ihe mestet cull be represented as follows.

Consider a price searching commodity market. Define.

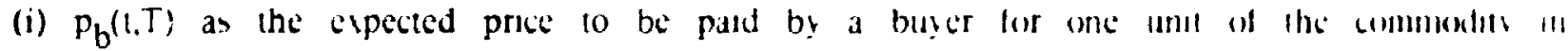
the cash market at time $T$. Fipectations are taken al ume $t$.

(ii) $p_{s}(t, T)$ as the expected price to be recenved by a ecller for onte unil of the commendus. in the cash market at time T. Again, expectauons are laken al lime 1.

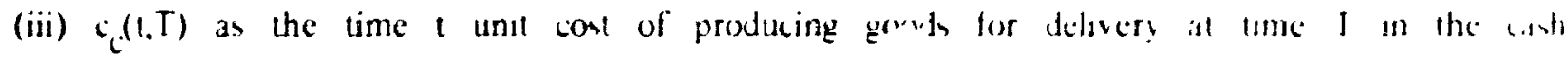
markel.

Competition in the production of cash market goods cnutuses $p_{(1, I)}=q_{(1 .}(1)$.

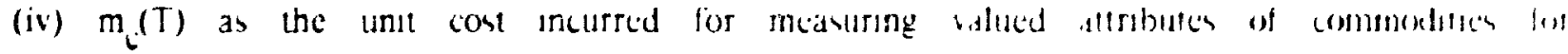
delivery in the cash market at time $I$.

Clearly $m_{c}(T)=p_{b}(t . T)-p_{s}(1 . T)$. The total unit coste of measurement inclide the cosm at

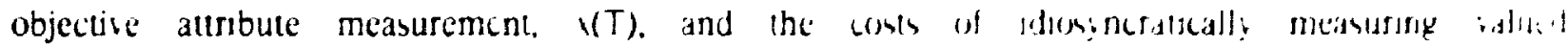
characteristics. $m_{j}(T)$. Thus. $m_{c}(T)=(T)+m_{1}(T)$. 
I lutures market, which requires delwery at lime $T$ is also concurrenuly operating with the cath markel. In specalsing the characteristics of goods eligible for delivery, the futures contract adopts the same objecture measures lused in cash market trading. but does not present any upportunily for purchasers to idiostncratically assess commodity values. Define:

(1) $y^{(1.1)}$ is the tume 1 cost of producing contract goods for delivery at time $T$, at the bolumic and rate of output velding lowest per unit production costs. Contract goods are those commondincs atherme veruly 10 the objectuc specilications in the futures contract.

The cus of meavirement for delisery via futures is, therefore $\mathrm{A}(\mathrm{T})$, which following universal Praclice in futures markets (ste chapter II). is assumed to be borne by the seller. The munmum pres at which the seller will be induced to produce and deliver via the futures (ontritu (the munmum sell proce). 1s. therefore:

(‥) min $f(1.1)=4(1 . T)+1(T)$.

In indisulual's biluatwon of the cash market commodity:

(i,i) $\because(l)=v_{1}(1)+r_{m}(T)>p_{b}(1 . T)=c_{c}(t . T)+v(T)+m_{i}(T)$

is the sum of the balues placed on commodity attributes from an ability to objectively and dwosmiatkall, meinute charactermus when purchasing in the cash market. These values are kimoled,$(1)$ and $1 \mathrm{~m}$ (l) in cquation (3i). As a price searching market is the revealed prelerrid governitlce structure for cash market transactions, the implication is that the costs of Himballn! ba contals morporating only the commoditues objectively measured attributes. must chesel the blus to market participants:

$(1.1)+1(1)>1(1)$.

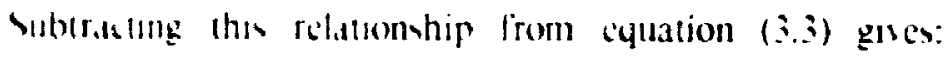

(i.4) $b_{m}(1)>k_{i}(1.1) \cdot c_{j}(1 . T)+m_{1}(T)$.

the right hand whe of equatoon $(3.4)$ is the additional cost of production and measurement

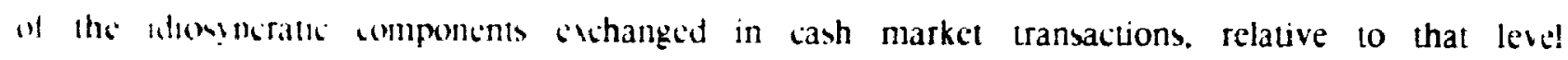
"1 atrubites mcorporated in contrat zoods. The relationship implies that individuals generate I virplu from an opportunity to vibjcatively assess the characteristics of commodities 
transacted via a price searching governance struclurs. This sturplus is grester the lowst the per unit cost of trader's idosyncratic measurement in the cash marhet. m,(1).

As the delivery market in contract goods is assumed to detopl the wime whicelle

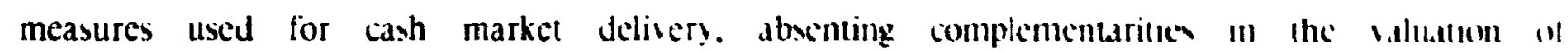
objectively and idiostncratically measured characteristics, the saluation of abjectucl! meistred characteristics will be identical independent of the market in which deliver! st l.the'll. 11

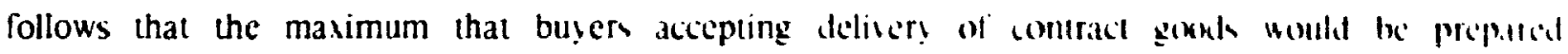
10 pay is:

(3.5) $\max f_{b}(t, T)=p_{b}(t, T)-v_{m}(T)$

This implies from equations (3.3) and (3.4):

$\max c_{p}(t . T)+x(T)>f_{b}(t . T)$

Substituang from equation (3.2) biclde:

(3.6) $\min f_{s}(t, T)>\max f_{b}(t, T)$

The mavimum price busers are prepared to pas lo lake delevers of contriut gexkls is lew than the minimum acceptable to sellers. This difference in buyng and sellıng pricts, funtu

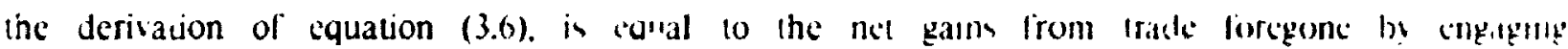
in a delivery of contract goods, $v_{m}(T)-\left\{c(t, T)-c_{i}(1, I)\right\}-m_{i}(I)$. and is cusclly relluclcat in the difference in trades' buy-sell spreads in the cash and fintures markets. Hut scil spreads in the market for contract goods will also differ between Iraders if per unul custs of idiostncratic measurement differ across market participanis. All elsc cyual. $1,(1,1)$ b.1lles

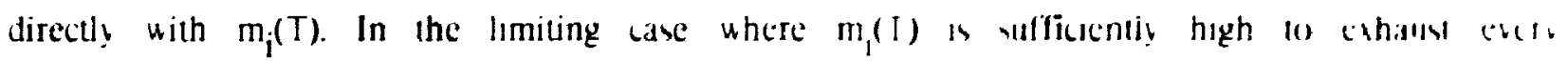

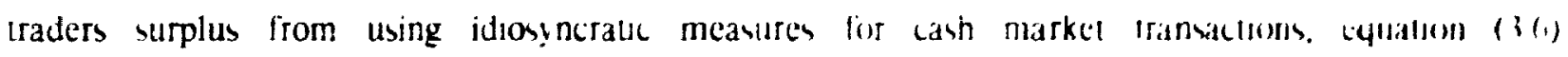
holds with equality. A price taking cash market will then be the preferred gouvermarles suructute for organising exchange.

The analyss has implicauons for the equilibreum selticment price of fulures comliach The bounds upon the linal setuement price of the futures contract afe letermuners b. 
pusentual arburage transactuons between the lutures price and the delivery market for contract eeneds created by the terms of the lutures contract. Any difference between the cost of produstuen and delevery of contract goods and their value will, therefore. necessarily result in a tinge of indeterminacy in the futures settement price. The more contractually incomplete the contratt, the greater this range of indeterminacy. From the intertemporal perspective of the present analyss. It is clear that the attainable difference between the two futures prices III I spresd portlolio, proor to the inducement of arbitrage transactions, will in general, no longer stmply reflect the level of net carrying costs belween delivery periods. It will also Imorpor.ale an element reflecting the higher cost of transacting via the incomplete futures contrat. The determuniatic relations in equations (3.1a) and (3.1b) no longer necessarily oblain.

A smple numerical crample will clarify the intuition. I.et the time 1 expected pricestrceuph per contract unit to buscrs/sellers be $\$ 100$ and $\$ 90$ on the relevant cash mishet at lume 1, Of the \$ll cont of measurement. let $\$ 7$ be the cost of objective

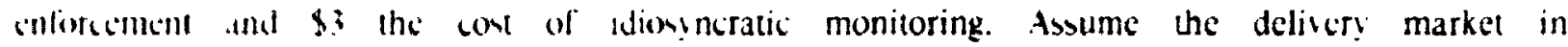

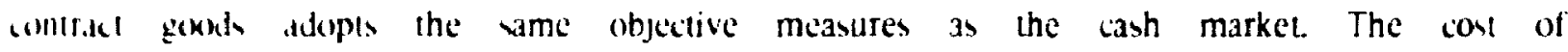
mesurstikem for delsery is then $\$ 7$. I et the time 1 per unit cost of production of contract

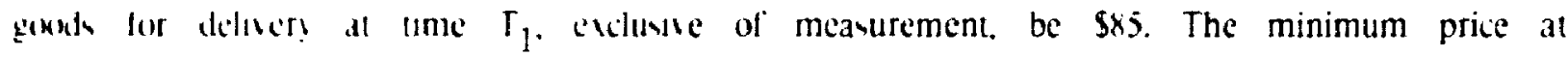
which wllem will be induced to plan production and deliver va the futures contract is. from

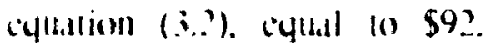

If hugce dorive ant urplus from transacting in price searching cash markets. from cyluthon (3.6). their caluation of contract goods must be less than \$92, sat \$88. This is the mavimum prece a buger would pa! al time 1. for a deliver! of contract goods via futures at lmo $I_{1}$. The tuture sotulement price can, therefore, ary between $\$ 88-\$ 92$ without inducing armirage tramsetsoms in the delivery market ior contract goods. The range of arbisage miletermumat in the settlement price is $\$ 4$. which is equal to the net gains from trade forgene br trimulung in the deliver! market for contract goods rather than the regular cash 
market.

Now introduce a per unit cost of vorage from $r_{1} 10 \mathrm{r}$, II $\$ 111=(1,1) \quad,(1,1,1)$ Lising analagous reasoning to that above, the matinum price butcrs will pat al tume 1 for . planned delivery of contract gooks at time $T$, is $\$ 9 \$$. The minimum price at which wllew will produce and deliver that unit is \$102. Once more. there w $1 \$ 4$ range wilhin whuh $f\left(t, T_{2}\right)$ can fluctuate without inducing delivery transactoms vid futures.

The implications of this arbitrage indetermmacy lor the price hehavour of mentempmisl spread transactions in the futures market can now be understood. (insider the vlltatlon lidtilly a trader if the nearby and distant futures prices are di the levels reprexelled br the

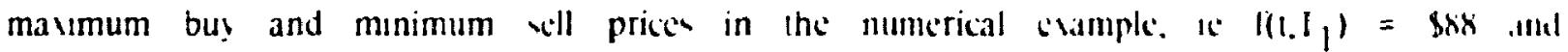

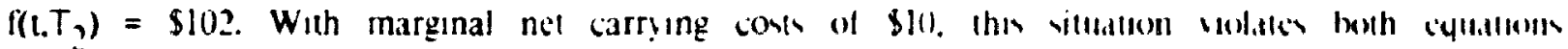
(3.1a) and (3.1b).

Conventional analisis would abvirat from an! range of atburage indelermunter in

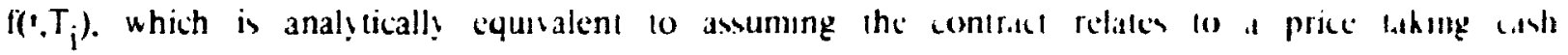
market. In that case, a spread trader lacung these futures prices could earn at inkl, iclumu of $\$ 4$ per spread position from the simultancous extectlion. at time 1, of a long prostlom int

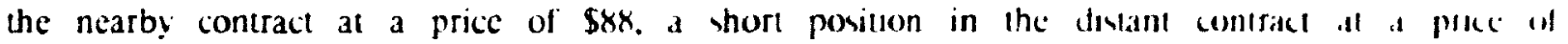

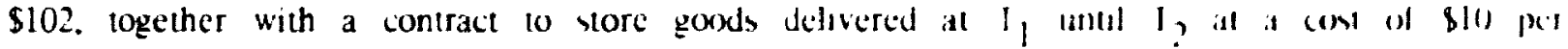
unit. This conventional approach is equivalent to assumeng that huy sell spreath ill cast

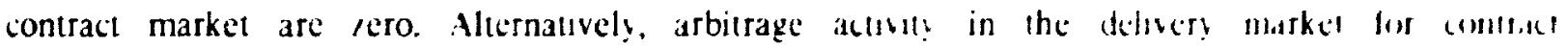
goods sufficiently constrains the futures prese to enable the spread trades to encoufe but ant sell orders in the market at the prevailing lintures prote.

Returning to the original numerical esample of a contractlatly incomplete cortact. Asth a St range of sittement price indeterminact pes contract, this assumpion is ifo lompes warranted. Consequently, the percuved returns to arbitrage activity ase likely 6 be dresch 
vemilicantly. Comster the limuling case wherc potential arbitrage transactions represent the onlt elfecluve market constraint upon futures settlement prices. A spread order to bu! nearby and scll distant contrack at the market, would be execuled at $\$ 92$ and $\$ 98$, respecuvely. These order cseculson prices would totally mitigate the profitability of the arbitrage transaction. If exceuted, the trading strategy would yicld a return of $-\$ 4$ per spread position. Notice that the abolute magnutude of the negative return is equal in sire to the range of arbitrage Indecterminaly in the fiutures price. This is not concidental, but as the structure of the crample makes clear. will be a general result which holds in every market where arbitrage Iranbittions in the delivery market for contract goods are the only constraints on futures price changes. Io conclude, the analysis suggests that the reluctance of spread traders to ingage in intertemporal arbitrage as a result of the incompleteness of the futures contract. will thet only increase the price variability of spread positions, but mas, in general. preclude the revioration of the cyultbrium conditions. equations (3.1a) and (3.1b).

This meaturement col phenomena. to the present author's knowledge. has not been previoust analined in discussons of the intertemporal relationship between futures prices. .llhough Workng: (1944) dixcussion of equilibrium cash-futures price differences makes the following oberation:

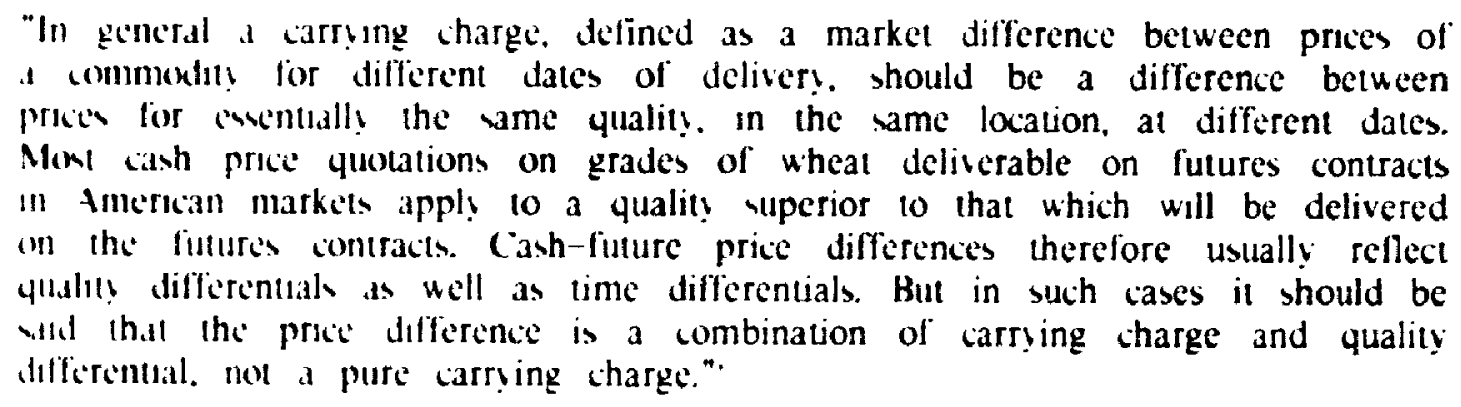

Vils that if the relesant ash market uere price laking, the measurement devices used

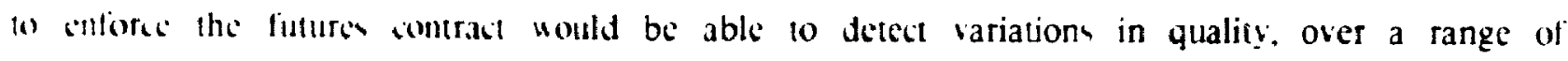
yualikes. with the sme cfficient? as the cash market. Thus. discounts and premiums for the

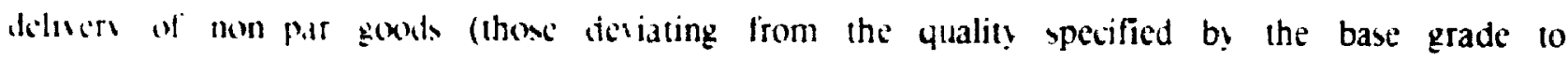


which the futures contract and price pertain) could be stablished chatly in decordunce with the commercial differences found in the regular spor murhet. In this sasc. Norhinges "ylualits

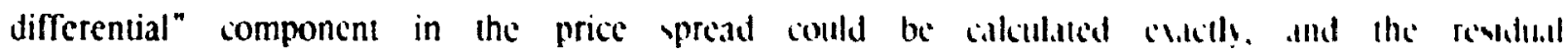
would be the pure carrying charge. However, the wadespread ise of tived rather lh.un commercial differences to price non-par deliveries stegests that the increased culoremient and measurement efforts required to implement such commercial differences are not cios ellictirc The quality differential cannot then be calculated with precison.

A proposed solution to the difficulties this introduces for the calculdtion of ute c.lltwill charges is suggested by Brennan (1958) who writes:

\begin{abstract}
"Rather than compare a current cash price with the current quotation of . distant futures price. the current quotation of the fittures price for delivert in it distant month was subtracted from the ciurrent quotation of the futures price for delivery in the current month or a near month. This was done 10 cnsure that the prices being used referred to identical conmoditios."
\end{abstract}

In Brennan's view. the resulting price spread reflects marginal net carrying comls.' Prum discussion indicates two conditions are required for this solution to be corret, Itenther it

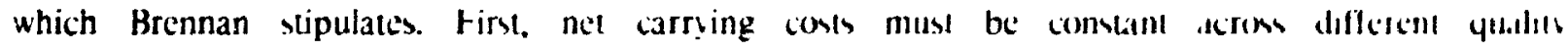
grades of the commodity between $T_{1}$ and $T_{2}$. Second. and more importantly. the commodutr contract must be written on a commodity lading in a price takng cash market. ()therwise. the calculated price spread may, as the previous ctample makes clear, in gencral contaun an element deriving from the range of arbitrage indeterminacy in the proung of futures cor ilste Thus, even if Brennan's procedure is implemented, for comtractually meomplete contrats the observed spread is unlikely to reflect a pure carrying charge. 


\section{II: MIASI KI.MINI (OSIS A.U) HLTLKFS PRICH BHHAVIOLR}

In all sllempt to more formall: examine the relattonship between intertemporal futures proces in the presence of incomplete contracts, this analysis specifies a simple model of the sanatem of proes of storable commodiues. A model with similar structural affinities is used by (iarbade and siber (1983h) to elldy the hedging properties of futures contracts relating 10) commonditses with heterogencous cash market varieties.

Comvider a commodil! exchange lading futures contracts pertaining to a storable commexdit!. Apart from vipulation of the maturily or deliver! period the tume during which P.irlecs Io mutstanding fulures contracts are obligated to undertake the promised transaction). the ofjectuce peufication, governeng contractual performance are identical across contracts.

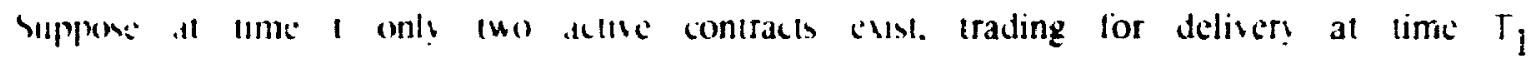
(nearby comeracl) and I, (dwant contract). respecticly. The contracts are for a commodil! with a ciasmal harusis. Ind both deliver! periods fall within the same crop year. The futures price al lume 1 for a contrat maturing at time $T_{i}$ is $f\left(t, T_{j}\right)$. The intention is to lormulate a gencral model of the diname inferaction botueen $f\left(t, T_{1}\right)$ and $f\left(t, T_{2}\right)$ encompassing bolh contraludll! complete and incomplete contracts.

The andys begm by assuming that within a trading period. the average value of the prici ratu $t\left(1, l_{1}\right) / f\left(t, T_{2}\right)$ is $1+c$. In general $i>0$. but the analysis would not change for 1. 1) Kcarranging cyuation (3.1a). II is clear that $\left.c=k\left(t . T_{2}\right)-c\left(t . T_{1}\right)\right\} / f\left(t . T_{1}\right)$. the ratio bI net carrumg conts to the price of the nearb! contract.

for implicits, the following dicusion asumes $c$ is non-stochastic within a trading perist. I hw wumpuon is uncontroverstal in an enviroment of stationary interest rates, and "hen wirn coms ate abolute, or ficed in monetary salue per unit of time. It is more

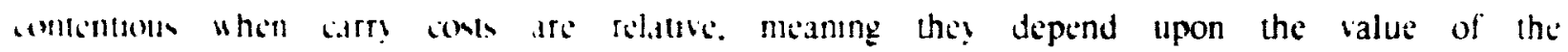




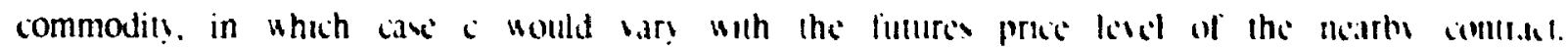

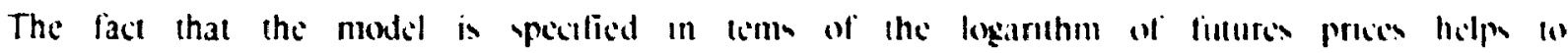
reduce the overall impact of price lesel changes on the balle of $s$. and stuch comsulstillums

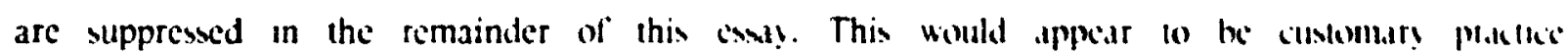
(Williams (1986)). Honever, it hould be recognised that al sume sicrifice in lerms of

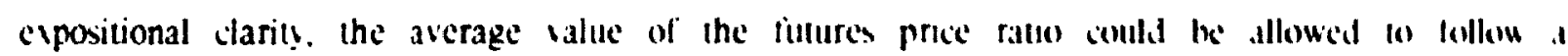
scasonal or cyclical pattern. and the substantial concitusions of the dilulsus would he unaffected. The distinction berween relative and abolute carr! cons is fullher dixused ill chapter 4 .

The model specilies that the lozarithm of the price of the mearbs comract and the logarithm of the price of the distant contract. the latter reduced by $1+c$ are compuned of two components. a component $\phi$. representing the walue of commondil! alrobutes which call he measured objectively, and an idion!ncratic component $\psi$, which is divided between the luct contracts:

$$
\ln \left\{\left(1 . T_{2}\right) /(1+c) l=0-\beta \psi\right.
$$

where $\alpha+\beta=1$.

One could call Inif(t.T $\left.T_{2}\right) /(1+4)$ the nearby equsvalent price for the contrate mullum at $T_{2}$, as $1 t$ is the futures price (net of carryng cusls) for the contract maturnge il 1 , which would prevail at lime 1 given the balidity of the assumpisons anderlyng cyudtums (3.1a) and (3.1b).

The $\phi$ element of the model is the proce laking component of the futures prece lis value is determined from the contract market's proxessing of information llows, deconed ia, affect the value and cont of commodity characteristes, that are objectuvely pecoliced in the terms of the futures contract. from cyuatuon (3,-) and (3.x). is a werghted avetage of 
the livo contracl prices:

$$
\phi=\beta \ln \left(\left(1, T_{1}\right)+\alpha \ln \left(f\left(i_{1} T_{2}\right) /(1+c) l\right.\right.
$$

and as the content of information flows occasioning traders price revisions cannot be expected i) lollow a sylcmatic pattern, is specified to vary as a random walk:

$$
d \phi=\sigma_{\phi} \cdot d \omega_{\phi}
$$

where:

1) d/ is a (jalus-Weiner process.

ii) $0_{\phi}^{?}$ is the variance of the change in the common component per unit of time. As - is the price taking component of the information llow, any changes therein will be eflictively arbitraged across the enure constellation of futures prices.

Ihe component $\psi$ constlutes what shall be termed the idios!ncratic element of futures prect variability. Changes in $\psi$ are designed to capture variations in setulement prices occuring usthin the range of arbitsage indeterminac! in the futures price resulting from the incompletences of the contract. from equations $(3.7)$ and $(3.8)$ the idiosyncratic component is: (3.11)

$$
\psi=\ln \left(1 . T_{1}\right)-\ln \left(f\left(1 . T_{2}\right) /(1+c)\right\}
$$

Lewed from the perspectite of the outside modeler, the idiosyncratic component is also yecilical to vary a a random walk:"

\section{$(3.) \quad \cdot 4=o_{\downarrow} \cdot d / \psi$}

whers:

t) $\mathrm{d}_{\psi}$ in a Gallss-Weiner process. uncorrelated with $\mathrm{d} / \phi$.

11) $v_{\psi}$ is the tariance per unit of time of the idiosyncratic component.

I theriptum of the behatiour of contrat market clearing prices is contained in the

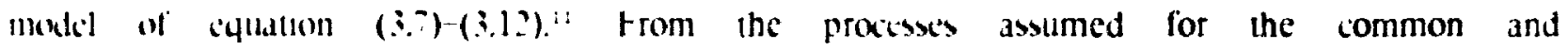
dhemincratic components of the settlement prices given by equation (3.10) and (3.12). the 


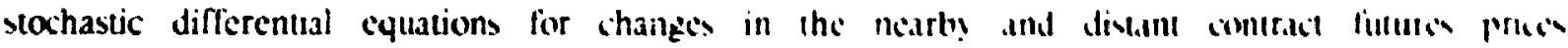
may be writlen:

$$
\begin{aligned}
& \mathrm{df}\left(\mathrm{t} . \mathrm{T}_{1}\right)=f\left(\mathrm{t} . \mathrm{T}_{1}\right) \sigma_{\phi} \mathrm{d} / \phi+f\left(\mathrm{t} . \mathrm{T}_{1}\right) \alpha \sigma_{\downarrow} \mathrm{d} / \downarrow \\
& d f\left(1 . T_{2}\right)=r\left(1 . T_{2}\right) \sigma_{\phi} d \phi_{\phi}-r\left(1 . T_{2}\right) \beta v_{\psi} d / \psi
\end{aligned}
$$

with instantaneous bariances:

$$
\begin{aligned}
& \operatorname{var}\left(f_{1}\right)=\operatorname{arr}\left(\mathrm{d}\left(1, T_{1}\right) /\left(\mathrm{l}\left(\mathrm{T} \mathrm{T}_{1}\right)\right)=o_{\dot{\phi}}^{\prime}+a^{\prime} o_{i}^{\prime}\right. \\
& \operatorname{var}\left(f_{2}\right)=\operatorname{arr}\left(\mathrm{d} f\left(\mathrm{t}_{1} \mathrm{~T}_{2}\right) / f\left(: \mathrm{T}_{2}\right)\right)=\sigma_{\phi}^{2}+\beta^{2} \mathrm{o}_{\psi}^{2}
\end{aligned}
$$

This specification of the model has determinate implications for the interictum leviuten medils and distant contract prices, and consequently for the bchaviour of the intracommenlut y ycill,

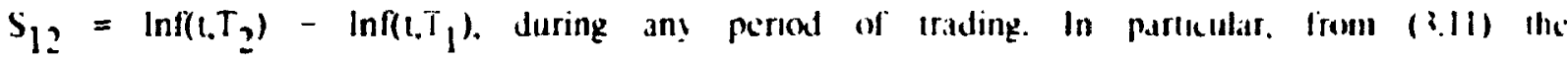

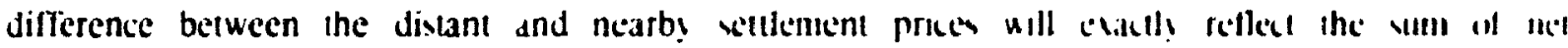
carrying costs and the idios!ncrate element of fitures price varability. $\downarrow$. Assumme met carrying costs are nonslochastic, it follows from (3.12) that $\sigma_{\psi}^{2}$ will als) be cullal (1) the

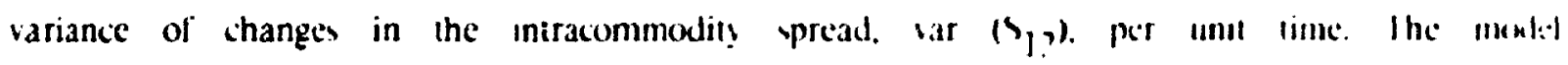

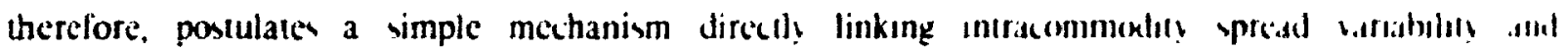
the contractual incompleteness of futures. Notice that for a contrat perlamme lo a puse taking cash market. $\psi=0$. The intertemporal fulures proce pread will cyud net callumt costs. and assuming the latter are constant. the implied inlinite sidsterty of arbitrape scritcis ensures the sariability of changes in the spread will be cro throughesut the tradeng perfent

Prior to a consideration of the cestable implicatuons gencralcd by the moxdel. Iwo luithut

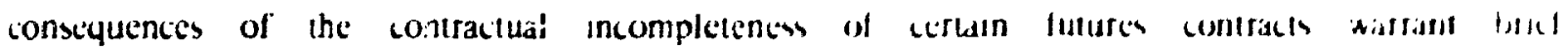

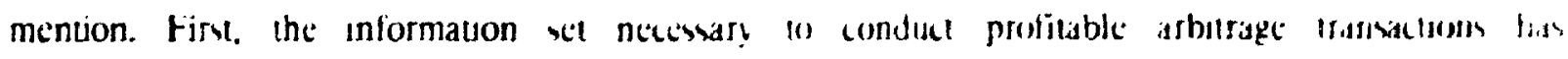
increased, as individual spread traders must nou form an eslimate of the range of arbuliapt

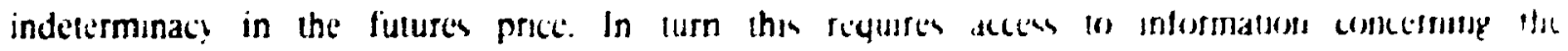

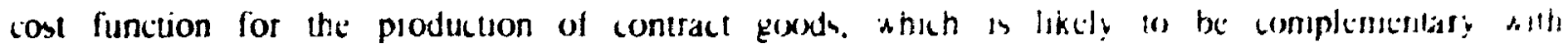


Acluvilles such as producing. soring and processing the commodity for cash market delivery. At any particular time. the relationship exhibited by contract market prices obtaining specifically from desired arbitrage transactions will reflect the information set of the trader with the lowest buy-ecll spread currendy active in the market As it is a characteristic of price sarching markcts that buy-scll spreads vary among trading principals, the intertemporal fiutures price spread may be expecied to vary as more informed traders enter and leave the marker.

Sicond. the range of arbitrage indeterminacy increases the potential oppontunity for manipulation of the value of the contract by traders with lower costs of access to the contraul market. On all evisting commodity exchanges, only exchange member-brokers may Ixcomic partics to. and effect translers of. contractual obligations. Although Commodity Futures Irading (iommission (C $\left.{ }^{\circ} \mathrm{TC}^{\circ}\right)$ rules require futures exchanges 10 prohibil member-brokers fro.n t.sking the opponite side of a clients order without consent. brokers may still trade for their oun acount, a practice lermed dual trading." One mechanism through which member-brokers .Ife alleged to be able to manipulate settement prices is by comparing order books and trading coupcratusly on the exchange floor. Constraints on such practices, serving to make the futures market more of a lair game. emanate from two sources. CrTC and futures Whange regulations and more importandy. the wensitivity of the futures price to potential .mburage transactions. ${ }^{2}$ cosll! enforcement implies the former will be imperfect With respect I1 the latler. a grealer range of arbitrage indeterminacy in $f\left(t, T_{i}\right)$ allows member-brokers morc dixritom in establishing prices within the bounds established by arbiuage order flow. thus increasng the expected cous to non-members (outsiders) of their trading activities. The pustultal for this redistributive exploitation of other contract holders increases the risk of marhct partucipation, reduces liquidity, and inhibits the transferability of contracts. In the limit the cuccution costs of outside order flow may be severe enough to lead to failure of the controct marhet. 


\section{a. Tesiable Implicarions}

Although the parameters of the model previously outlined are themselies unotmetsithle direculy, the prior measurement cost analysis does generate simple cmpirical prediclions which are amenable to testing. relating to the nevus of pricing relationships ahibited betwicen upen and spread commodity portfolio's in futures.

Specifically. consider the price volatility of changes in a yrsead relatise 10 .11 position contract portfolio in a particular futures contract:

$$
\operatorname{var}\left(S_{12}\right) / \operatorname{var}\left(F_{i}\right)=\left\{\operatorname{var}\left(F_{1}\right)+\operatorname{var}\left(F_{2}\right)-2 \operatorname{cov}\left(F_{1}, F_{2}\right) \mid / \operatorname{var}\left(F_{i}\right)\right.
$$

Assume for simplicity that open position variability is equal across contracts." II " cvidenl that as the uieasures stipulated in the futures contract more clonely approvintate thone utilixid in cash market trading, or the more contractually complete the lutures contract. the lower the variability of price changes in a spread position relative 10 an open pustlion portlulio. An intuitive demonstration follows. Setung $\operatorname{var}\left(f_{1}\right)=\operatorname{var}\left(f_{2}\right)$ implies the ratios redating ypreat in open contract price volatility may be written $2(1-\rho)$. where $\rho$ is the correlation cox:ficisull between contractual price changes. From equations (3.13) and (3.14):

$$
\operatorname{cov}\left(\mathrm{F}_{1}, \mathrm{~F}_{2}\right)=\operatorname{cov}\left(\mathrm{dr}\left(\mathrm{t}, \mathrm{T}_{1}\right) / \mathrm{f}\left(\mathrm{t}, \mathrm{T}_{1}\right) \cdot \operatorname{dr}\left(\mathrm{t}, \mathrm{T}_{2}\right) / \mathrm{f}\left(\mathrm{t} . \mathrm{T}_{2}\right)\right)=\sigma_{\phi}^{2} \quad \alpha \beta \sigma_{\psi}^{2}
$$

which together with (3.15) and (3.16) gives:

$$
\rho=\left(\sigma_{\phi}^{2}-\alpha \beta \sigma_{\downarrow}^{2}\right) /\left(\sigma_{\phi}^{2}+\alpha^{2} \sigma_{\downarrow}^{2}\right)^{1 / 2}\left(\sigma_{\phi}^{2}+\beta^{2} \sigma_{\downarrow}^{2}\right)^{1 / 2}
$$

Thus, from (3.19) $\partial \rho / \partial \sigma_{\psi}^{2}<0$ which direcl!y implies $\partial i v a r\left(S_{12}\right) / v a r\left(f_{i}\right) / t$ is $a_{\psi}$, (1) as earlier maintained. 


\section{I MPIRICAI UFRIFICATION}

As developed. the measurement cost model of futures price behaviour maintains that an: contractual incompleteness of futures contracts is manifest in the pricing relationships. oullined above. exhibitel between different portfolios of commodity futures. In lieu of direct measurement of futures price colatility this analysis adopts the minimum initial speculative matgin reytuirements wablished by the respecive commodity exchanges on open and spread perstums as proy measures for the price variability of contract portfolios. ${ }^{\text {s }}$ This pront not conly cmables a large data sit to be compiled at comparatively low cost. but also has the adrantage of gencratung results without imposing strong assumptions concerning the class of possble procesces governing observed futures price volatilits. In particular, it does not require liutures price changes are normally distributed. The margin requirements are incorporated into the model as follows.

Denote the exhange minimum margin requirements on a spread position between delivery months $I_{1}$ and $I_{2}$ as $m$. and those on an open position as $\delta_{i} m(\delta \geq 0, i=1.2)$. cimsder a preat portiolio consusting of 4 , positions. with tota: inargin requirements $\bar{m}$ equal (1) these an an open portfolio contaming $q_{i}$ contracts:

(i..i) $\quad y_{1} m=y_{1} \delta_{1} m=m$

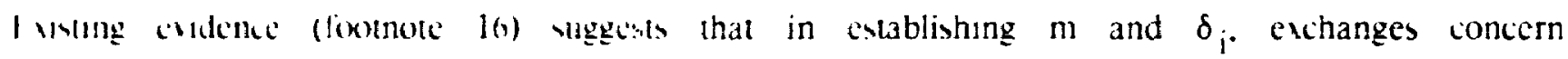

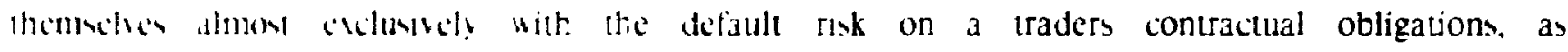

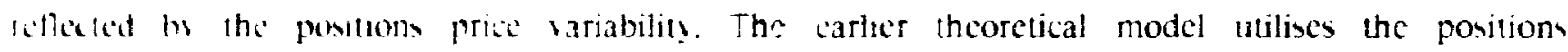
oun puse varume a an appoprate measure of this perceived default risk implying from $\left(\therefore 1^{-\top}\right):$

$(: 21) \quad \psi_{i}^{\prime} \operatorname{arc}\left(s_{1},\right)=4_{1}^{\prime} \sin \left(t_{1}\right)$.

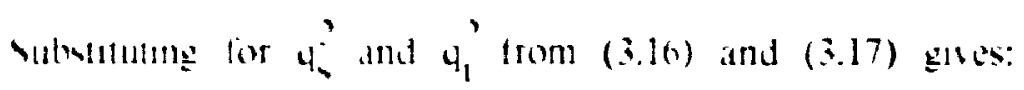

$(\because \cdots) \quad\left(m^{\prime} m^{\prime}\right) \operatorname{ar}\left(s_{1}\right)=\left(m^{\prime} \delta_{1}^{\prime} m^{2}\right) \operatorname{arr}\left(F_{1}\right)$ 
thus:

$$
\delta_{i}=\left(\operatorname{var}\left(F_{1}\right) / \operatorname{var}\left(S_{12}\right)\right)^{1 / 2}
$$

from (3.22). $\delta_{i}$ can be interpreted as the number of spread positions in deluers month $I_{1}$ with equivalent (perceived) default risk to one open posithon. Farlicr analivis wablished th.t! the denominator in the right hand side of equation (3.23) tends 10 cro as the complutalsse disadvantage of trading via futures diminishes, thereby increasing $\delta_{i}$ for a gullen open contr.ul price variability. In the contest of margin requirements, therefore, the implaitlon of the measurement cost hypothesis is that the ratio of the level of open to ypread pontlion mally!ll requirements will be incersely monotonically related to the proportuon of contractual pula variability atuributable to price fluctuations within the range of arbitrage indetcrmusht III

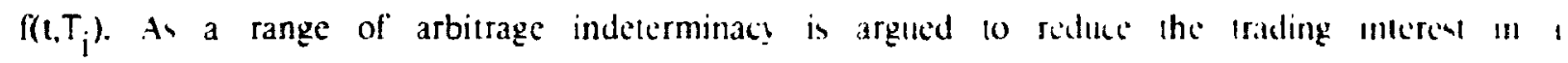
contract, corroboration of the hypohesis would be evidenced if higher salues of $\delta_{1}$ werk. associated with the more actively trated futures contracts.

\section{a: Data Description and Test Procedures}

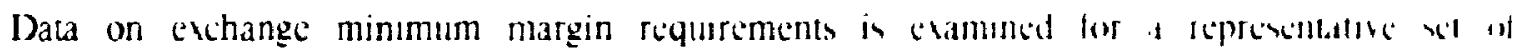

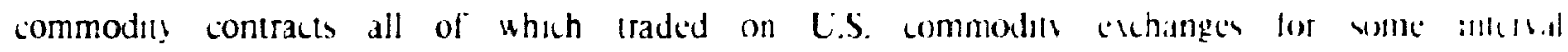
during the 1970-19x4 period. The one hundred and theven commodilies for which dila coulit be solicited from the respectue exhanges and/or dearng houses are hated in lable 3.1

The test procedurc employs the non parametric Wikoxon Mann-Whilney W(L) blatustu

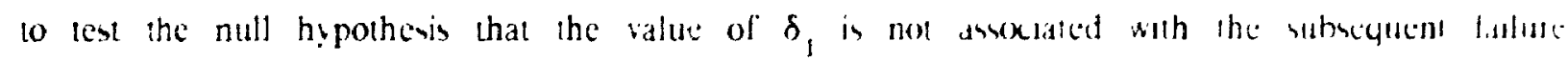
of the contract market, against the alternatuve hypothess that $\delta$, is negestively related lin subsequent market failure. Market failuse is defined as ether: (1) whtual delsument of the commodity contract by an exhange during the 1970-1984 peroxd: or (11) dommanc: if th: contract at the end of $19 \times 4$. 
(learly, this chose of ust hypothesis employing the markel success/failure dichotomy may be interpreted as somewhat scucre, given the measurement cost hypothesis does not Imply market lature is a necessary outcome of contractual incompleteness. Conceivably a hypothess lest could have been structured relating $\delta_{1}$ to a continuous variable. Average open incerest or trading volume in the contract over the period of observation would have been the obvous possible choses.

Ihs prexedure mat be objected to on several grounds. First. the choice of a level of volume or open unterest below which a contrace market is deemed to be 'thin' is completel! athutiary, and imparts an unecessary degree of ad hocery to the lest procedure. Contract dermancy of delisment is uncontroversial. Moreover. reported bolume statistics as indicators of werall trading meres! in a futures contract are potentially misleading. A large reported volume mat simply be reflecting the trading activitues of either traders with large futures positions, or exchange flower traders. To this evtent thes are not a true indicator of the width of participation in the market. and the degree to which it is suceeding in its function of promoung the transferability of contracts through broadenng the base of market activit!.

scumd. cren presumung an acceptable definition of 'thinnes' for the contract market wolld be lound and asuxiated with the level of the continuous sariable, the fact that the degrex of trating interest in a contract is sensitive to the sage in the contracts life cycle at which 11 is measureal must be alloned for. For example. the more recents introduced

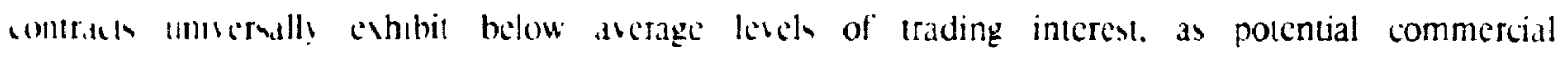
and hodgeng order flow axcerdins both the need for the instrument, and its ability to fulfill I1) minded function. Trading interest $x$ aloo sensitive to developments in the relevant cash murket (c.g. government policy). An! continuous variable that is adopted must be able 10 disunguish betweeen ininness arsing from an unherent contractual weakness, and that temmung from the ensironment custung at the tume the measurement is taken. 
The recorded salue of $\delta_{i}$ for cach commolity is calculated unme onte of ens procedures.

\section{Procedure 1:}

Fo: contracts with continuously active trading and those introluced during the 1970 - 1984 period remaining active until the end of 1984. $\delta ;$ i measured as a nemghted average of the relative open/spread (minumum) exchange preculatuc margin requiroments ill effect for that commodity over the observation interval. The weight dllofed to sidch ralle il margin requirements is the length of time for which it was operause. for combrals dallswid or becoming dormant during the observation period, $\delta_{1}$ is the ratio of margen tequirements

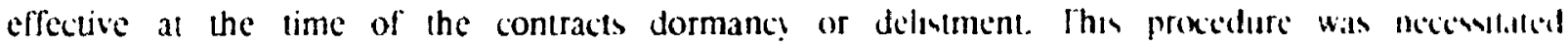
b! the inability to obtain continuous observations for many of the delisted comlrats ovet the complete period of interest.

Utilseng procedure 1 , the alues obtained for $\delta_{1}$ in the lotal comtrat sumple bist uldely. Some indication of the raration of $\delta_{i}$ can be oblanted by wh classlyme the

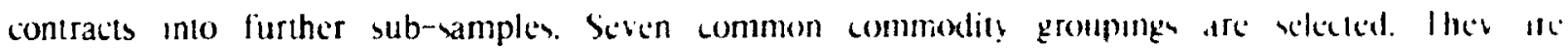
presented below, logether with their values for $\delta_{1}$ (in parenthisis).

(1) Financial (incl stocks): 2-lear $\mathrm{T}$-Notes (3) Compositc Inder (1k).

(2) Currencles: Italian I.ira (1.5) - Swiss Francs (10.96):

(3) Grains: Oats (1.5) - Wheat and Corn (mark 10 markel):

(4) Foodstuffs: Skinned Hams (1.14) - Rough Rice (15):

(5) Metals (incl. coins): Copper (1.67) - Gold, Silver (mark (6) marke1):

(6) Fuel Oils: Heating Oil. Industrial $0_{1} !(2.5)$ Propanc (jas (6):

(7) Woods, Hibres: Stud I umber (1.3 - Cotton (3.1).

The computed $W(U)$ statistic for the cotal commodity sample is prescunted in the liss row of Table 3.2. together with the associated probability valts: assuming validuly of the sull 
hypothess. Ihe ewdence indicates rejection of the null hypothesis (at a $99 \%$ significance Icvel) for the fill commodity sample in favour of the postulated alternative. a negative Assetation between $\delta_{i}$ and the subsequent failure of the contract market. Almost identical results are obtaned repeating the procedure using a subset of the full sample which excluded the seven non redeliverable contracts (the second row of Table 3.2).

Ihe difficult! inherent in procedure 1 is that a possible bias is incorporited into the revills it. on average, times of contractual delistment correspond to periods in which $\delta_{i}$ was low acroms all futures contracts. The effect of this bias is to favour an unwarranted rejection whe thull hypothess. Consequently. a second procedure is also utilised to calculate $\delta_{i}$ in an cifort to remedy the possible effects of unch a bias.

\section{Proncilure ?:}

Procedures 1 and 2 differ in their treatment of the continuously active contracts. Linder percidure $\therefore \delta_{i}$ is measured as the minimum relative open/spread exchange speculative margin feyurtament in affect for continuously traded commoditics over the 1970-1984 period. Adopung the proxedure has one of two affects. If the conditions giving rise to the possible bias under prexciture 1 do in fact hold, then the bias will be removed. Under any other undiluth. the scoud procedure imparts a bias in the opposte direction, favouring acceptance at the null hrpothesis when tatuslical rejection ma! in fact be justified. In this respect. the les conditum under this latter procedure could be described as more conservative thar $t^{2}$ e firmer. An the fitour rejection of the measurement cost hypothesis.

Onc mors. Whpting procdure? produced wide varation in $\delta_{i}$ values. The ranges wrom the sertl commodily sub-groupings are:

(1) Fmumial (ind r(xhs): 9()-Da! T-Bills (2.5) - Value line (16.5):

(.) Currenckes: Mevican Peso (1) - British Pound (3.75);

(:) Grams: Oats (1.5) Wheat and Corn (mark to market): 
(4) Foodstuffs: Skinned Hams (1.14) - Rongh Rice (15);

(5) Metals (incl. coins): Copper (1.67) - Giold. Silser (mark (1) marhet):

(6) Fuel Oils: Heating Oil. Industrial Oil (2.5) - Gulf No.2 ()ll. I calcd (i.ds (5):

(7) Woods, Fibres: Stud Lumber (1.33) - Pl!̣uod (3).

Test results utilising this second procedure are presented in labic 3.2 for the lolul commodity sample and the associated storables subset. Once deain. for louth simples the results indicate rejection of the sull hypothess with a high $\left(990^{\circ}\right)$ degree of conlidellse. confirming carlier fiudings.

An assessment of the sensitivity of the findings to the aggregation provens adopled c.lll be ascertained by sub-classificauon of the non-deliverable contrats into the seven commoshly groupings in Table 3.3. Classilication by commodity groupung could be percetved as vomewhil ad hoc, in tha: a priori, there may not be an! convincing rationale for contrac"s wilhull a particular category to exhibit similar dtribute measurement charateristes. However. fanch that such sub-classification procedure is often adopted in andlysing futures comtrats. the tcullts may provide certain insights by faculitatung comparion whth other studies.

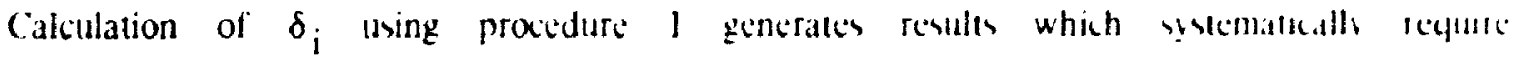
rejection of the null hypothess in favour of the allernatuve. at least al a $45 \%$ level at significance. Noting the potential bias inherent in this method. this as perhaps not vurpmostyg Invoking the second procedure to compute $\delta_{j}$. iwo intercaling departures from the finmlial pattern are evident. First. the lest is unable to rejecl the null hypothess for finatuctist commodities. Second, the results for currency contracls sugeest that actively toaded commondins have lower values for $\delta_{i}$, exactly the spposite preducuon of the present thecors. Ise) explanations for such firdings suggest themedves. fhey could be smply mamfertatums of the bias alluded to earlier; this possibslity is pastucularly likely with respect is the currem: results." Another possibility. which scrves 10 confirm rather than contradict the precceclune arguments, is that of all commodity classes in riable 3.3. the contractlod speciticalions adopted 
in the linanctal (and currency) contracts could be arqued to most closely conform to those Imlired in cash trading. In other words these are the commodities most likel! to possess price laking cash markets. If such conjectures are viable. one would not, a priori, expect rejectuon of the null hipothesis in these contracts, as $\psi=0$. No range of arbitrage indelerminant esists in their settlement price.

\section{IV: CONCIUSION}

Ihs esal atlempls to further articulate, and formalise in a form amenable to empirical writication, recent theories proposing a wstematic connection between transferability, as a presluced allmbutc of contracts. and the perceived trading success of commodily futures contrial markets. A bref comparativs vildt of the contractual differences between cash and fittures matkets highlighted the coss asscciated with altempts to enhance transferabilut in flutures. Cicmerally these attempls take the form of changing the contractual measures which

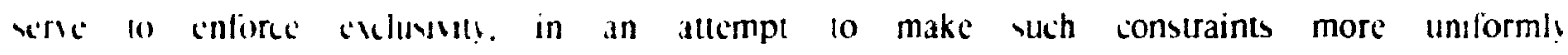
enforccible wer a whder range of potential trading principals.

An arhutrage model of futures price determination is constructed, which espliciu! Imorpordtw meavirement conviderations, and the costs of incredsing the estent of the market .te idemtilied a being reflected in the news of pricing relationships exhibited between certain cummodict futures portfolios. B! linking portfolio price tariablility to commodity exchange matgln reymitimems, a lest of the model is proposed and conducted using data on one humbred and clesen futures contracts which traded during the 1970 - 1984 period. The sulls whtaincd are broadly corsistent with the measurement cost theories of futures price behasour proposed by McManus and Acheson. ard Telser.

Ihe fact that the oberved laatures of so many futures contracts fit within the phoposed frumework is emcourang and attest to th generality. Moreover, the importance of 


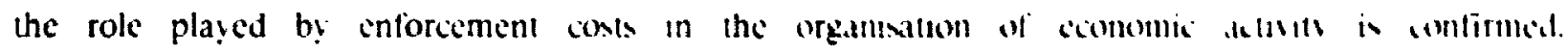
However, it is not espected that the simple conomiring frameworh proponsil here wll

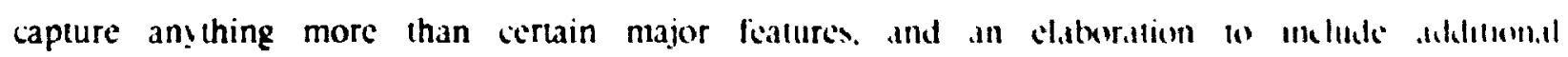

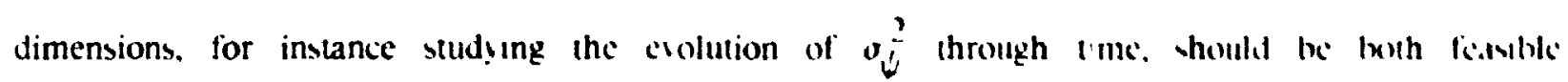
and rewarding to students of market organisation. II w just wh a relinement 10 the memisl which is considered in the nev chapter. 
I able 3.1

Commodity futures Contracts and Fichanges

\section{(HICACi) MFRCANTII FXCHANGI}

Hesh Broflcry, Furo Dollar, L.S. Siluer Coins, Copper. Pola'oes, Nest Fggs, Hogs, Butler. skmned Hatms. Stud lumber. Cattle, Feder Catde. Pork Bellies, Froren Fggs. Boneless Beef. I umber. Canduan Conn. Tuikeys, Plywood. Gawoline. No. ? Oil. Milo.

INIHRNAIIONAL MONFY MAKKET (Chicago Mercanule Fichange)

Brimsh Pound. Desllehemark. Suss tranc. Prench Franc. Canadian Dollar. Ven. Dutch

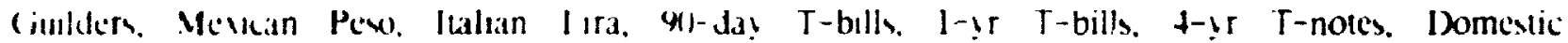
$(1)$, S \& P $5(N)$.

\section{(HIC I( F() H()ARI) OF TRAI)}

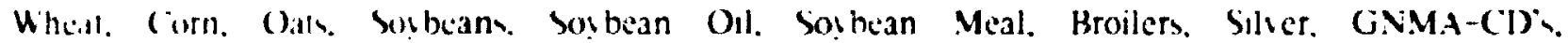

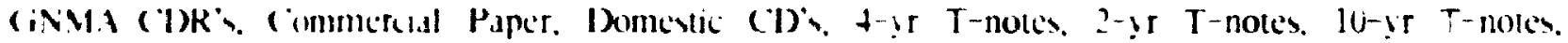
i inend.

\section{IIII) IMIRICA COMMOI)ITY H.ICHANGH}

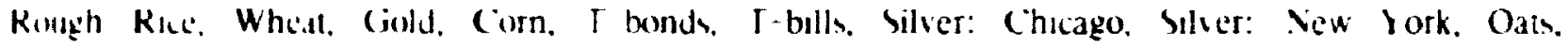

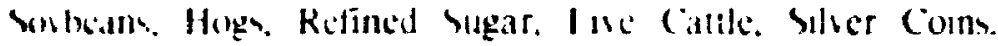

\section{NIU IORE MERCANTII FICHAVGH}

Palladum. N.Y. Yo. 2 Ohl. laded Giss (N.Y.). Gulf No. 2 Oil. I.eaded Gas (Gulf). Crude (Bl, I chl. Deuluhemark. Plinood, Heatung Oil. Industrial Oil. Aluminium. Round While

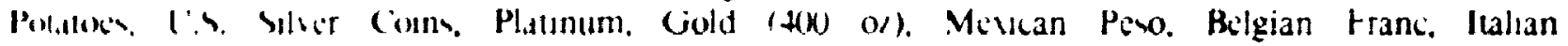

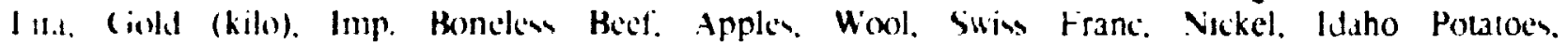
Briwh Pound. Cinatian Dollar. Buter.

\section{R.WUIS (II) R(I)ARI) OF TRAI)F}

Sorbeall, Surghum. Com. Oats. Value I ne Index.

\section{NIK IORK (OTION FICHANGH}

Collun \#. 1 ro/s'n Conc. Orange Juice. Propane Gas.

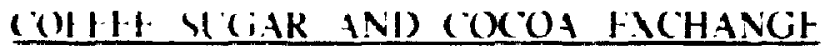

Silgit \#1:. conod. 
NFW YORK FLTLRES FICHANGH

Composite Index.

AMFX COMMOIITY FXCHANGI

GNMA.

COMMODITY FACHANGF INCORPORATFI) (COMPI)

Gold. Silver. Copper. Zinc. 
Iable 3.2

Kexults of Wilcoxon-Mann-Whitney $L$-Text:

rull Sample

Commodity samplc

$\mathbf{W}$

U

d

$\mathbf{3}$

Z

Procedure 1

All Marke-1

1793.5

617.5

48

63

$-5.34 * *$

All storables

1625

$+49$

48

56

$-5.94 \cdots$

Proxcilure?
III Markels

$21+2$

966

48

63

$-3.26^{* *}$

.II Storablew

1935

749

48

56

$-3.74^{* *}$

** Sizmlicant al lo level

- significant al 5"r kevel

a: is the number of active contracts

d: " the number of dormant contracts

$W$ : is the Wilcowon-Mann-Whitne! W-statistic

(': " llo Wikowon Mann-Whitne! (-abalusic

/: A . s stund.trd normal random variable 
Table 3.3

Results of Wilcovon- lann-Whitney $1-$ I (x):

Commodity Sub-Siampls

\section{Procedure 1}

Commodity Sample

w

i d

d

.

Financial

(Incl.Stock)

Metals

(Incl.Coins)

Currencies

Grains, Food Oils

Foodstufts

Fuel Oils

Woods, ribres'

\section{Procedure?}

rinancial

(Incl.Stock)

Metals

(Incl.Coins)

Currencies

Grains, Food Oils

Foodstuffs

Fuel Oils

Woods, Fibres'
36

58

69

15

76

j

62

59.5

117

15

$x+1$

3

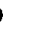

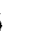

9

5

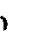

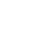

,

$x$

$1:$

!:

14

(1)

II

(1)

4

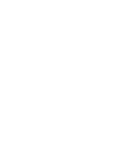

i

4 
- "sigmaficant al lon level

- Signilicant al 50, level

'insulficuent dala

w. 11 . d. and $Z$ as in Table 3.2 . 


\section{FOOTNOTES}

1. The analysis confines itself to spreads between contracts maturing in the sime crop year to avoid the complications introduced by the level of stoxk carryover relitule It new crop producuion when elamining spreads across crop years. Nor is this ewil! concerned with the explanation of the difference between contemporancous fulures and spot prices (the basis) which is controversial. Disagreement centers upon id the basis reflects simply storage cost variables or the lutures price contains an prectid premium and a forecast of the malurity period spot price. The etpected ph, inII is usually defined as the bias of the futures price as a forecast of the lillowe ypor price. For an excellent recent survey of the two hypothesis (and xime empirical evidence which favours the former) see fama and french (1987).

2. Our usage of the term spread is more specific than that gencrally encountered int the literature, where a spread or straddle is often vaguely delined as the simullancour purchase and sale of "similar" futures contracts, in which the ollieelling contracls II! II involve intertemporal, intermarket, or intercommodity transacti ins. That is, the purchise (sale) of a futures contrict on a given exchange is made in conjunction with lite slc of a different delivery month in the same commonii, contract (the present taxige): in a different exchange for the same (cast) commodis, cither in the winc or different delivery months: or in a different but related commodity. where the exact comnotatien of "related" is often not clearly specified.

3. A price taking cash market is one where some traders purchase eoroks subject only il! an impersonal. objective description. if traders subjectively monitor some attribules is the transaction. and/or if one irading principal's identity is of value to the ether contracting parties, the market is said to be price scarching.

4. The analysis is relerring to futures prices net of marginal carrying costs.

5. While arbitrage activity in the delivery market for contract goods delermines the limis of the competitive constraints impacting on settlement price moventents. It is ifot the only relevant constraint A second major influence is the trading attivity of $f(x) 1$ traders (exchonge member-brokers) on the commodity exchange itsell. Indeced. scilleIllinl price rhanges occasioned by floor traders assuming the upposite side is non member market orders when trading for the.r own account, would likely be distribitled within th': limits set by the range of arbitrage indeterminacy in the settement prict.

An analysis of the exact distribution of settement price changes resulting from flext trader activity. while germane for certain problems (Silber (1984)), is not tslevant 10 , the present analysis. It is sufficient 10 assume that floor iraders pmsitions aste mot bound away from the competitive constraints imposed by outside order flow. and incir individual behaviour does not differ systematically across contract markels. (nn custing evidence (Working (1967, 1977)), both appear reasonabic assumptuons. Undes these conditions, the conclusions reached above will continue to hold.

6. Working (1949 p.t). This statement could be constructed as supromituve of thice McManus-Acheson view. Presumably the spread is being quoted in this mantinct because a cash quotation for the commodity described in the futures contrate carmul be obtained.

7. See the discussion in McManus and Acheson (1979 p. 391). (jarbade and silbes (1'78,3) also discuss the procedures specified in contracts to price non par Jelivesices and is 

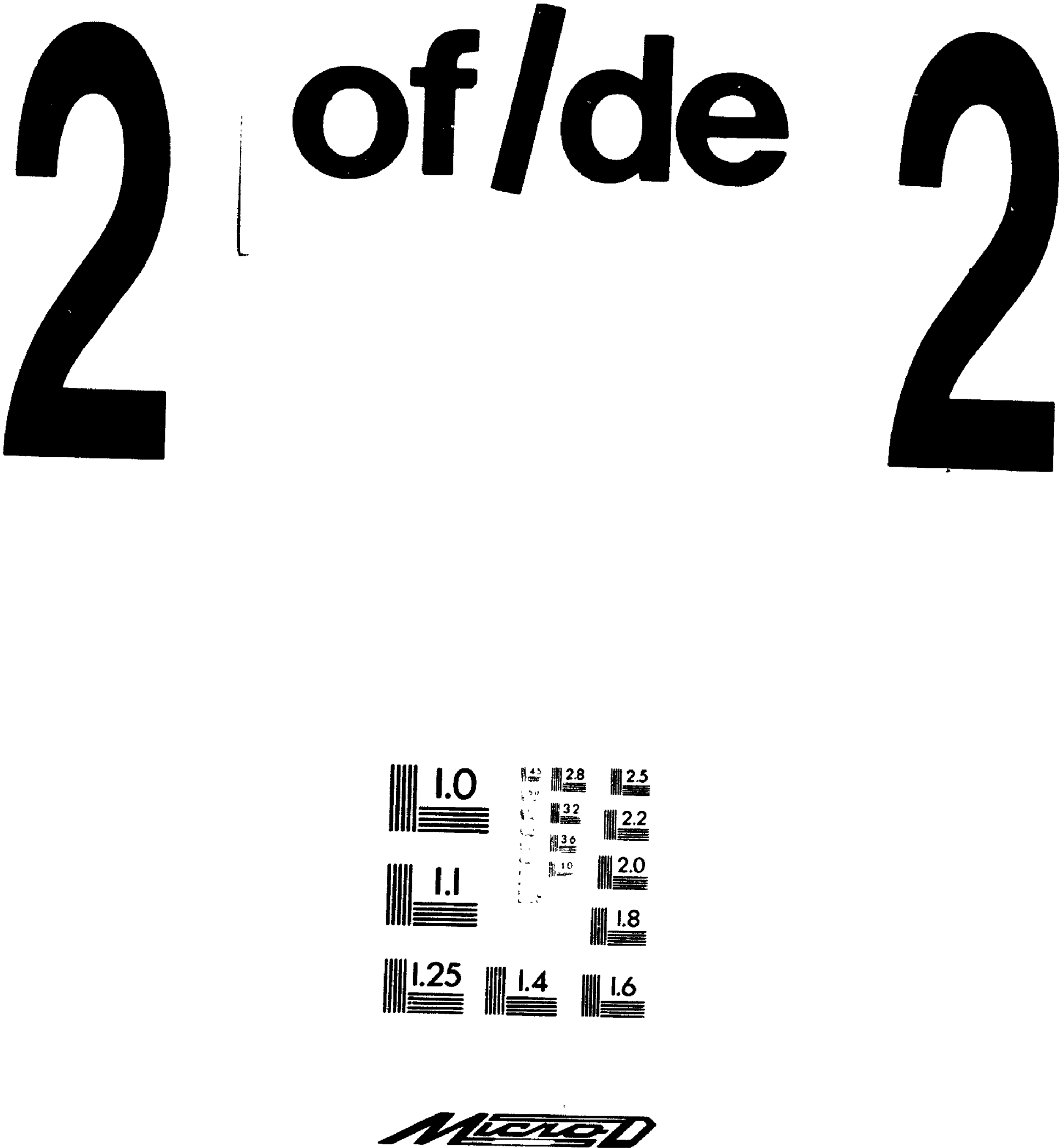
relevant in this context.

8. Brennan (1958 p. 65 fn. 9).

9. Brennan's procedure can perhaps be defended on the grounds that since there is no independent measure of the marginal convenience vield it is suitably detined as the residual in equation (3.la). This being the case, as carlier discussed, equation $\left(3, l_{1}\right)$ becomes an identity and cannot be violated. This paper's contention is that silth it procedure is erroneous. There is further discussion of this and relaled issues laler in the essay.

10. At this point the model differs from that of Garbade and Silber (1983). Their counterpart to the present idiosyncratic component is a 'difference componen' which they assume to follow a transitory, stable first-order process around / formulation implies the existence of a correlation between settement price changes within the range of arbitrage indeterminacy in the futures price. which would not bo consistent with the current approach.

11. In this simple model. both $\sigma_{\phi}^{2}$ and $\sigma_{\Psi}^{2}$ are assumed time invariant. A rationale lor the time independence assumption for $\sigma_{\phi}^{2}$ is provided in Anderson and Danihing (1983) and Richards and Sundaresan (1980). For an alternative perspective arguing J $_{\phi}$ will increase as the delivery period of the contract approaches sec Samuclson $(1 \%(5)$ and Stein (1979). The parameter $\sigma_{\psi}^{2}$ will clearly be sensitive to the unit cost of production and delivery of contract goods. which ii: general could be expected to vary over the life of the contract. The justification for holding of constant in this analysis is an empirical one, arising from a later use of initial speculative margin requirements as proxies for contractural price variability. It is universally the case that prior (1) the delivery month, the levels of such margin requirements are invariant with respect (o) time to contract maturity. Volatility issues are considered more fully in chapter 4.

12. This abstracts away from the buy-sell spread existing in price taking markels, which has been effectively normalised to /ero.

13. See 17 C.F.R. reg. 155.2 .

14. Additional to those restrictions on trading activity indicated above. CFTC rules reyurre trading days of exchanges be divided in 30-minute segments, and tr tdes must be recorded in particular segments (117 C.F.R. reg. $1.35(\mathrm{~g})$ and $1.35(\mathrm{~d}))$. Although at the time of writing. customer orders need not be lime stamped immediately upon execution. they must be recorded at the time received on the exchange floor to the nearest minute (17 C.F.R. reg. $1.35(\mathrm{a}-1))$. For recent discussions of the naturc and adequacy of current futures market regulation in preventing manipulation sec fixhel and Grossman (1984). Fdwards and Fdwards (1984) and Grossman (1986).

15. This involves setting $\alpha=\beta$ although this assumption is not necessary for validity of the argument which follows.

16. A detailed survey of the literature discussing the establishment of the exchange minimum margin requirements, indicates that the central role in their detcrminaliom must be ascribed to contractual price volatility. Moreover, a submission by commodily Exhange Inc. contained in Senate Committee Hearings (1981)) incorporates the explust formula used by the Exchanges margin committee to establish margins as:

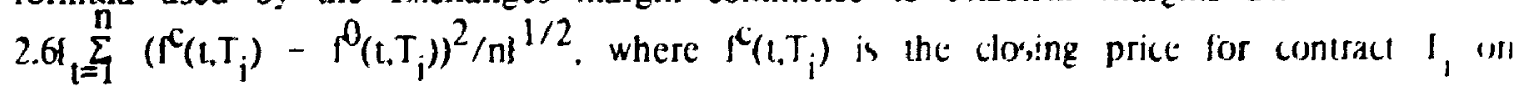


day $l_{j} ; n$ is the number of trading sessions over which the calculation is performed. Fffectively, the Commodity txhange Inc. procedure assumes contract price changes are independently distributed random variables, then, based on historical data calculates price changes having less that a $1 \%$ chance of being exceeded in any given trading session. For recent work on margins see Telser (1981), and Brennan (1986). Insightful carly empirical work on the determinants of margin requirements includes McCain (1969) and Kuhn (1976).

17. Telser (1986 p. S18)

18. The currency results under Procedure 2, reflect the low value of $\delta_{i}$ for the Mexican Peso, which was equal to one over the period 19-24 July 1979, and from 21 August 1981 to the end of the sample period. While classified as an active contract in this study. the Peso contract was delisted by the International Money Market on 20 November 1985. 


\section{CIIAPTEK IV

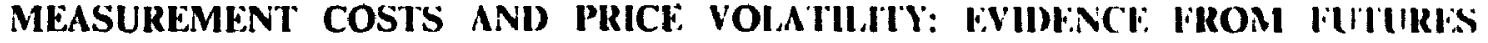 MARKETS}

\section{INTRODUCTION}

In a recent manuscript. J. Williams (1986) expresses the belicf th..:

"...volatile, distinct spreads are a necessary condition for a viable futures manket... it follows that the study of futures markets must ultimately become a stluly of spreads, and by extension, a thcory of futures markets must rest tupon . III explanation of spreads."

This chapter utilises the model developed in chapter III 10 analyse the beh.tviour of llie price volatility of futures spread positions as the constituent contracts approach maturity. Ihe novel feature of the analysis, lies in its explicil incorporation of measunement cus considerations as a determinate element in explaining the dynamics of lutures price behavioutt. The contribution of the chapter is the formulation of testable implications with Iespect II) the behaviour of commoaity spread portfolios. which complement and exlend the cullrent litcrature. Tiic results of the analysis indicate that measurement costs impact not only upon yuestums of comparative institutional choice, but also have determinate implications for the behavient of financial asset prices.

Section 1 outlines the model drawing selectively on the analysis of the precceding chapter. Throughoat, the discussion is motivated by the desire to clearly identily lestalile implications of theoretical results. In section 11 , a comparison is made between llie cillpurit.1 predictions of the analysis and existing alternatives. Finally, section III speculies ant summarises the results of an altempt to empirically corroborate the measindencint cont hypothesis, and compares the findings of the analysis to those if other studies havme occasion to examine the volatility of commodity spread portfolios'. A brict conclusion lollows. 


\section{I: THE DYNAMICS OF SPRFAD BFHAVIOUR}

Ir. Chapter III, the bounds upon the final settlement price of futures contracts pussessing a delivery option were shown, following McManus and Acheson $(1979,1983)$ to be deicrmined by potential arbitrage transactions in the delivery market for contract goods. The model of riutures market cquilibrium developed in an attempt to examine the theoretical implications of measurement cost considerations on price behaviour is summarised in equations (3.8) - (3.12). Inspection of the parameters of the pertinent expressions for open and spread portolio price change volatility indicate any general dynamic theory of contractual price changes must be able to account for the evolution of $\sigma_{\phi}^{2}$, and $\sigma_{\psi}^{2}$ over the life of the contract.

In its present form, the model is agnostic regarding changes in the variance per unit lime of the common component. $\sigma_{\phi}^{2}$. This is sufficient to guarantee an inability to provide dear predictions concerning the price variability of open positions overtime. ${ }^{3}$ Any testable implications of the model are, therefore, necessarily confined to an examination of the d!namic volaulity of commodity spread portfolio's, which are dictated by changes in $\sigma_{\psi}^{2}$ as the contracts approach maturity.

Al any moment in time, an upper bound is placed on $\sigma_{\psi}^{2}$ by the range of arbitrage indeterminacy in the futures price. One of the determinants of this range is the difference in the cost and value of contract goods. A priori. therefore. neglecting unobservable changes in the valuation shedule of contract goods, $\sigma_{\psi}^{2}$ will be sensitive to variations in their unit cost of production and cislivery. To clarify, assume a cost function for contract goods with the propertice discussed in Alchian (1953); (i) for a given total volume of production. the mininum per unit cos of production increases with the rate of production at an increasing ralc: (ii) for a given rate of production. over sorne range of output, minimum per unit costs decline with planned volume of output: (iii) minimum per unit costs of production with 
respect to increased rates of production decreasi as the total contemplated volume of oulput increases. Two cases have bcen analysed:"

a. The Production Process is certain, and Inpul Commuments maybe fully Hedged.

To begin, assume no production of contract goods occurs. There then evists a ume interval $\left(T_{i}-t\right)$. $\left(T_{i}-t \leq T_{i}-\bar{t}\right.$ where $\bar{t}$ is the lime the futures contract begins Irading) through which the upper bound on the range of arbitrage indeterminacy will increase, reflecting inc higher cost of producing and delivering contract goods closer to the maturity periol. There is a constraint impacting upon the increase in the range of arbitrage indeterminacy in the settiement price. This is provided by the cost of delivery of the lowest quality gomals. produced for sale on the regular cash market. which meet the terms of the contract. Once this constraint is reached, the lower bound on the range of arbitrage indeterminacy will alw) increase, to equal the expected value to buvers of the lowest quality cash goods mectmg contractual specifications. If no contract goods are produced for delivery, this synthesis of pricing relations in cash and futures will occur at/by contract maturity. Formally. 10 caplurc the effect of the increase in the upper bound of the range of arbitrage indeterminaly overtime, the model specifies $\partial \psi / \partial\left(\mathrm{T}_{\mathrm{i}}-\mathrm{t}\right)<0, \partial \sigma_{\psi}^{2} / \partial\left(\mathrm{T}_{\mathrm{i}}-1\right)<0$ where $\mathrm{T}_{\mathrm{i}}$ - is the time lell to maturity of the contract maturing in delivery month $i$, and $t-\bar{l} \geq 0$.

\section{b: The Production Process is ceriain, and Input Commitments are not fully Hedged.}

One notable implication of the analysis is the tendency for futures prices to rise ave' the life of the contract. An incentive therefore, exists to produce contract goods ahcial of time at the lowest cost volume and rate of production, and sell them during the mallurn! period by which time the futures price will have risen sufficiently to make the activil: profitable on average. As discussed in Chapter II, the presence of two conditions is mecessiry for production of contract goods to occur. First, potential holders of contracts must be unaware of its occurence, as transactions in goods produced as a result of the existence of 
an incomplete futures contract generate ex post losses to traders. Under full information. the asscoiated trading losses cannot persist in equilibrium as they may be avoided by dealing in the regular cash market. Sccond. the level of open interest in the contract market must be sufficient to sustain the level of planned deliveries. Given the assumed properties of the cost function, any constrained volume effects may serve to raise production costs sufficienty to make planned production of contract goods unprofitable (even for risk neutral traders). Absent either of these two conditions, futures price movements will follow the pattern identified in (i).

\section{c: The Maturily Effect and Spread Volatillty}

Thin analysis consciously ignores the possibility that contract goods are produced for delivery. Altention is primarily concentrated upon the consequences foi spread portfolio volatility of:

(i) an increase in the level of arbitrage indeterminacy dictated by the approach of the maturity period of its constituent contracts, and

(ii) tranges in spread length. The reader is left to judge whether the restrictions so imposed in the generality of the analysis preclude its usefulness.

Ihe effects of time to maturity on spread volatility are first summarised in a simple form amenable 10 empirical tesling. The fact there is no range of arbitrage indeterminacy in

their futures price i.e. $\sigma_{\downarrow}^{2}=0$. implies spread positions in conuacts with specifications exacty duplicating the governance structures in price taking cash markets will exhibit no systematic tendenty for changing volatility with the approaching maturity of their constituent contracts. An! variability in spread positions arises simply frrm unexpected changes in the parameters c(imvituting marginal net carrying cos!s.

The propertics of spread contracts relating to price searching cash markets evidence two reletant leatures. Farlier discussion maintained $\partial \sigma_{\psi}^{2} / \partial\left(T_{i}-1\right)<0$, which as $\operatorname{var}\left(S_{12}\right)=\sigma_{\downarrow}^{2}$ 
implies $\partial \operatorname{var}\left(\mathrm{S}_{12}\right) / \partial\left(\mathrm{T}_{\mathrm{i}}-1\right)<0$. This provides the lirst testable implication of the analysis:

Hl: For contracts relating to price searching cash markets, the lariability of a yreut portfolio increases with the approach of the maturity period of its component contracts.

The form of the model also permits conjectures as to the relative volatulity of the spreads constituent contracts as the! approach maturity. Prior analysis addressed to the discussion of the production technology underlying the cost function. dictates that increases in the range of arbitrage indeterminacy will first manilest themselves in the nearby lutures proce $f\left(L, T_{1}\right)$ comprising the spread. This has implications for the distribution of $0_{\psi}^{\text {? arms }}$ contracts. Specifically. if one assumes that the cost function for deliverable goxuls depends on remaining lime to maturity $\mathrm{T}_{\mathrm{i}}^{-1}$ and is independent of the lime of year during which production takes place, increases in the variance of the idiontucratc component $\sigma_{\psi}$ over inc time interval $T_{i}^{-t}(i=1,2)$ will have a greater impact on the open contract variability of the nearby relative to the distant future. implying $\alpha^{2}>\beta^{2}$. From equations (3.10) and (3.11) inc derived testable implication is:

H2: The ratio nearby/distant open contract price volatility var $\left(F_{1}\right) / v a r\left(F_{2}\right)$. will be pustively related to spread variability.

\section{d: Further Implications}

A.B. Paul (1986) reports:

"a curious statistical finding. During the last lew wecks of trading in moxt commodity futures contracts, there has been an unmistakable lendency for their prices to rise relative 10 prices for the next maturity.. Specilically, an analyss of data for twenty-two contracts... show that in two-thirds of the cases the price of the expiring contract has risen selative to the price lor the nex1 maturing futures by a small but statistically significant and financially rewarding amount"s

Paul christens this phenomena the liquidation bias in futures price spreads, and allsibutes is occurence to one (or some combination) of four possible explanations (i) an inventory 
syluecs: (ii) a delivery tupense ryueere: (iii) a congental weakness on the demand side of the market; and (IV) the lact futures prices behave like cash prices during the delivery month of the futures contract." Although cxpressing a be the final reason (iv) may be a major explanation for the liquidation bias. Paul recognises it cannot apply to non-storables or to commodities with non-overlapping trading and delivery periods.

This cssay building on McManus and Acheson (1979. 1983) identifies a fifth alternative. We argue that understanding the measurement costs thherent in futures trading provides a key to unloxking the possible source of certain statistucal regularities that have been identified in commodity futures price movements. The liquidation bias identified by Paul is one such paltern. The Paul vludy determined the average percentage-point increase in the relative price of the nearby to the distant fulure, was significandy greater than unity in:

(i) three of the twenty-two contracts examined, over the period from the fifth to the seventh weck prior 10 the end of trading in the nearby contract.

(ii) four of the Iwenty-two contracts. in the period from the lifth to the third week prior 10 the end of trading, and

(iii) liflecen of the Iwenty-two contracts. from the third to the first week before the end of the trating period.

In nunc cancs the increase in the nearby price was between $0.25 \%-0.75 \%$ of the distant, in Iwo calces betueen $11.75 \%$ - $1.25 \%$ and in four cases between $1.25 \%$ - $4.00 \%$. Gains 10 spread Iraders with long positions in the nearby contract would have been substantial if they did not pay commissions i.e. if they were exhange member-brokers.

The cmpirical widence cited by Paul is consistent with the measurement cost model if crtann conditions hold. First, all the commodities showing evidence of the liquidation bias must trade in price searching cash markets. Given the measurement cost model maintains the major lactor excasioning the relatuve increase in the nearby futures price is the rise in the unper bound of the range of arbitrage indeterminacy impacting on its settement price, Paul's 


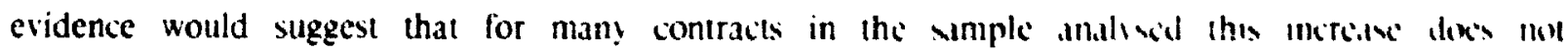

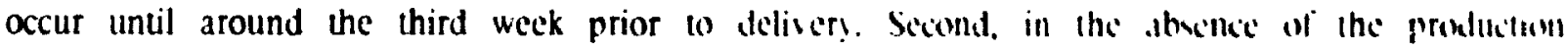
of contract goods. at/by the commencement of the telivery perionl, the range of arbirnge indeterminacy will disappear. Thus, the measurement hypothesis implies the liquidatuon mas effect is absent during times when trading and deliver! overlap. Sullicient comdltuons for the two explanations to be complementary are cither:

(i) that trading in the commodities in Paul's sample cepires prior to the deliser! peronl (c.g. potatoes), or in situations where this requirement is not met.

(ii) the relative price increase constituting the liquidation bias ociurs prior to the lchurs period of the contract.

ldeally, one would like to be able to infer from this dixilusion wme comblete predictions regarding the relationship between upread length and pread voldtility. whish evidently depends on the interaction betueen $T_{2}-T_{1}$ and $T_{1} t$. Infortumatcly no dear (uI hypothesis emerge from the model in its present form, unles $\Gamma, I$ the time at which the range of arbitrage indeterminact in the distant contract begins to increase exceds, I, I, A this is more likely the closer together the contracts mature, ance mat hypuhewe

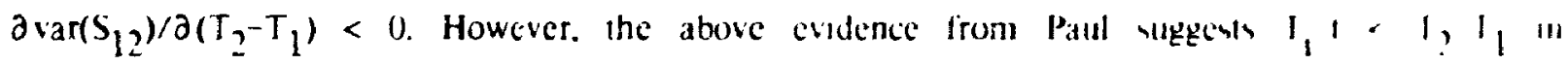
which case the model remains agnowic as to the vign of $\partial \operatorname{var}\left(S_{1}\right) / \partial\left(I_{2}, I_{1}\right)$.

\section{II: AITTRNATIVF. HYPOTHFSIS RFGARIDING SPRHAI) HFHAVIOL:K}

\section{a. The Malurity Theory}

One may compare the empirical implicatuons of this meisurement cost theors if commodity spread behaviour with the alternatives currently esisting in the fllerature. (iatclimos and Vora (1984) utilise Samuelson's (1965) model of futures proce volatulity is construct t well-defined hypothesis for the bchaviour of commodily preads. Therr theory. ourluned beten. 
14 dependent upen iwo restrutive assumpuons. first, the stochastic process characterising spol prices mast be of a speulic form. In particular, the non-deterministic component of spot prices must follow the mean-reverting process:

(1.1) $\vec{p}_{1}=a p_{1} 1+\tilde{\mu}_{1}$

where:

(1) $\bar{p}_{1}=$ the non-deterministic component of the spot price at ime 1

(II) $\quad a$ = damping lactor $<1$

(iii) $\quad H(\tilde{\mu})_{1}=0 H\left(\tilde{\mu}_{1}, \tilde{\mu}_{1+n}\right)=0$ if $n \neq 0 .=\sigma_{\mu}^{2}$ if $n=0$.

sccoms. flllures press must be unbiased estimates of espected spot prices at maturity. such thit the non determmmule component of the futures price obsersed at time t, for a contract malurung al lume T. W guren by:

(t..2) $\left.\quad\left(1, I_{1}\right)=H_{1}\left(M T_{1}\right)\right)$

Civen thexe swumptions. at ume I. the mean and variance of changes in open and spread prmilum are guven by:

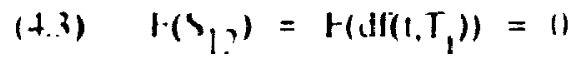

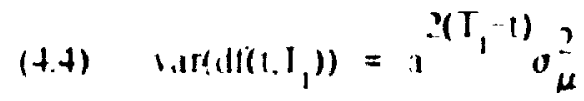

(H.S) $\operatorname{var}\left(S_{1}\right)=a^{\left(I_{1}(-]\right)}\left(1 a^{\left.\left(T_{2}-T_{1}\right)^{2}\right)} \sigma_{\mu}^{2}\right.$

convdered in lerms of mesurement costs, this theory becomes a special case. The unbiasilnew asmption underlying equations $(4.3)-(+.5)$ dictates its relevance is limited to lutures contruls asociated with price takng cash markes, within which spot prices must follow the ypectic process indleated.

10. Inifi. Kulledge (1976) points out that if $a=1$. the spot price follows a random walk. the barance of fulures price changes is constant, and the variance of a spread position W cro. Morcower, alternative specifications of the process generating spot prices, for instance the sciond order defference equation: 


$$
p_{1}-(1+b) p_{1-1}+b p_{1-2}=\tilde{\mu}_{1}
$$

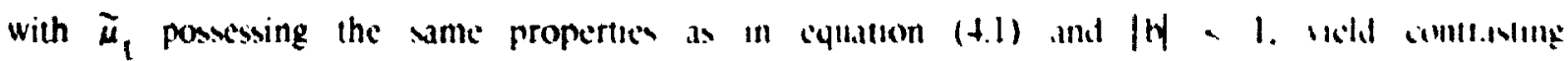
results for the variability of fulures prices. In partucular from (4.6):

$$
\operatorname{var}\left(d f\left(t, T_{j}\right)\right)=o_{\mu}^{2}\left(1-b^{T-1+1}\right)^{2} /(1-b)^{2}
$$

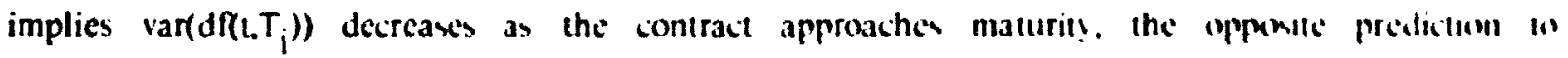
that derived from (t.t).

Noing the theoretical limitations, the cisclino and lora amslyss highlights the influence of three factors simultaneously effecting upread variability in cyuathon (4.i). Ihex: are: (i) the volatility of cash prices. $\sigma_{\mu}^{2}$. (ii) the time left to maturity of the ncurb consract $T_{1}-t$, and (iii) the length of the spread. $T_{2}-T_{1}$. The effects of lume left 10 mallurirs and spread length on spread colatility can be oblaned by differentiatung cquation (4.i) wills respect to $T_{1}-1$. and $T_{2}-T_{1}$ respectively to obtain:

(4.8) $\quad \dot{v a r}\left(S_{12}\right) / \partial t=-2 a^{2\left(T_{1}-(-1)\right.}\left(1-a^{\left(T_{2}-T_{1}\right)}\right)^{2} o_{\mu}^{2} \ln (a)>0$

$$
\left.\partial \operatorname{var}\left(S_{12}\right) / \partial\left(T_{2}-T_{1}\right)=-2 a^{2\left(T_{1}-(-1)\right.}\left(1-a^{\left(T_{2}-T_{1}\right)}\right) a_{\mu}^{2} a^{\left(T_{2} T_{1}\right)} \ln (a)>1\right)
$$

The solatility of the spread increases the closer 10 maturity the nearby contract and the greater the time period between maturits of its constituent contracts. (omparing cquation $(t h)$ with the propositions advanced earlier. the 'maturity' model and the measurement umis menlel yield similar predictions with respect to the effect of time to maturity on spread vitlabilits. if and only if the futures contracts relate to price starching cash markets. When the cash market is price taking. in contrast to cquation (4.8). the n"asurement cost mented implics $\partial \operatorname{var}\left(S_{12}\right) / \partial t=0$. Of course. application of the 'maturity' model 10 price searching wh markets involves something of a paradox. Th1s is because the theory, hy assumption. reytures the current futlises price to be an unbiased estimator of the expecled cash price al contlus maturity. In general. as the measurement cost model makes clear. this could be true enly fon contracts relating to price laking cash markets. 


\section{b: The Convesience Yield Theory}

Prior dixussion indicated the importance accredited to marginal net carrying costs as a determinant of intracontract price spreads for storable commodities. One component of such custs which has altracted evtensive dixcussion, is the tangible benefit derived from having the commoxlly available in inventory. for which Kaldor (1939) coined the term the (marginal) convenuence licte. The sources of the convenience sicld to holding inventory are succinculy dexribed by lelor (1958).

Hirs. the availability of thoks permits a processor or producer to maintain a given level of output at a lower cost than would be required without stocks. similarly. an inventory firm can maintain a given tate of sales at lower cost. sccond, holding stocks permits the rate of production or sales to be varied at a lower comt than would be incurred if the firm attempted to purchase the stocks as the! uere needed. Immediate purchases are more expensive than leisurel! purchases that permit the firm to learn the state of the market and to make the hest Iransiction it can."

Irtm the dexription, it is evident that the marginal convenience yield is a stochastic sarlable. Which arives because holding slocks in inventory can have productive value. The theorclual prediction is that its importance is invetsely related to the stock of the commodity hith in vorage. According to Brennan (1958). "The smaller the level of stocks on hand the gitedter will be the convenience licld of an additional unit." Thus. the marginal convenience mold is ower xme range. cesponsive to changes in the level of inventory. It is essentially ('to for comnokitus when inventory levels are high, and would acquire greater importance in the pricing of vtorable commodities with seasonal supplies, particularly agricultural crops. In the present contev, the espectation is that fluctuations in the marginal convenience yield will hate a more prominent effect on the futures prices of contracts which mature later in the stop 'ycur'. :" Ihus. controlling for the length of spread. one would expect more variability in pread price changes arising from fluctuations in the marginal convenience yield. the closer the delsery perrod of the distant contract to the end of the crop year. Neither the maturity of medsurement theor! contains such a prediction. 


\section{c: The State Variable Hypothests}

Anderson and Danthine (1983) provide perhaps the most general moxtel of futures price behaviour in a multiperiod, partial cquilibrium setting, in which agents make pronluction decisions in the cash market and simultancously assume positions in futures to mavimise the expected utility of end-of-period wealth. During the holding period, production and demand uncertainty are progressively resolved through the realiation of publicly observable randiom variables. Their model demonstrates that the ex ante volatility of littures prices in higher (lower) during the periods when a relatively large (small) amount of supply and demalnd uncertainty is resolved. Anderson (1985) refers to this theory as the slate variable hypothesis.

In its current form. the theory is elegant and theoretically consistent as an explaniltion of price determination. However, the present essay contends that to date it has nol been refined to a form suitable for empirical corroboration. The design of procedures 10 inipleme'nI the hypothesis depends crucially upon assumptions made regarding the specific nature of the supply and demand uncerlainty impinging upon particular commodity markets. Anderson (1485 p.333) proposes that for most commodities, the resolution of uncertainty tends to occur al linc same time during the calendar year, and consequently follows a strong seasonal pallern which should manifest itself in the data. This approach is replete with methodological dangers. Unless one has developed a theory of the scasonal patterns one is attempting $1 \mathrm{f}$ explain, the temptation may be to conclude that the variability is higher at cerlain limes simply because. ex post, that is the time the majority of the information relating to the uncertininly in supply and demand factors must have become publicly available. In this sensc. the state variable hypothesis currently lacks predictive content and is simply dexriptive ol the phenomena it purports to explain. Consider the following:

"Identifying the sources of seasonality in a nonagricultural commodity such as silver is more complex. Since silver stoks are usually large relative is production, the sources of volatily are likely to come mostly from the demand side. Here then is a complex mixture of factors affecling ciemand for last in photographic materials, for jewelry and silverplate. and for bullion as a store of 
value. We lind the net result of these factors tends to be relatively high volatility in May. October and November and relatively low volatility in January. rebruary and March."

In this respect the measurement cost, maturity and convenience yield theories may be considered refinements of the state variable hypothesis allowing for empirical refutation of ex ante predictions. In view of these considerations, the state variable hypothesis is not explicity considered in the remainder of this essay as an independent theory of futures price determination.

\section{III: FMPIRICAI. VFRIFICATION}

\section{a: The Behaviour of Spread Positions in Futures Contracts}

Before the refinement of empirical procedures which attempt to discriminate between the threc models of commodity spread bchaviour outined earlier. a brief summary of prior investigations may help clarify the context and contribution of the current study. Previous analysis of the solatility of spread positions (Meyer (1979), Breeden (1983)), and Castelino and Vora (1984)) either test mechanical trading rules to discover if spread positions can reduce the risk of investors positions in commodity futures contracts, or attempt to identify the relationship between spread length. defined as the number of months between delivery periods of the component contracts, and spread price variability. The studies differ with revict to the nature and number of the markets they analyse, the frequency of observations. the measurement of variability. and choice of statistical tests.

Meyer (1979) derives and tests the profitability of three sets of mechanical trading rules based on the relationship between contract prices and carrying charges for pork-belly spreads orce the 1904-71 period. Lising weekly observations of Friday closing prices for five contract month:: fibruary, March. May. July. August. he concludes not only that spreading would hac bectl profitable for each of the three strategies utilised, but also that spread length is 
positively related to profitability.

Breeden (1983) investigates the relationship between spread colatility and spread length for twelve futures contracts; corn, oats, soỵbeans, soybean oil, soybean meal, wheal, plywerkl. silver, commercial paper. GNMA, GNMA-CD. and Treasury bonds all trading on the ('hicago Board of Trade. The study uses month-end closing prices and examines spreads within the period January 1960 - April 1980. Two measures of variability are adopled: (i) righı cumulative frequency; in which an $x \%$ frequency of Sy means that $x^{\%} \%$ of the months examined showed a price change greater than or equal to \$y. and (ii) spread standard deviations. Breeden concludes that for both measures of spread variability there is a pronounced pattern of significant increases in spread volatility with increases in the spread length. He also indicates that spreads involving contracts nearer maturity tend to be "slightly more variable" than those for distant contracts. ${ }^{13}$ Although his last comment could be interpreted as supportive of the maturity hypothesis, no statistical tests are conducted (1) determine the significance of his results. Moreovel, as the measurement theory would predicl. the pattern is not uniform across commodities and on casual inspection appcars more pronounced in the "thinncr" contract markets.

Castelino and Vora (1984) also examine the relationship between spread volatility and spread length for six contact markets; wheat, corn, soybcans, soybean oil, roybean meal trading on the Chicago Board of Trade, and copper trading on commodity Fxchangc Incorporated (COMEX). Several spreads are constructed, all involving the July contract. Using daily prices, and adopting the variance of spread price changes as the measure of volatility. their study concludes that spread volatility increases as spread length increases. ${ }^{\text {. }}$

The findings of the latter two studies in particular, are consistent with the maturity hypothesis, in that they can be theoretically rationalised using the Samuclson $(196,5)$ model of futures price behaviour. However, they also vindicate other hypothess, including both the measurement cost and convenience yield models. Therefore, as they stand, they (to) not 
lacilitate discrimination among alternative theses regarding the behaviour of spread portfolio volatility. Morcover, the test procedures adopted rely heavily upon the assumption that the standardied sample variances are distributed normally or lognormally. Not only is this assumption open to question, it is also analytically separate from the spread length effect, and should not be part of the maintained relationship. This raises the question of whether the results of the tesis are robust to different assumptions relating to the distribution of futures price changes."

A lurther consideration not previously accounted for also distinguishes the present from prior analyses. Iones (1981) correctly points out that; "spreads and the values of spreads bchave quite dirferently depending upon whether the carry costs are absolute or relative." ${ }^{15}$ Absolute carry costs are fixed dollar costs of carry per unit of time. They depend on the quantity but not the value of the commodity being stored. The main component of such costs are physical storage costs. Relative carry costs are those which depend upon the value of the commodity. The financing costs of both physical and financial commodities are relative carry costs. Their main determinants are the price level of the commodity and the rate of interest. ${ }^{-}$Considerations of the distinction between relative and absolute carry costs introduces a complexity into the analysis of spread behaviour not explicitly accounted for in previous literature. Namely, with relative carry costs, the value of contractual price relationships changes with the level of prices and interest rates as well as with the level of absolute storage costs. Somc market commentators dismiss this phenomena as unimportant. Williams (1986) is typical:

"... movements in storage fees cannot account for the observed volatility of spreads.... Nor are movements in interest rates, and by extension capital costs. large enough to explain the magnitude of movements in spreads....As a first approvimation, therefore. a theory of futures markets can ignore interest expenses and physical storage costs....They are trivial and essentially constant components of spreads." "

Hlthough support for such statements must ultimately be sought empirically, on present sidence one is reluctant to concur with William's contention. In a recent study. Fama and 
French (1987) utilise the theory of storage to identify factors affecting the variability of the basis (the future-spot price differential) over the life of the futures contract. for metals. one commodity classification in which relative carry costs are important, the behaviour of prices is found to be "consistent with the hypothesis that the basis tracks nominal interest rates"." The latter explain $83 \%$ of the six-month variance for gold and $60 \%$ for silver. The analylical similarities between basis and spread volatility are sufficient to merit the conclusion that failure to account for volatility effects of changes in the relative carry cost componemt of spreads could conceivably mitigate the usefullness of the empirical results.

\section{b: Data Description and Test Pracedure}

This study examines the spread behaviour of four commodity contracts: cocoa Iradini on the Coffee. Sugar and Cocoa Fxchange, cotton trading on the New York (ollon Exchange, and copper and silver, both trading on COMLX. The price series were ablained from three sources. The cocoa and cotton data were made available on a magnetic lalpe supplied by the Ceucer for the Study of Futures Markets. Columbia Business Sih(x)l supplemented by issues of the Wall Street Journal. The silver and copper data were transcribed from COMEX statistical yearbooks for 1980-84. Daily closing prices for the lour contracts are used over the 1980-84 period to construct the spreads. As the concerns of the model are with storage (rather than production) arbitrage, the analysis of the coxos alld cotton data is confined to an analysis of spreads between contracts setting in the same crop year. $^{20}$ The crop year for cocoa begins on October lst, for cotton on Scptember lst. The first observation on the price spread is taken the trading day foilowing expiration of the trading period in the distant contract the preceeding crop year. The last obscrvation is lakun the trading day prior to the delivery period of the nearby contract comprising the siprciul. Thus, the study excludes delivery month price observations from calculations of spruad volatility. 
The results are based on estimates of the model:

$$
V_{j, l}\left(S_{12}\right)=a_{0}+a_{1}\left(T_{1}-t\right)+a_{2}\left(T_{2}-T_{1}\right)+a_{3}\left(T_{2}-T_{c}\right)+a_{4}\left(V_{j} d f\left(L T_{1}\right) / V_{j} d f\left(L, T_{2}\right)\right)+u_{t}
$$

where:

i) $V_{j}$ is a measurc of the variability of contract price changes in commodity j. and

ii) $T_{c}$ is the first month of the crop or calendar year.

All the other notation is as previously defined. As in Castelino and Vora (1984) and most other recent studies of futures price volatility ${ }^{21}$, the basic unit of observation is the change in the natural logarithm of the daily settlement price. Spread changes are measured as $\ln \left(f\left(t+1, T_{2}\right) / f\left(t, T_{2}\right)\right)-\ln \left(f\left(t+1, T_{1}\right)_{e} / f\left(t, T_{1}\right)_{e}\right)$. The distant equivalent price, $\ln f\left(t, T_{1}\right)_{e}=\ln \left(t, T_{1}\right)$ $+\ln (1+r . n / 360)$. where $n$ is the number of days between the first eligible delivery day of the Iwo contracts, and $r$ is the actual or implied 90-day Treasury Bill futures price on the International Money Market of the Chicago Mercantile Exchange at time $t$ for a 90-day Treasury Bill deliverable in period $T_{1}:=$

The reason for using log differences is that a priori, one would expect the dispersion of prices 10 change in the same direction as the price level. Using log differences corrects for this obvious source of nonstationarity. This study is the first in the futures literature altempting to explicitly control for changes in the level of relative carry costs arising from price level or interest rate changes during the contract holding period. Evidence solicited from commodity exchange oflicials indicate changes in factors affecting absolute carry costs were insignilicant for the commodities examined over the period of observation."

The choice of a measure of variability to employ raises the perennial question of the nature of the distribution of commodity futures prices. Two tests are performed on the current data sample to characierize spread price changes relative to the normal distribution, namely kilrtosis and the ratio of the range to the standard deviation. The specifics of the Lsts are documented in Hudson. leuthold and Sarassoro (1987), with the results from the present ample given in Table 4.1. The kurtosis test rejects the normality assumption for 
about $46^{\circ}$ of the contracts examined. Cocoa appears to be the ieast normally distributed. the null hypothesis of normality being rejected about $633^{\circ}$ of the tintc. Fumination of indivillual contracts revealed that positive kurtosis occured more frequently than neqative by a fictor of about three to one. These results suggest some degree of leptokurtosis, more obscrvations in the tails than expected theoretically.

As with kurtosis, the cocoa results show the most non-normality of all the commonllics in tests using the ratio of the range to the standard deviation. (For more information on this test see David. Hartley and Pearson (1954)). As distributions with an escessive number of extreme observations in either tail translate into a high $R / S$ value. this test may bow more normality than the kurtosis test, as triggering of daily price limits could prevent price moves of the magnitude required by the informational shock occasioning them. The $\mathrm{R} / \mathrm{S}$ test indicates that about $62 \%$ of the spread distributions studied could be classificd as normal.

As a consequence of these relatively inconclusive results, two measures of variability .tle utilised in this study. First, results based oai the variance of daily price changes are reprerled. It is recognised that if futures price changes are not (log) normally distributed, and insleid conform to a member of the non-Gaussian family of distributions better than to the nummill distribution, then the sample variance is an inefficient measure of volatility. Despitc the qualifications, the variance is utilised as that is how the maturity and measurement cosis hypothesis are derived.24 Moreover, many recent studies (astclino and Vora (1984). Anderson (1985), and Milonas (1986) included, are similarly undeterred by these consideratums and also adopt the variance. Use of the same dispersion measurc facilitates comparism of results. To corroborate findings obtained using the variance, a measure of variability biscil upon the .28 to .72 interfractile range is also constructed, following the procedure in liallia and Roll (1968, 1971). This measure of variability has been incorporated into recent studes, notably by Miller (1979) and Grauer (1977). They lind largely the same pallurns of dispersion for interfractile ranges as for variances. 
Ihe variability measures are obtained by fooling price observations from a single contract lor a single calendar month, of a single year. In effect the assumption is that the daily log changes of futures prices conform to a stationary distribution within the month, but are nonstationary over time periods greater than one month. This is consistent with models of asset price determination, to the degree that these models do not imply the mean and variance of prices change drastically over short time intervals. One could specify a model in which the distribution of the log change of daily prices varied gradually (daily) over time. Implementation of this approach requires specification of the functional form of the time path of the mean and variance of the distribution. This introduces a possible source of misspecification bias.

The vector of independent variables utilised in the study is defined as follows:

(i) $\mathrm{T}_{1}^{-1}=\mathrm{MAT}=$ time. in months to maturity of the nearby contract comprising The spread.

(ii) $T_{2}-T_{1}=$ SI.ENGTH $=$ the number of months between the first delivery day of the component contracts constituting the spread.

(iii) $T_{2}-T_{C}=$ CONVEN $=$ the number of months into the crop (calendar) year the distant contract in the spread matures.

(iv) $\operatorname{Vdf}\left(\mathrm{t}_{\mathrm{T}} \mathrm{T}_{1}\right) / \mathrm{Vdf}\left(\mathrm{I}, \mathrm{T}_{2}\right)=\mathrm{RATIO}=$ the ratio of the price volatility (appropriately measured) of the nearby to the distant contract comprising the spread.

The rationale for the inclusion of the MAT and SI.FNGTH variables has been wplained. The maturity hypothesis would espect $a_{1}$ to be negative in equation (4.10). while the measurement cost hypothesis states that for contracts relating to price searching cash matkets $a_{1}<$ (), but for those pertaining to price laking cash markets $a_{1}=0$.

The coeflicient on the spread length variable $a_{2}$ is expected to be positive under the Illalurity hypothesis. Unfortunately, both the measurement cost and convenience yield theories are agnostic regarding the sign of this estimate. 
The CONVtN variable attempts to capture the effect of lluctuations in the matemsl convenience yield. The convenicnce yield model argues this lariable will have a more pronounced effect on futures price volatility the later into the crop lear the contract matures as this is when inventories are low and the variable assumes prominenic. Thus, for worable commodities expected to possess a convenience tield, cocoa and cotton in the present stul!. $a_{3}$ is expected to be positive."

Finally, the RATIO variable attempts to further discriminate between the maturity and measurement cost hypothesis. The former requires $a_{4} 10$ be positive for all four contrack. a it evolves from the Samuelson (1965) model which specifics (using the notation of cyllutoul (4.10) that:

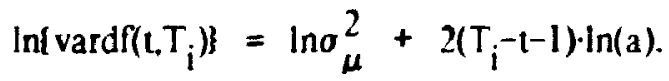

Thus:

$\partial \ln \left(\operatorname{vard} f\left(\mathrm{t}, T_{i}\right)\right\} / \partial\left(T_{i}-\mathfrak{l}\right)=2 \ln (\mathrm{a})<0$.

In effect, testing the maturity hypothesis involves iesting the joint restriction $a_{1}<11 . a_{4}$. 11 . The measurement costs hypothesis also predicts $a_{4}>0$ for contracts relating lo phec searching cash marke.s. However. the sign of $a_{4}$ for futures contracts in which the reliteil cash market is price-taking, depends on the assumption one makes concerning the behavium of $\sigma_{\phi}^{2}$ over the life of the contract. For theoretical tractability, the preceeding analysis hell $\sigma_{\phi}^{2}$ to be time independent. If this assumption is relaxed. then $a_{4}$ would be $>(1$ (r. (1) if one believed $\partial \sigma_{\phi}^{2} / \partial\left(T_{i}-1\right)<0(>0)$.

\section{c: Classification of Cash Markets}

With respect to the four contracts in the current data sample. can anytheng construcliwe be ascertained regarding the extent to which their pertinent cash markets may be said lo be price laking or price searching? This information would at least enable the formulation if! prior conjectures as to the significance of the parameters in equatuon (4.14). (wI) considerations are relevant. The first relates to the empirical results of chapter 3 . Ihcre 11 
was argued $\delta_{j}$. the ratio of the level of open to spread position initial speculative margin requirement is inverscly related to the comparative disadvantage of transacting via futures, or the degrec 10 which the relevant cash market is price searching. The computed values of $\delta_{i}$ for the present four commodities are cocoa 2.75. cotton 3.1. while copper and silver must simply be marked to market daily. This suggests that the futures contracts are better able to duplicate cash market trading nıethods in silver and copper than in cocoa and cotton.

Supporting evidence is presented in Garbade and Silber (1983) in their discussion of the structure of premiums and discounts for non-par delivery. They maintain that the use of cyuivalence systems in futures contracts to determine non-par pricing rules is used when the underlying attribute of the commodity on which the differential is based "can be isolated through a technological extraction process." in In the terminology of this essay, this corresponds 10 a traders ability to measure the valued attributes objectively. Thus, the more contractually complete the futures contract, the greater its ability to adopt equivalence systems in its settlement procedures. Both the silus and copper contracts on COMEX utilise equivalance swem pricing for nonpar deliveries. while the cocoa and cotton contracts adopt fixed (non-commercial) differentials, or what Garbade and Silber term a penalty system. Recalling the comments made in the introduction to chapter 3 , one would. a priori, expect the Idios!nctatic element of contractual price variability to be larger in the two latter than the 1wo former contracts. With these considerations in mind, one may tentatively refer to the vilver and copper cash markets as price taking, and the cocoa and cotton cash markets as price varching.

\section{d: Eimpirical Results}

What follows are the results of the parametric tests of equation (4.10) based on least yuares estimation procedures. The principal reason for adopting a parametric approach is that it allow, the emplotment of statistical tests that have greater power than the nonparametric approaches (chiclly Rank tests) cmbraced by other researchers addressing related issues. The 
approach has a further adrantage in that it alıments ones abulity in introxluce adilition.t factors that are believed to influence futures price bolatility. the inloraction of which sinnol be accommodated by rank tests.

Before discussing the results. I draw the reacters attention to a potentially importumt source of nonstationarity bias, arising from the fact that the information thow into the contract market is not random. This effect is perhaps more pronounced lor scasolial commodities as forecists of crop sizc, inventory levels and stuch, are made at specilic limes during the vear by government agencies and independent analysts. As mentionced cirlier in discussion of the state variable hypothesis. one may expect the effect of the information flow is to create increased price volatility at around the lime the information becomes public.

A procedure to correct for these effects, suggested in Castelino (1981). and IItilised in this study, is to divide the spread price variability measure by the geometric average price variability of its component contracts:- The underlying assumption is that the variability of each futures price is subject to a uniquely defined information set. which is a function af the current time period $t$, and the maturity period of the contract $T_{i}$ Ihis fiuncliun is assumed to be the same across crop vears. This normalising procedure allows the variability measure to be independent of the month and year in which it is estimated.

The results of the linear regressions are reported in Tables (4.2) - (4.5). H-or ihe iwo contracts cocoa and cotton to which a price searching cash market is tentatively ascribed. the signs of coefficient estimates are largely in conlormuly with both the malurity and measurement cost hypothesis. The t-statistics (given in parcntheses) suggest that the MAl. SLFNGTH and RATIO coefficients are significandy different from rero al a $5 \%$ level of significance. The only exception is the MAT variable for the normalised variance cuualuen in cocoa, which although of the expected sign is not significantly different from /ero. 
Ihe convenience ficld theory performs relatively poorly. In cocoa, the estimated coxflicients are pmitive as the theory predicts, but in ail cases appear insignificandy different from /cro. In the cotton equation. all the estimates are of the opposite sign to that predicted. and in one case (cotton(4)) significanty so, suggesting spread volatility diminishes as the maturity date of the distant contract approaches the end of the crop year. The templation: is 10 conclude that at least for cotton and cocoa, fluctuations in the marginal convenience yield are not empirically important as determinants of the volatility of commodity spreads.:"

The more interesting results are those relating to the silver and copper contracts. Potentially they enable one to discriminate between the maturity and measurement cost hypothess. Perhaps the most striking conclusion to be drawn on examination of the findings. is that the results appear sensitive to the measure of volatility employed. Consider the silver results in Table (4.4). Lising the variance as the variability measure, they apparenty lend trong vipport to the maturity hypothesis. However. the estimated MAT coefficient in the normalised interfractile range equation, silver(4), is insignificanty different from zero as the measurenent cost hypothesis would expect. The coefficient on MAT in the non-normalised interfractile range equation. silver(3), would suggest silver spread volatility decreases significantly with time to maturit! of the nearby contract, a result neither theory can explain. The SI.NGTH coefficients are signed in accordance with the maturity model. Thus. it appears the barance results are in conformily with the maturity model, and the interfactile range "Nimles are elther ambiguous, or support the measurement cost model. As an attempt to assess the validity of either theory. one must conclude the silver results are somewhat inconclustre.

With the copper regression estimates, a clearer pattern emerges. Three of the four MAT corficients arc insignificandy different from tero. which supports the measurement cost hipuhiss. The fourth. copper(i) is significanty positive. corroborating neither model. As for 


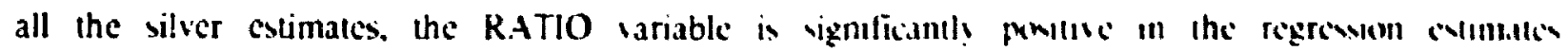

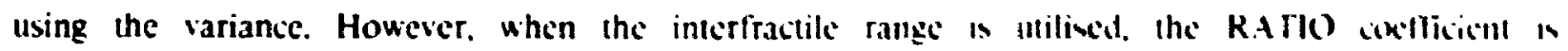
insignificantly different from aro. In the contevt of the prenent mokdel, the behasiour of th: RATIO variable in silver and copper is difficult 10 enplain. One plausble suggewson s th.tt seasinal factors may account for its behaviour. as the state lariable hyputhesis would levil one to believe. Once again in the copper equations, the SI HNCTH variable is ugmiticant and positive as expected under the maturity hypothesis. However. given the SI FNeilH variatle is not the critical one for purposes of hypothesis discrimination. the copper results mats lic interpreted as supportive of the measurement cont as opposed to the malurily hypithess.

The findings of this analysis may be briefly compared to thowe of other related slidies employing the same commoditics. Rutledge (1976) conducts a lest of the hyputheris of an inverse relationship between open contract price lariability and time 6 malturnt implicel th the process described in equations (4.1) - (4.4). He IIS' daily price obererustions, and measures variability as the absolute value of (log) price differences. A gomeness of iil test lor a three-way contingency table is employed, with data grouped by colaulity of cush prisc. volatility of futures price and time to maturily. He accepts the samuclusn hipsthess len cocoa and silver, which is consistent with our findings for the former commonlutv. and tor the latter employing the variance as the volatility measure.

Grauer (1977) using month-end idtures prices for open contracls in len commonlitics. one of which is silver, rejects the Samuclson hypothesis. Adoptung the varbance and the interquartile range as the variability measures, the study derres friedman' non paramerse lest statistic for a two way analysis of variance. The present slver sesulls with ihe interfrictule range volatility measure are consistent with his conclussons.

Finally. the universal posiuve relationship between spread length and spread wolatili. confirms the lindings of Breedan (1983) for slver, and Castclino and Vora (lek4) for coppes This study provides additional positive evidence for the relatuonship in the case of coxos anst 
collon. 


\section{Table 4.1}

Kurtosis and Ratio of Range to the Standard Deviation lests

\begin{tabular}{|c|c|c|c|}
\hline Commodity & $\begin{array}{c}\text { Number of Spread } \\
\text { Distributions }\end{array}$ & $\begin{array}{l}\text { Number } \\
\text { Kurtosis }\end{array}$ & $\begin{array}{l}\text { Fuhibiting } \\
k / S^{b}\end{array}$ \\
\hline Cocoa & 46 & $29(63 \%)$ & $22\left(48{ }^{\circ}(0)\right.$ \\
\hline Cotton & 43 & $21 \quad\left(49 \sigma_{0}\right)$ & $17\left(H r^{\prime \prime \prime}\right)$ \\
\hline Silver & 54 & $18(33 \%)$ & $16\left(3\left(k^{\prime \prime}\right)\right.$ \\
\hline Copper & 54 & $24(44 \%)$ & $19\left(34^{\prime \prime} 0\right)$ \\
\hline
\end{tabular}

a: All tests were concluded at a $0.01 \%$ level of significance.

$b: R / S$ is the ratio of the range to the standard deviation. 
Table 4.2

linear Model Results: Cocoa Spreads

\begin{tabular}{|c|c|c|c|c|}
\hline $\begin{array}{l}\text { Independent } \\
\text { Variable }\end{array}$ & Cocoa (1) & Cocoa (2) & Cocoa (3) & Cocoa (4) \\
\hline INTHKCEPT & $\begin{array}{c}-7.173-05 \\
(-6.93)\end{array}$ & $\begin{array}{l}-0.2594 \\
(-8.22)\end{array}$ & $\begin{array}{l}-0.0012 \\
(-2.66)\end{array}$ & $\begin{array}{l}-0.1605 \\
(-3.34)\end{array}$ \\
\hline MAT & $\begin{array}{c}-1.141-06 \\
(-1.98)\end{array}$ & $\begin{array}{c}-0.00113 \\
(-0.61)\end{array}$ & $\begin{array}{c}-1.458-04 \\
(-6.18)\end{array}$ & $\begin{array}{c}-0.0598 \\
(-4.01)\end{array}$ \\
\hline SILNC;TH & $\begin{array}{c}2.795-06 \\
(2.93)\end{array}$ & $\begin{array}{l}0.0120 \\
(4.15)\end{array}$ & $\begin{array}{c}4.217-04 \\
(11.44)\end{array}$ & $\begin{array}{l}0.0342 \\
(9.47)\end{array}$ \\
\hline CONVTN & $\begin{array}{c}7.165-07 \\
(1.00)\end{array}$ & $\begin{array}{c}0.00175 \\
(0.79)\end{array}$ & $\begin{array}{c}2.411-05 \\
(0.71)\end{array}$ & $\begin{array}{l}0.0049 \\
(1.58)\end{array}$ \\
\hline RATIO & $\begin{array}{c}5.570-05 \\
(7.99)\end{array}$ & $\begin{array}{l}0.2151 \\
(10.38)\end{array}$ & $\begin{array}{c}6.00101 \\
(3.73)\end{array}$ & $\begin{array}{l}0.1254 \\
(4.27)\end{array}$ \\
\hline $\mathrm{R}^{2}$ & 0.63 & 0.66 & 0.60 & 0.54 \\
\hline $\begin{array}{l}\text { F-STAT } \\
(4 / 305)\end{array}$ & 30.80 & 50.34 & 42.12 & 31.96 \\
\hline 1) $w$ & 1.99 & 1.99 & 2.11 & 2.02 \\
\hline$S H K$ & $2.11-05$ & 0.0629 & $8.29-04$ & 0.0884 \\
\hline SSR & $1.350-07$ & 1.205 & $2.089-04$ & 2.374 \\
\hline NOH & 310 & 310 & 310 & 310 \\
\hline
\end{tabular}

The following cocoa spreads are analysed: Dec-Mar.: Der.-May; Dec.-July; Dec.-Sept; Mar.-May: Mar.-July: Mar.-Sept: May-July; May-Sept.; July-Sept.

The lirs price observation is taken on the March 1980 -May 1980 spread on 1 June 1979. The las, on the July 1984 -Sept 1984 spread, on 30 June 1984. 
Table 4.3

Linear Model Results: Cotton Spreads

\begin{tabular}{|c|c|c|c|c|}
\hline $\begin{array}{l}\text { Independent } \\
\text { Variable }\end{array}$ & Cotton (1) & Cotton (2) & Cotton (3) & Collon (4) \\
\hline INTERCEPT & $\begin{array}{c}-1.705-05 \\
(-2.04)\end{array}$ & $\begin{array}{c}-0.10047 \\
(-2.67)\end{array}$ & $\begin{array}{c}0.00139 \\
(3.02)\end{array}$ & $\begin{array}{l}-(0.1516 \\
(-1.85)\end{array}$ \\
\hline MAT & $\begin{array}{c}-1.0784-06 \\
(-2.05)\end{array}$ & $\begin{array}{c}-0.00598 \\
(-2.38)\end{array}$ & $\begin{array}{c}-1.055-05 \\
(-4.34)\end{array}$ & $\begin{array}{c}-0.01669 \\
(-3.07)\end{array}$ \\
\hline SLENGTH & $\begin{array}{c}4.548-06 \\
(4.44)\end{array}$ & $\begin{array}{c}0.01965 \\
(5.67)\end{array}$ & $\begin{array}{c}2.53-1) 4 \\
(4.95)\end{array}$ & $\begin{array}{l}0.0435 \\
(4.79)\end{array}$ \\
\hline CONVEN & $\begin{array}{c}-3.769-07 \\
(-0.46)\end{array}$ & $\begin{array}{c}-0.00176 \\
(-0.68)\end{array}$ & $\begin{array}{c}9.303-0.5 \\
(-2.07)\end{array}$ & $\begin{array}{c}-0.0070) 8 \\
(-1.03)\end{array}$ \\
\hline RATIO & $\begin{array}{c}1.134-05 \\
(4.35)\end{array}$ & $\begin{array}{l}0.1791 \\
(12.20)\end{array}$ & $\begin{array}{c}6.481-(04 \\
(2.73)\end{array}$ & $\begin{array}{l}0.2797 \\
(6.59)\end{array}$ \\
\hline $\mathrm{R}^{2}$ & 0.58 & 0.59 & 0.57 & 0.62 \\
\hline $\begin{array}{l}\text { F-STAT } \\
(4 / 212)\end{array}$ & 14.847 & 59.96 & 9.24 & 19.91 \\
\hline$D-W$ & 2.12 & 2.01 & 2.15 & 1.44 \\
\hline SER & $1.53-05$ & 0.0794 & $8.77-04$ & 0.156 .5 \\
\hline SSK & $4.948-08$ & 1.329 & $1.62-114$ & 5.171 \\
\hline NOB & 217 & 217 & 217 & 217 \\
\hline
\end{tabular}

The following cotton spreads are analysed: Oct-Dec: Oct-Mar: Oct-May: Oct. luly: Dec.-Mar.; Dec.-May; Dec.-July: Mar-May; Mar.-July; May-July.

The first price observation is taken on the March 1980 -May 1980 spread on 1 lunc 16,7", The last on the May 1984 -July 1984 spread, on 30) April 1984. 
Table 4.4

L.inear Model Results: Silver Spreads

Independent

Variable

Silver (1)

Silver (2)

Silver (3)

Silver (4)

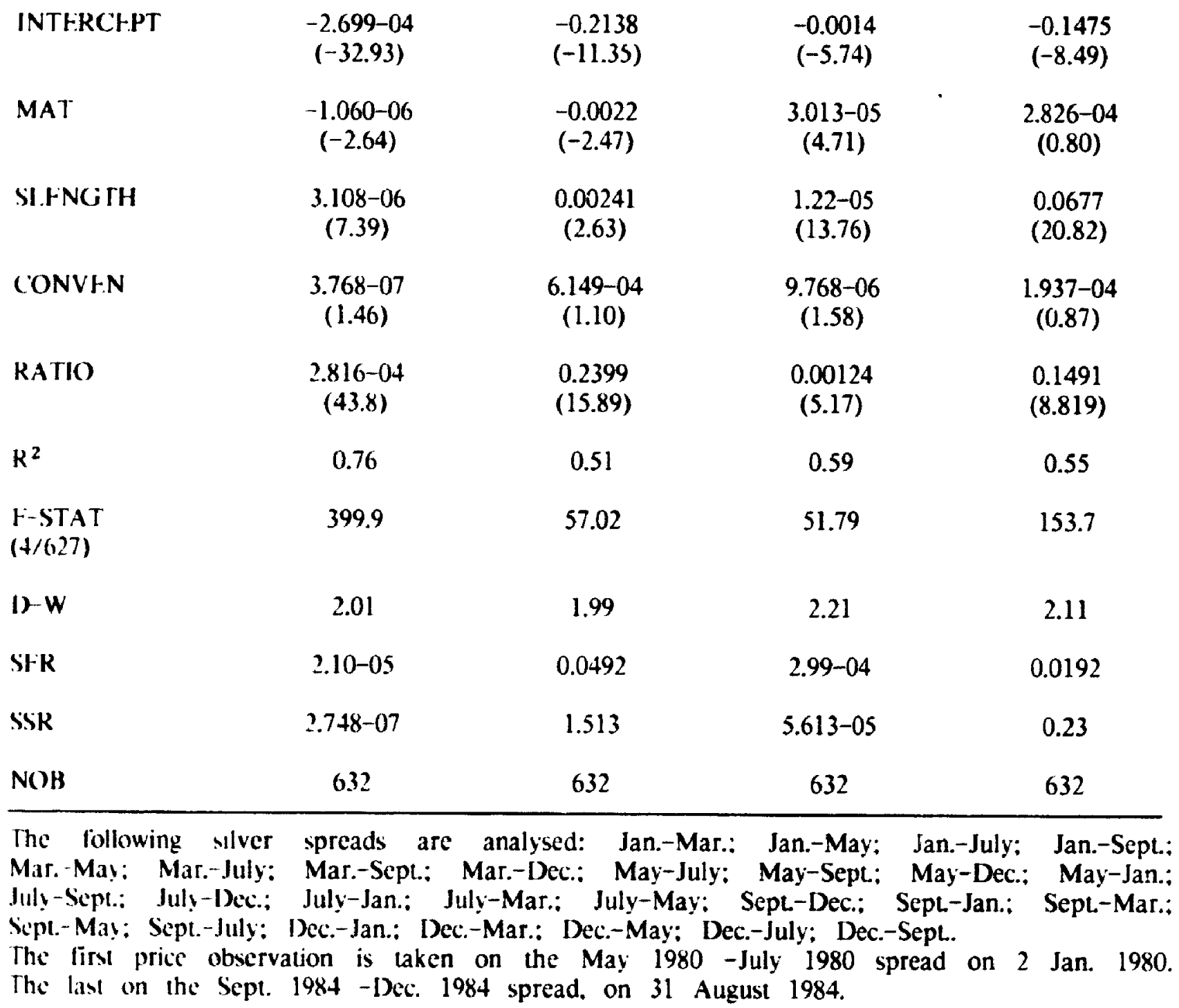


Iable 4.5

linear Model Results: Copper Spreads

Independent

Variable

Copper (1)

Copper (2)

Copper (3)

Copper(4)

\begin{tabular}{|c|c|c|c|c|}
\hline INTERCEPT & $\begin{array}{c}-2.457-04 \\
(-5.11)\end{array}$ & $\begin{array}{r}-0.293 \\
(-4.97)\end{array}$ & $\begin{array}{c}1.4(08-044 \\
(0.52)\end{array}$ & $\begin{array}{r}-0.0294 \\
(-0.84)\end{array}$ \\
\hline MAT & $\begin{array}{c}1.183-05 \\
(1.7)\end{array}$ & $\begin{array}{l}0.0112 \\
(1.08)\end{array}$ & $\begin{array}{c}2.479-05 \\
(2.2)\end{array}$ & $\begin{array}{c}0 .(x) 138 \\
(1.01)\end{array}$ \\
\hline SLENGTH & $\begin{array}{c}1.033-05 \\
(3.51)\end{array}$ & $\begin{array}{c}0.00762 \\
(1.38)\end{array}$ & $\begin{array}{c}1.808-04 \\
(13.55)\end{array}$ & $\begin{array}{l}0.0199 \\
(12.65)\end{array}$ \\
\hline CONVEN & $\begin{array}{c}7.117 .06 \\
(2.61)\end{array}$ & $\begin{array}{c}0.0059 \\
(1.78)\end{array}$ & $\begin{array}{c}1.479-05 \\
(1.75)\end{array}$ & $\begin{array}{c}0.001199 \\
(2.01)\end{array}$ \\
\hline RATIO & $\begin{array}{c}8.402-05 \\
(12.31)\end{array}$ & $\begin{array}{l}0.1785 \\
(21.31)\end{array}$ & $\begin{array}{c}-4.123-04 \\
(-1.7)\end{array}$ & $\begin{array}{c}(1.11 .14 \\
\text { (11.71) }\end{array}$ \\
\hline $\mathrm{R}^{2}$ & 0.51 & 0.59 & 0.45 & 0.45 \\
\hline $\begin{array}{l}\text { F-STAT } \\
(4 / 627)\end{array}$ & 34.02 & 92.6 & 43.62 & 41.74 \\
\hline$D-W$ & 2.00 & 2.06 & 2.23 & 2.12 \\
\hline SER & $2.42-04$ & 0.297 & $5.38-104$ & 0.06604 \\
\hline SSR & $3.668-05$ & 5.5227 & $1 . x 13-04$ & 2.76 \\
\hline NOB & 632 & 632 & 632 & 6.32 \\
\hline
\end{tabular}

The following copper spreads are analysed: Jan.-Mar.; Jan.-May; Jan.-July; Jan. Sipl.; Mar.-May: Mar-July; Mar.-Sept.; Mar--Dec:: May-July: May-Sept.; May IDec:; May lant: July-Sept: July-Dec.; July-Jan.; July-Mar.; July-May: Sept-1)ec; Sept.-Jan.: Sept. Mar.: Sept-May; Sept-July: Dec.-Jan.; Dec.-Mar.; Dec-May; Dec--July; Dec--Sept..

The first price observation is taken on the May 1980 -July 1980 spread on 2 Jan. I9x(1). The last on the Sept. 1984 -Dec. 1984 spread, on 31 August 1984. 


\section{HOOTNOTHS}

1. Williams (1986 p.22). Peck (1981) expresses similar sentiments.

2. Sec Williamson (1979) and Barzel (1982) for a discussion of this literature.

3. If demand uncertainty dominates supply, and if factors affecting ultimate demand are supject to progressively larger shocks as the demand date approaches, one may expect $\sigma_{d}^{2} 10$ increase overtime. This is clearly a special case and cannot be rationalised in the present context. Stein (1979) constructs a model where open contract price variability increases as the delivery date approaches. Also see Samuelson (1965, 1976)

4. McManus and Acheson (1979 p. 49f. 1983 p. 15n. The exchange may have the option of using relatively more expensive objective measures as proxies for the cicluded subjective, personal measures to define a product equivalent to that traded in the regular cash market. As contract goods deliverable become more narrowly defined, the contract becomes increasingly susceptible to corner problems. Evidience indicates (Garbade and Silber 1983b) that exchanges commonly incorporate the objective measures used in cash trading supplemented with little else when specifying deliverable goods. not wishing to impose higher costs on traders than they would incur in regular spot trading. Consequently, the implications of such (costly) complete contracts are ignored in the remainder of this essay.

5. A.R. Paul (1986 p. 313).

6. The third explanation could be interpreted as a version of the Keynes-Hicks theory of normal backwardation in which commercial interests hedging inventories, who are typically net short. pay a risk premium to speculative longs as an inducement to take the opposite side of the transaction.

7. Hoth of these assumptions are open to criticism. The assumption of a first-order autoregtessive process for spot prices is very restrictive, and is not supported cmpirically (sce Labys and Granger. 1970 ch.3). Samuelson (1976) constructing an exact crgodic model weakens his own earlier proposition by establishing that for very long-lived futures contracts, the variance of the contractual price changes when delivery is very distant will necessarily be less than the variance of the same contract sufficiently close to delivery. This prediction is much less precise, and its empirical usefulness questionable. Non-stationacity of cash prices (including trends), causing $\alpha$ to ciceed unity. or nonconstancy in $\sigma^{2}$ over time will also violate the results. (Ruttedge (1976). Miller (1979). Anderson (985)). Finally. Cox, Ingersoll and Ross (1978) demonstrate the hypothesis that the current futures price equals the expected spot price at contract maturity does not generally hold for a wide class of assets. A similar conclusion, for contracts relating to price searching cash markets is obtained utilising a measurement approach in McManus and Acheson (1979). Nevertheless, it maybe of interest to test the Castelino and Vora hypothesis in its own right, the approach taken in this chapter.

8. Telser (1958 p. 253$)$

9. Brennan (1958 p.54). French (1986 p.S4l) is more precise. maintaining that "at low inventory lavels, the convenience yield is relatively high. As the inventory rises, the marginal convenience sield falls at a decreasing rate." 
10. From the description, it is evident that the marginal convenience vicld is a wh-hislle variable which arises because inventory can have productive value. The theoretical prediction is that its importance is inversely relaled to the sloxk of the commonlit! held in storage. Clearly, incorporating the influence of the convenience vicld. there is no presumption that the net carrying costs premium is positive, a conclusion Kalilor (1939. p.3) expresses in general terms stating:

"stocks of all goods possess a yield...and this yield which is a compensation to the holder of stocks, must be deducted from carrying costs proper in calculating net carrying costs. The latter can, therefore. be negative or positive."

Indeed, the phenomena of negative net carrying costs, or markel inversion $(f(1, T)<$, $\mathrm{f}\left(\mathrm{t}, \mathrm{T}_{1}\right)$ ) has been extensively documented and discussed in the literature. much of the clearest analysis building upon Working (1949). For a recent discussion vic Williams (1986), which is essentially a convenience yield theory of spread price volatility couched in terms of a discussion of the demand for accessibility (1) inventories.

11. Anderson (1985 p. 341 fn.7).

12. When a range of closing prices is given. Meyer uses the average price within the range.

13. Breeden (1983 p. 30).

14. It is unclear from the context whether the Castelino and Vora study uses closing ur setuement prices.

15. These issues are considered in somewhat more detail a litte later.

16. Jones (1981 p.6).

17. The difference between absolute storage carry costs and relative linancing carry c(mis can be illustrated by gold. The storage costs for gold have recenty beeen $\$ 12.5$ peI kilogram per month, obviously quoted as an absolute carry cost. The linancing ums for gold are typically $0.5 \%$ over the Furodollar rate, quoted as a relative carry cost.

18. Williams (1986 p. 31$)$.

19. Fama and French (1987 p. 61).

20. Castelino and Vora (1984) select July as the front end contract in constructing thell spreads as "it either represents prices for the new crop year, or new cror, ycatr information is heavily discounted into its price." This statement is somewhat contentious. The crop years for three commodities are relcvant, wheat. corn, and soybeans. Soybeans are harvested from September to November with yicld estimatcs appearing in crop reports from August loth through December loth. The corn wop year begins on October lst. Thus, for four of the six spreads (soybean, soybcan meial. soybean oil, corn) Castelino and Vora lake spread price observations across crop ycars. This could significantly bias the results if crop carry-overs and supply shocks are a significant price factor.

21. See for instance Miller (1979), Castelino (1981), Anderson (1985) and Milonas (1986).

22. I experimented with several alternative methods of calculating the distant cyuivalen! 
price, the main difference from the present procedure being in the interest rate used to calculate holding charges for spreads with component contracts maturing more than 9) days apart. The differences did not impart any qualitiive changes at all to the results.

23. Public warchouse fees for agricultural commodities appear stable over periods as great as several years. For example, Continental Grain is one of four companies running registerce grain warehouses in Chicago. As of late 1982 they had not changed their storage fee in three years. (Information courtesy of Thomas Dreps, Cash Grain Department. Continental Grain). Over the last decade. warehouse fee's on copper have only changed a couple of times (Ronald Andresen. Director, Metal Services, COMEX.) Warchouses registered with the London Metal Exchange change their rates only every low ycars (Williams (1986)).

24. The most recent studies that the present author is aware of are Helms and Martell (1986). and Hudson, l.euthold and Sarassoro (1987). The former, using transaction-to-transaction data for selected wheat, corn. GNMA and Treasury Bond contracts traded on the Chicago Board of Trade in the period May 1974 - March 1979. conclude that the normal distribution fits the data better than any non-normal table distribution. However, their results also suggest that the underlying generating process does not appear to be stationary. The latter examine the distribution of futures price changes during the period January 1974 through December 1982 for wheal, soybeans and live catule. Their results suggest a distinct move to normality and independence of commodity futures price changes in these contracts, particularly since 1976. Among other things, they attribute this tendencey to the decline in the number of limit moves in the post 1976 period in these contracts. Both papers contain succincl summaries of previous work in the same area. beginning with Mandelbrot (1963). to which 1 refer the interested reader.

25. One would not expect the CONVEN variable to be significant for the metal contracts, as for any reasonable inventory level, the marginal convenience yield is essentially sero. See Prench (1986).

?. Garbade and Silber (1983b p. 252).

27. Details of the procedure are available in Castelino and Vora (1984, Appendix B).

2x. This is not to deny the convenience yield may occupy the central role in any cuplanation for why futures price spreads rarely reach full carrying costs, defined as the total storage, insurance and financing expenses of holding the commodity in inventory. Sec Williams (1986) for clarification.

.4. This phenomena has been noted by several authors including Telser (1958). Anderson (1985 p. 332) lerms it the Samuelson hypothesis, as Samuelson (1965) provides the lirst theoretical argument supporting its validity. This nomenculture is somewhat unfair to Samuclson for the reasons Samuelson (1976) himself indicates.

3). The leature of the model providing a rationalisation for the liquidation bias is dixussed in section $\mathrm{I}(\mathrm{c})$. 


\section{REFERENCES}

Akerlof, G., The Market for Lemons, The Quarterly Journal of Fionomics. \$4, (147(1). $488-500$.

Alchian, A.A., Costs and Outputs, in M. Abramoviu et al., The Allociation of fionomic: Resources, (Stanford University Press, 1959).

Alchian, A.A., Why Money?, Journal of Monev. Credit and Banking 9. (1977). 133-1+1).

Amemiya. T.. Qualitative Response Models. A Survey. Journal of Ficonomic Iitcralurc 14. (1981), 1483-1536.

Anderson. R.W., Some Determinants of the Volatiltty of Futures Prices, Iournal of Fulures Markets 5. (1985), 331-348.

Anderson R.W., and J.P. Danihine, Cross Hedging. Journal of Political Fconomy 89. (1981). 1182-1196.

Anderson, R.W.. and J.P. Danthine. Hedger Diversity in Futures Markets. Fionomic Journil 93. (1983). 370-389.

Anderson, R.W., and J.P. Danthine. The Time Pattern of Hedging and the Volatllity of Futures Prices, Review of Fconomic Studies 50. (1983b), 249-266.

Baer, J.B., and O.G. Saxon, Commodity Facharges and Futures Trading (Harper ant Brothers, New York, 1948).

Barzel, Y., An Alternative Approach to the Analysis of Taxation. Iournal of Political Fconomv 84, (1976). 1177-97.

Barzel, Y., Some Fallacies in the Interpretation of Information Costs. Journal of Jaiw intil Economics 20. (1977), 291-307.

Barzel, Y., Measurement Costs and the Organization of Markets. Journal of Iaw and Economics 25. (1982), 27-48.

Bowe. M.A., Measurement Costs and Contractual Price Volalility in Futures Markets. minici. Simon Fraser University (1986).

Bowe. M.A. Measurement Costs. Margin Requrrements and Market fallure in turures Markets, mimeo. Simon Fraser University. (1986).

Breeden. D., Spread Variability in Futures Markets, Center for the Study of rutures Markets Working Paper \#CSFM-49. Columbia Business School, (1983).

Brennan. M. J., Supply of Storage, American Fconomic Review 4x, (1958), 50- 72.

Brennan, M.J.. A Theory of Price Limits in Futures Markets. Journal of Financial Fuonomics 16. (1986), 213-233. 
Carlion. 1).W., The Costs of Eliminating a Futures Market and the Effects of Infation on Market Interrelatıonships. Center for the Study of rutures Markets Working Paper \# (SFM-69. Columbia Husiness School. (1983).

(arlton. D.W., Fulures Markets: Their Purpose, Their History, Their Growth. Their Successes and Falures. Journal of Futures Markets 4, (1984), 237-71.

Castclino. M., futures Markets: The Maturity Effect on Risk and Return, unpublished PH.D Dissertation. The City University of New York, 1981.

Cistclino M., and A. Vora. Spread Volatility in Commodity Fulures: The Length Effect, Journal of Fulures Markets 4. (1984), 39-46.

('hcung. S., A Theory of Price Contrd. Journal of Law and Economics 17. (1974), 53-71.

('hicago Mercantile Fxchange. Rules of the Chicago Mercantile Exchange (Chicago. 111., 1985).

Commodity Futures Trading Commission, Uses of I.ivestock Futures Markets by Iarge Hedgers. Addendum to 1984 Annual Report. (Washington, D.C.. 1985).

('o) I.. Ingersoll. J., and S.A. Ross, A Theory of the Term Structure of Interest Rates. Ressarch Paper No.468. Graduate School of Business, Stanford University.

Cragg. J.G., and R.S. Uhler. The Demand for Automobiles. Canadian Journal of Fconomics 3. (1970), 386-406.

Crow. J.R.. Riley. J., and W. Purcell. Economic Implicatıons of Nonpar Delivery Paints for the Live Cartle Futures Contract, American Journal of Agricultural Economics 54. (1972), 111-115.

Mavid. H.A., Hartley, H.O. and F.S. Pearson. The Distribution of the Ratio, in a Single Normal Sample Range 10 Standard Deviation. Biometrika 41. (1954). 482-493.

Fislcrbrook. F.H. Monopaly. Manipulation and the Regulation of Futures Markets, Journal of Business Supplemen: 59. (1986). S103-S127.

Fulwards. F.H., Futures Markets in Transition: The Uneasy Balance Between Government and Self Regulation. Journal of Futures Markets 3. (1983), 191-205.

Fituards. I.N. and F.H. Fdwards. A Legal and Economic Analysts of Manipulation in Futures Ifarkets. Journal of Futures Markets 4. (1984), 333-366.

Fama. F.F., and K. French. Commadiry Futures Prices : Some Evidence on Forecast Power. Premiums and the Theory of Storage. Journal of Business 60, (1987), 55-73.

Fuma. F.t. and R. Roll. Some Properties of Symmetric Stable Distributions, Journal of the American Statistical Association 63. (1968), 817-836.

Fama F.F., and R. Roll. Parameter Estımates for Symmetric Stable Distributions. Journal of the American Statistical Association 66. (1971), 331-338.

Fixchel D.R., and S. Grossman. Customer Protection in Futures and Securttes Markets. Iournal of Fulures Markets t. (1984). 273-295. 
Fischer. S., Relative Shacks. Relattve Price Varlablity. and Intlation. Bronkings Pupers on Fonomic Activity 2, (1981), 381-431.

French. K., Detecting Spat Price Forecasts in Furures Prices. loumal of Husiness 54. (148(1). 539-554.

Garbade. K.D., and W.L. Silber. Cash Settlement of futures Contracts: An ticonomic Anulvis. Journal of Futures Markets 3. (1983a). 451-472.

Garbade K.D., and W.L. Silber, Futures Contracts on Commodities with Multuple l'arieties: An Analysis of Premiums and Discounts, Journal of Business 56. (19836), 249-27.2.

Goldberg, V., Regulation and Administered Contracts. Bcll Journal of tiononics 7. (147(1). 426-48.

Goldberg. V., and J.R. Erickson, Quantity and Price Adustments in Long Term Coke Contracts: A Case Study of Petroleum Coke. Journal of Iaw and Fionomics iI. (1987). 369-398.

Grauer, F.L.A., Equilibrium in Commodity rutures Markets: Theory and Tes/s, unpublivhed Ph.D dissertation. Stanford University. 1977.

Gray. R., The Relationship Among Three futures Markets, food Rescarch Inulitule Studien I. (1961), 21-32.

Gray. R.. Price Effects of a Lack of Speculation. Food Research Inslitute Siludics 7. Supplement, (1967), 177-194.

Grossman. S. An Analysis of the Role of 'Insider Tradıng' on Fulures Markets. lourmil il' Business Supplement 59, (1986). S129-S146.

Helms, B.P., and T.F. Martell. An Examination of the Distribution of Futures Price Changes. Journal of Futures Markets 5, (1985), 259-272.

Howell. I.D.. Influence of Certificated Stocks on Spot-fiutures Price Relattonships for Coxtom. Technical Bulletin No. 1151. United States Department of Agriculture Washinglon D.C.. (1956).

Hudson, M.A., Leothold. R.M. and G.F. Sarassoro. Commadity Futures Price Changes: Recent Evidence for Wheat. Soybeans and Live Catlle, Journal of Futures Markels 7. (1987). 287-301.

Johnston. J., Fconometric Methods. (McGiraw-Hill, New York, 2nd Fdition. 1972).

Jones. F., Spreads: Tails, Turtles and All That, Journal of fulures Markuts I. ([gy]). 565-596.

Judges. G.G. et al., Introduction to the Theory and Practice of tronomicirics. (John Wilc: and Sons, New York. 1982).

Kaldor. N., Speculation and Economic Stabllity, Review of Fconomic Situdies 7. (1934 411$).$ $1-27$.

Karpoff. J., A Theory of Trading Volume. Journal of Finance 41. (1986), 10699-1087. 
Kendall, M.C;. and A. Stuart. The Advanced Theorv of Statistics Vol. 2. 3rd Fdition. (Griffin. Iondon 1979).

K.nncy, K.W., and B. Klein. The Economics of Block Booking, Journal of law and teonomics 26, (1983). 497-540.

Klein, B. and K. Ieffler, The Role of Market Forces in Assuring Quality. Journal of Political ficonomy 89, (1981), 615-641.

Kuhn, B.t., An Estımation Model for Futures Contract Margin Requirements, unpublished PH.D. dissertation. Stanford University, 1976.

Kyle. A.S. A Theory of Futures Market Manupulations. in R.W. Anderson ed., The Indusurial Organization of Futures Markets. (I.exington Books, I.exington M.A. 1984).

I abys W.C.. and C.W. Granger, Speculation, Hedging and Commoditi Price Forecasts. (I.exington, Mass: Heath lexington. 1970).

Maddala. (i.S.) limited Dependent and Qualitative Variables in Fconometrics (Cambridge (Iniversity Press, Cambridge. 1983).

Mandelbrot. B., The Variation of Speculative Prices, Journal of Business 36, (1963). 394-419.

Mictain. W.G. An Empirical Investigation into the Effects of Margin Requirements in Organized Commodily futures Markets, unpublished PH.D. dissertation. Stanford Universily. 1969.

Mctiadien. D.. Conditional Logit Analysis of Qualitative Choice Behaviour. In P. Zarembka, id. Fronticrs in Fionometrics (Academic Press, New York, 1971).

Mctadden. 1).. The Measurement of Urban Travel Demand, Journal of Public Fconomics 3. (1984). 303-328.

McManus. John ('.. The Costs of Alternative Economic Organizations. Canadian Journal of fionomics 8. (1975), 334-350.

McManus, I.C. and $K$. Acheson. The Costs of Transacting in Futures Markets. Carleton (Iniversity Discussion Paper \#79-22. (1979).

McManus J.C.. and K. Acheson. The Cost of Increasing the Extent of the Market: Trading in rulures. Carleton University Discussior Paper \#83-07. (1983).

M.hl. I. Obxectives of Federal Regulation of the Commodity Exchanges. Journal of Farm tconomics 19. (1937), $313-318$.

Mcicr. R.I.. Application and Aralysis of Pork-Belly Commodity Spreads, in R. Leuthold ed., Commodit: Markets and Futures Prices (Chicago Mercantile Exchange. Chicago. 1979).

Millcr. K.. The Relation Between Vdattity and Maturty in Futures Contracts, in R Leuthold ci. Comm ïts Markets and Futures Prices (Chicago Mercantile Exchange. Chicago, 1979).

Milonas N.T., Price Variability and the Mat..:y Effect in Futures Markets, Journal of Fulures Markets 6. (1986). $443-460$. 
Newberry. D. The Manipulation of Futures Iarkets by a Dominant Producter, itl K.H. Anderson cd. The Industrial Organization of Fulures Markels. (I crington Haxhs. l.exington M.A. 1984)

New York Mercantile Fxchange. Kules of the Now rork Mcrcantile Fichange (Now Yorh. New York. 1971).

Paul, A.B., Liquidation Bias in Futures Price Spreads. American 'ournal of Agriculturial Economics 68. (1986), 313-321.

Peck. A., Comments on The Economics of Hedging and Spreading in Furures Marke's: Journal of Futures Markets, 1. (1981). 287-289.

Powers, M. Effects of Contract Provisions on the Success of a Futures Contract. Iourmal of Farm Economics 49. (1967), 833-843.

Richards, S.F. and M. Sundaresan. A Contınuous Time Model of Furures Prices in a Multigood Economy. Journal of Financial tconomics 9. (1981). 347-371.

Rutledge D., A Note on the Variability of Futures Prices. Revicw of Fonomics and Stallswiss 58. (1976), 118-120.

Rystrom. D. Regulation, Information and the Behaviour of the Prices of Stats on tulure, Exchanges, unpublished Ph.D. dissertation. University of Oregon, 19x?.

Samuelson. P., Proof that Property Anticipated Prices Hluctuate Randomly. Induslli.l| Manazement Review 6, (1965). 41-49.

Samuelson. P.. Is Real-World Price A Tale Told by the Idio of Chance. Kivicw if Fconomics and Statistics, 58. (1976), 120-123.

Sandor, R., Innovation by an Exchange: A Case Siudy of the Development of the Plywiant Futures Contract, Journal of $\mathrm{I}$ aw and Fionomics 16, (1973). 119-136.

Stein. J.L., Spot, Futures and Forward. Research in Finance 1, (1979). 225-311.

Telser. LG. Futures Trading and the Storage of Cotton and Wheat. Journal of Pallicial Economy 66. (1958), 233-255.

Telser. L.G. Why there are Organized Futures Markets. Journal of law and foconomics it (1981), 1-22.

Telser. 1..G., Margins and Futures Contracts. Journal of fulures Markets J.(1981a). 225 253.

Telser, I. G., Futures and Actuals Markets: How They are Related. Journal of Busill'ss Supplement 59. (1986). S5-S20.

U.S. Congress, Hearings before the Committee on Banking. Housing and Urban Alfairs of the Senate. on May 29th and 30th. 1980.

White, H., A Heteroskedastucily Consistent Covariance Matrix Estumalor and a Direct Test fer Heteroskedasticity. teconomctrica 48, (198(1)). 817-38. 
Williams, J., The Fionomic Function of Futures Markess (Cambridge Unive sity Press. (ambridgc, 1986).

Williamwon. O.t... Franchese Bidding for Nalural Monopalies: in General and with Respect 10 CATV, Bcll Journal of Fonomics 7. (1976). 73-104.

Williamson. O.F, Transaction-Cost Economics: The Governance of Contractual Relations, Journal of law and Fconomics 27, (1979). 233-261.

Williamson, O.F., Credible Commitments: Using Hoslages 10 Support Exchange. American reonomic Review 73. (1983) 519-540.

Workiny. H.. Theory of the Inverse Carrying Charge in Futures Markets. Journal of Farm reonomics 30. (1948). 1-28.

Working. H. The Theory of Price of Slorage. American Economic Review 39. (1949). $1254-1262$.

Working, H., rutures Trading and Hedging. American Economic Review 43. (1953). 314-343.

Working. H.. Whose Markets? Evidence on Some Aspects of Futures Trading. Journal of Marketing 29. (1954), 1-11.

Working. H., Tests of a Theory Concerning Hoor Trading on Commadity Exchanges, Food Kexarch Institute Studies 7. Supplement. (1967). 5-48. 

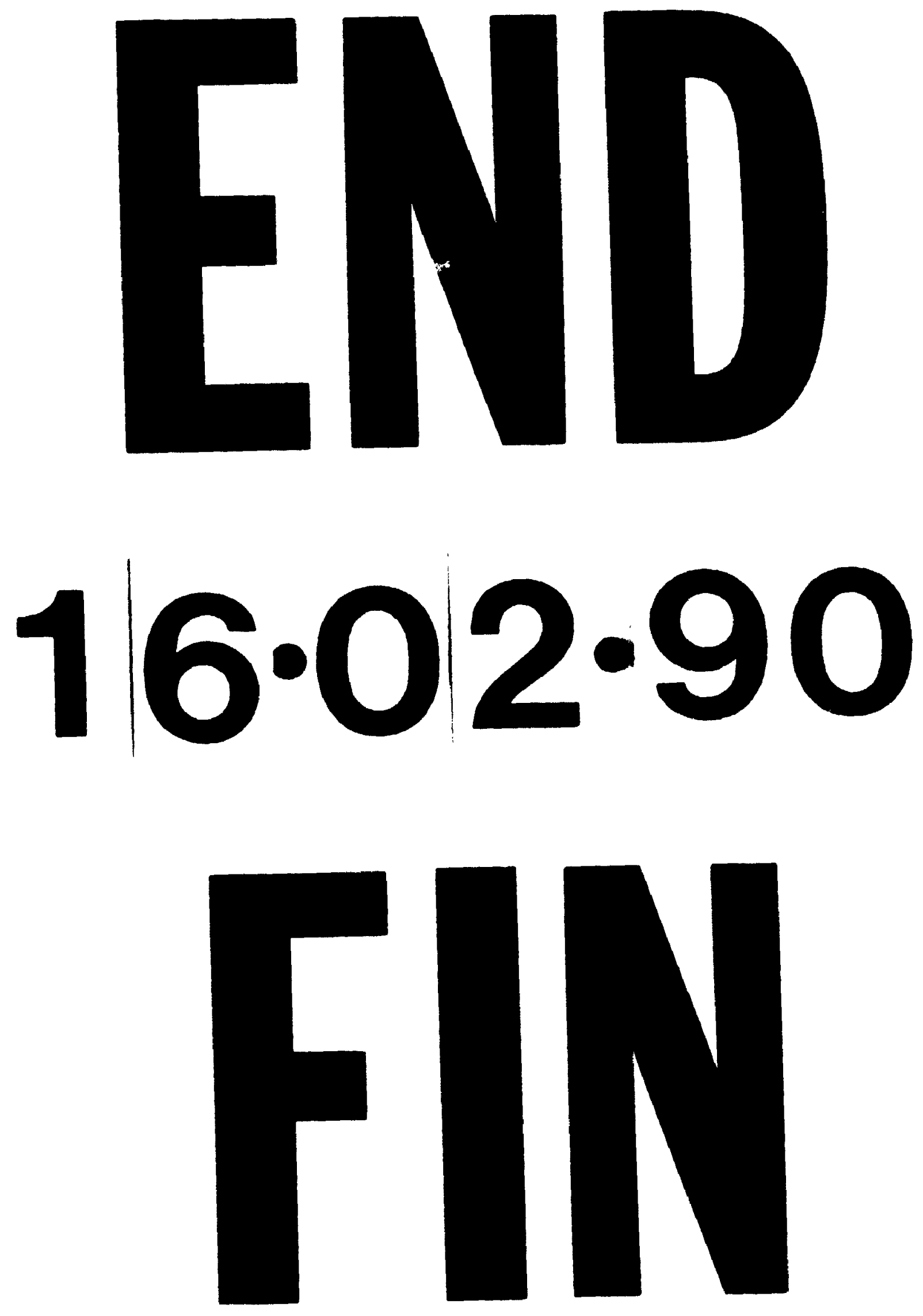